UNIVERSIDADE DE SÃO PAULO

FACULDADE DE ODONTOLOGIA

\title{
AVALIAÇÃO DA SATISFAÇÃO DOS PACIENTES \\ ATENDIDOS NA CLÍNICA INTEGRADA DO CURSO DE ODONTOLOGIA DA UNIVERSIDADE FEDERAL DO PARÁ
}

\section{IZAMIR CARNEVALI DE ARAÚJO}

Dissertação apresentada à Faculdade de Odontologia da Universidade de São Paulo, para obter o Título de Mestre, pelo Programa de Pós-Graduação em Odontologia.

Área de Concentração: Clínica Integrada

São Paulo 
UNIVERSIDADE DE SÃO PAULO

FACULDADE DE ODONTOLOGIA

\begin{abstract}
AVALIAÇÃO DA SATISFAÇÃO DOS PACIENTES
ATENDIDOS NA CLÍNICA INTEGRADA DO CURSO DE

ODONTOLOGIA DA UNIVERSIDADE FEDERAL DO PARÁ
\end{abstract}

IZAMIR CARNEVALI DE ARAÚJO

Dissertação apresentada à Faculdade de Odontologia da Universidade de São Paulo, para obter o Título de Mestre, pelo Programa de Pós-Graduação em Odontologia.

Área de Concentração: Clínica Integrada

Minter - FOUSP - UFPA

Orientador: Prof. Dr. Rodney Garcia Rocha

Co-Orientadora: Profa. Dra. Regina Fátima Feio

Barroso

São Paulo 


\section{Catalogação-na-Publicação}

Serviço de Documentação Odontológica

Faculdade de Odontologia da Universidade de São Paulo

Araújo, Izamir Carnevali de

Avaliação da satisfação dos pacientes atendidos na clínica integrada do curso de odontologia da Universidade Federal do Pará / Izamir Carnevali de Araújo; orientador Rodney Garcia Rocha. -- São Paulo, 2003.

126 p. : il., tab., graf.; $30 \mathrm{~cm}$.

Dissertação (Mestrado - Programa de Pós-Graduação em Odontologia. Área de Concentração: Clínica Integrada) -- Faculdade de Odontologia da Universidade de São Paulo.

1. Pacientes em odontologia - Universidade Federal do Pará - Atendimento 2. Satisfação do paciente - Odontologia 3. Clínica integrada - Curso de odontologia Satisfação do paciente - Estudos de avaliação.

CDD 617.06

BLACK D585 
Data da Defesa: 10 de Junho de 2003

\section{Comissão Julgadora}

Prof(a). Dr(a). Rodney Garcia Rocha

Julgamento:

Assinatura:

Prof(a). Dr(a). Nicolau Tortamano

Julgamento:

Assinatura:

Prof(a). Dr(a). Antônio José da Silva Nogueira

Julgamento:

Assinatura: 


\section{DEDICATÓRIA}

A vivência do Mestrado me mostrou que nenhum de nós pode cumprir tarefas transformadoras sem transformar-se a si mesmo. Descobri antes tarde do que nunca que não posso fazer o que preciso fazer sem tentar mudar meu jeito de ser. É mais fácil mudar um contexto socialmente envolvido, que mudar uma pessoa sem convicções.

A autotransformação acontece devagar e custa caro. Traz, contudo, vida e

força. É, ao mesmo tempo, sacrifício e libertação. Ter de mudar para ser fiel a si mesmo e buscar o meu crescimento como ser humano pela convivência com os colegas, professores, e técnico no labutar do compromisso com o conteúdo deste Curso, foi gratificante, foi com certeza uma das melhores razões para entregar-me a esta grande luta. Minha utopia de ontem é a realidade do meu amanhã, pois hoje sou Mestre.

Izamir Carnevali de Araújo 


\section{A DEUS QUE POR SUA INFINITA MISERICÓRDIA TUDO DEVO, GLÓRIA A TI SENHOR NO MAIS ALTO DO CÉU.}

Aos meus pais, Izabel e Edmir, exemplos de vida, honra, dignidade que sempre nortearam os meus caminhos contribuindo para a minha formação dedico este trabalho e o meu eterno amor.

A minha mulher e parceira, Marizeli, Amiga certa das horas incertas, que caminhou comigo neste trabalho e na minha vida, a minha eterna gratidão.

Aos meus queridos filhos Andréa e Fabrício pelo amor total e carinho permanente, grandes companheiros e amigos de vida.

A minha Irmã de lutas e de trabalhos conjuntos sempre presente e parceira Prof $^{a}$. Dra. Regina Fátima Feio Barroso, minha Co-orientadora neste trabalho o meu especial agradecimento do fundo do meu coração, pelas emoções já vividas e lutas vencidas e tantas ainda por vencer. 


\section{AGRADECIMENTOS}

Ao Querido Mestre e Professor Doutor Nicolau Tortamano, pela sabedoria, experiência profissional, ensinamentos durante o curso e pela amizade sincera construída nos anos de convivência, meu sincero e profundo agradecimento.

Ao Meu Grande Amigo e Orientador Professor Doutor Rodney Garcia Rocha pela forma competente com que me recebeu e conduziu durante todo o Curso, pela orientação científica, e humana fundamentais para o êxito deste trabalho e pelo exemplo de dedicação, excelência e paciência sem o qual jamais este trabalho teria sido realizado, muito obrigado e minha inesquecível gratidão.

Ao Magnífico Reitor da Universidade Federal do Pará, Profo ${ }^{\text {. Dr. }}$ Alex Fiúza de Melo, meu muito obrigado pelo especial empenho em tornar a minha participação neste Mestrado possível diante das dificuldades apresentadas.

Aos Professores Suely Lamarão (pelas dicas e informações) e Antônio José da Silva Nogueira Coordenadores deste Minter em Clínica Integrada, pelo trabalho conjunto e orientações precisas. 
Aos queridos Professores, Mário Sérgio Soares, José Leonardo Simone, João Humberto Antoniazzi, Flávio Eduardo G. Perez e Carlos Alberto Adde e Professoras Sibele e Maria Aparecida, da Disciplina de Clínica Integrada do Minter USP-FO e UFPA-CO, pela solidariedade e fraterna convivência desfrutada ao longo do Curso de Mestrado e pelo apoio nas nossas atividade.

À Sra. Vilma Aparecida de Vieira, funcionária da USP/Disciplina de Clínica Integrada "A Nossa Dona Vilma" meu especial muito obrigado pela forma amiga, carinhosa, fraterna e competente com que me auxiliou no dia a dia do meu Mestrado e pelas palavras carinhosas quando mais precisávamos, a Senhora foi e é Jóia.

A Disciplina de Clínica Integrada e a Faculdade de Odontologia da Universidade de São Paulo e ao Curso de Odontologia e a Universidade Federal do Pará pela oportunidade de vencer mais esta etapa acadêmica de minha formação

À CAPES pelo apoio durante o curso de Pós-Graduação, possibilitando o desenvolvimento deste trabalho

A Estatística Sandra Souza Lima, minha parceira e amiga no desenvolvimento da pesquisa, Muito obrigado.

Aos funcionários da Biblioteca, da Faculdade de Odontologia da USP, pelo auxílio, orientação e revisão geral em especial, As (o) Parceiras (o) e Amigas (o) Sra. Luzia Marilda Z. M. Moraes, Maria Aparecida Pinto (Cida) e Sr. Antônio Barboza de Souza, Muito obrigado. 
Aos funcionários do serviço de Pós-graduação da Faculdade de Odontologia da USP, muito obrigado.

Ao amigo e parceiro Helder Henrique Pinheiro pelo apoio e colaboração, na elaboração deste trabalho, meu muito obrigado.

E agora depois da longa caminhada, comovido agradeço aos meus queridos amigos e amigas caminhantes: Marizeli, Ceci, Jesuína, Lurdete, David, Davi, Wagner, Luciana, Andréa, Paulo Farias, Maneschy, Renata, Simone e Vaneska parceiros, companheiros e cúmplices desta tão árdua e gratificante jornada muito obrigado pela compreensão, apoio, troca de conhecimentos e amizade sincera.

E a todos aqueles que direta ou indiretamente colaboraram à execução deste trabalho. MUITO OBRIGADO. 


\section{SUMÁRIO}

p.

LISTA DE GRÁFICOS

LISTA DE TABELAS

LISTA DE ABREVIATURAS E SIGLAS

RESUMO

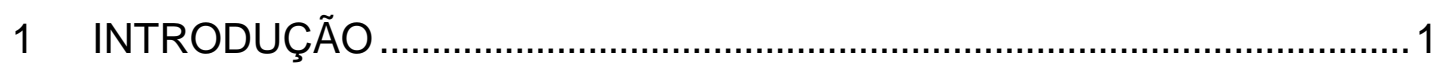

2 REVISÃO DA LITERATURA ….......................................................... 4

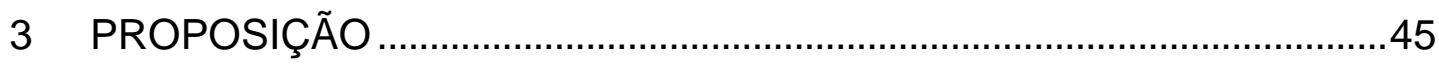

4 MATERIAL E MÉTODOS .....................................................................46

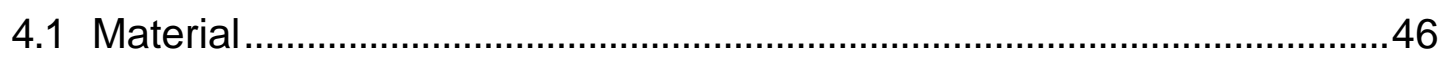

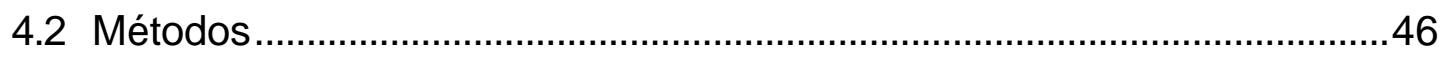

5 RESULTADOS E DISCUSSÃO ............................................................. 51

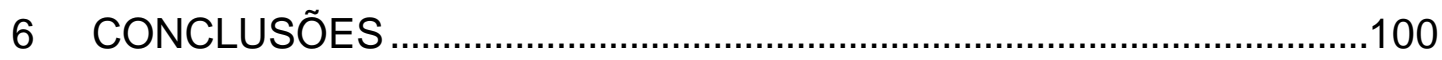

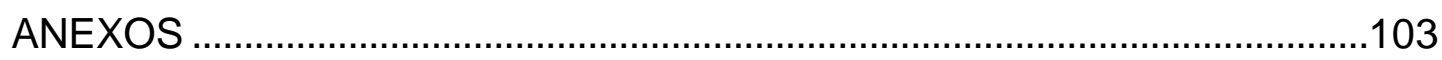

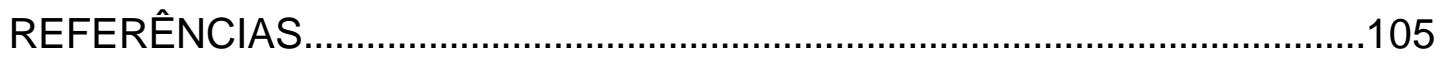

SUMMARY

APÊNDICES 


\section{LISTA DE GRÁFICOS}

Gráfico 5.1 - Distribuição (\%) dos pacientes da amostra por faixa etária e sexo, CICOUFPA, Belém, 2002 .55

Gráfico 5.2 - Análise (\%) da origem por Bairros dos pacientes da CICOUFPA, Belém, 2002 .56

Gráfico 5.3 - Estudo da renda familiar mensal dos pacientes da CICOUFPA, Belém, 2002 59

Gráfico 5.4 - Análise dos níveis de escolaridade dos pacientes da CICOUFPA, Belém, 2002 .60

Gráfico 5.5 - Análise das informações recebidas pelos pacientes sobre o tratamento odontológico na CICOUFPA, Belém, 2002 61

Gráfico 5.6 - Análise das informações recebidas pelos pacientes sobre procedimentos preventivos na CICOUFPA, Belém, 2002 ....62 
Gráfico 5.7 - Estudo das respostas dos pacientes sobre a utilização do traje adequado pelo aluno e professor na CICOUFPA, Belém, 2002 66

Gráfico 5.8 - Opinião dos pacientes quanto à sensação de dor no tratamento ao ser atendido na CICOUFPA, Belém, 2002 ....67

Gráfico 5.9 - Opinião dos pacientes quanto à sensação de medo no tratamento odontológico na CICOUFPA, Belém, 2002.........68

Gráfico 5.10 - Estudo da opinião dos pacientes analisando medo e sexo durante o tratamento odontológico na CICOUFPA, Belém, 2002 .71

Gráfico 5.11 - Análise da opinião dos pacientes quanto ao atendimento prestado pelo professor da CICOUFPA, Belém, 2002 .72

Gráfico 5.12 - Análise da opinião dos pacientes quanto ao atendimento prestado pelo aluno da CICOUFPA, Belém, 2002. .73

Gráfico 5.13 - Análise da opinião dos pacientes quanto ao atendimento prestado pelo serviço de triagem da CICOUFPA, Belém, 2002 .73 
Gráfico 5.14 - Distribuição dos pacientes quanto ao motivo da procura de atendimento na CICOUFPA, Belém, 2002 .78

Gráfico 5.15 - Análise da opinião dos pacientes quanto ao fato de ser atendido em um ambiente coletivo como a CICOUFPA, Belém, 2002 .79

Gráfico 5.16 - Distribuição dos pacientes por atendimentos especializados na CICOUFPA, Belém, 2002

Gráfico 5.17 - Análise da opinião dos pacientes quanto ao ambiente da CICOUFPA, Belém, 2002 .84

Gráfico 5.18 - Avaliação das notas, em escala de 0 a 10 , para 0 atendimento odontológico recebido pelos pacientes da CICOUFPA, Belém, 2002 .86

Gráfico 5.19 - Análise da distribuição das médias das notas por faixa etária, atribuídas pelos pacientes da CICOUFPA, Belém, 2002 .88

Gráfico 5.20 - Opinião dos pacientes atendidos na CICOUFPA se indicariam ou não os serviços para outras pessoas, CICOUFPA, Belém, 2002 93 
Gráfico 5.21 - Análise das sugestões dos pacientes para melhoria do atendimento na CICOUFPA, Belém, 2002 ……………….......94 


\section{LISTA DE TABELAS}

Tabela 5.1 - Distribuição dos pacientes quanto ao sexo na Clínica Integrada, COUFPA, Belém, 2002 .53

Tabela 5.2 - Distribuição dos pacientes da amostra por faixa etária e sexo, CICOUFPA, Belém, 2002 .54

Tabela 5.3 - Situação do vínculo de trabalho dos pacientes da CICOUFPA, Belém, 2002 .57

Tabela 5.4 - Análise da renda mensal familiar dos pacientes da CICOUFPA, Belém, 2002 .58

Tabela 5.5 - Análise das informações recebidas pelos pacientes sobre 0 tratamento por faixa etária na CICOUFPA, Belém, 2002 .63

Tabela 5.6 - Análise das informações recebidas pelos pacientes sobre procedimentos preventivos por faixa etária na CICOUFPA, Belém, 2002 .64 
Tabela 5.7 - Opinião dos pacientes sobre à sensação de dor durante o tratamento, relacionando com o sexo dos pacientes na CICOUFPA, Belém, 2002 .70

Tabela 5.8 - Análise da distribuição dos pacientes referenciados para tratamento por especialidades na CICOUFPA, Belém, 2002

Tabela 5.9 - Estudo da opinião dos pacientes quanto ao ambiente da CICOUFPA, Belém, 2002 .83

Tabela 5.10 - Avaliação das notas, em escala de 0 a 10, para o atendimento odontológico recebido pelos pacientes da CICOUFPA, Belém, 2002 .85

Tabela 5.11 - Distribuição das notas para o atendimento por nível de escolaridade dos pacientes da CICOUFPA, Belém, 2002 ......89

Tabela 5.12 - Distribuição das notas para o atendimento por idade dos pacientes da CICOUFPA, Belém, 2002 .90

Tabela 5.13 - Distribuição das notas para o atendimento por faixa salarial dos pacientes da CICOUFPA, Belém, 2002 .91 


\section{LISTA DE ABREVIATURAS E SIGLAS}

$\begin{array}{ll}\text { OMS } & \text { Organização Mundial de Saúde } \\ \text { CICOUFPA } & \text { Cínica Integrada do Curso de Odontologia da } \\ \text { UFPA } & \text { Universidade Federal do Pará } \\ \text { CO } & \text { Universidade Federal do Pará } \\ \text { USP } & \text { Curso de Odontologia } \\ \text { CI } & \text { Universidade de São Paulo } \\ \text { FO } & \text { Clínica Integrada } \\ \text { MINTER } & \text { Faculdade de Odontologia } \\ \text { PSF } & \text { Mestrado Interinstitucional } \\ \text { SB2000 } & \text { Programa de Saúde da Família. } \\ \text { MS } & \text { Levantamento das Condições da População Brasileira } \\ \text { MEC } & \text { Ministério da Saúde } \\ \text { ABENO } & \text { Ministério da Educação e Cultura } \\ \text { CAPES } & \text { Associação Brasileira de Ensino Odontológico } \\ \text { CFE } & \text { Capacitação Pessoal de Ensino Superior } \\ \text { CONSEP } & \text { Conselho Federal de Educação }\end{array}$




\section{RESUMO}

\section{AVALIAÇÃO DA SATISFAÇÃO DOS PACIENTES ATENDIDOS NA CLÍNICA INTEGRADA DO CURSO DE ODONTOLOGIA DA UNIVERSIDADE FEDERAL DO PARÁ}

Neste estudo foi avaliada a satisfação dos pacientes atendidos na Clínica Integrada do Curso de Odontologia da Universidade Federal do Pará (CICOUFPA), através de uma amostra aleatória simples de 200 usuários dos 600 inscritos, atendidos nos meses de Maio e Junho de 2002. Para esta pesquisa foi aplicado um questionário com 19 questões fechadas e 01 aberta, e os dados coletados foram submetidos a análise estatística utilizando-se o software Epi. Info. 604.d. com um nível de significância de 5\% $(\mathrm{P}<0,05)$. Os resultados indicaram que $66 \%$ dos pacientes da CICOUFPA não sentiram dor e 46\% não tiveram medo, $87 \%$ procuraram para tratamento especializado, $83 \%$ receberam informações sobre tratamentos curativos e $68 \%$ sobre procedimentos preventivos, a avaliação do atendimento pelo aluno e professor, mereceu uma aprovação de $98 \%$, sendo que $97.5 \%$ dos alunos e $62.5 \%$ dos professores estavam vestidos adequadamente, as recomendações sobre as melhorias foram relacionadas com a infra-estrutura e o serviço de triagem, $98 \%$ dos pacientes recomendariam o serviço, a nota média foi de 8.33 , e a avaliação do ambiente de trabalho obteve uma 
aprovação de $95 \%$ dos pacientes. Portanto os pacientes estão satisfeitos com o ambiente físico da CICOUFPA, acreditam na competência dos alunos e professores e indicariam o serviço para outras pessoas. 


\section{INTRODUÇÃo}

A Clínica Integrada é uma das matérias obrigatórias dos currículos mínimos dos Cursos de Graduação em Odontologia no Brasil.

Inicialmente, foi concebida como um estágio ao final do Curso de Graduação, onde o aluno deveria aplicar os conhecimentos adquiridos nas demais disciplinas clínicas.

A partir de 1982, a Clínica Integrada adquiriu o status de matéria, passando a organizar-se também em forma de disciplina.

Segundo Arruda (1997), a disciplina de Clínica Integrada no Curso de Graduação em Odontologia, visa desenvolver no aluno a capacidade em integrar o conhecimento e a prática de sua aprendizagem, realizada nas disciplinas específicas anteriormente percorridas. Os conhecimentos, habilidades e atitudes já adquiridos isoladamente, deverão ser reunidos de forma lógica e ordenados seqüencialmente, com a finalidade de executar-se a maioria dos procedimentos clínicos odontológicos, proporcionando ao paciente prognóstico favorável e previsível Associação Brasileira de Ensino Odontológico (ABENO, 1983/1985).

Inicialmente, pesquisas sobre qualidade e satisfação dos pacientes de serviços odontológicos em clínica integrada partiam da premissa de que 
já existiam certas necessidades estabelecidas para os usuários. Em sua maioria, estes conceitos são oriundos de estudos sobre satisfação. Trabalhos envolvendo percepções de pacientes agruparam alguns conceitos que eram referenciados ao julgar satisfação como: habilidade técnica do profissional, evitar que o paciente sinta dor, facilidade de acesso àclínica e ao tratamento, custo do tratamento, informações em relação ao tratamento, atitude do dentista, estética, higiene e função dos dentes (Leão \& Dias, 2001).

Portanto, na literatura, vários pesquisadores têm direcionado seus trabalhos para a área social, procurando averiguar a expectativa do paciente frente ao atendimento; os critérios utilizados para a avaliação por parte do paciente do tratamento recebido; o nível de satisfação e os resultados obtidos. Tais trabalhos servem para avaliar a qualidade da relação entre paciente e profissional, melhorando a eficácia do serviço.

Bordenave \& Pereira (1984) afirmaram que as clínicas das Faculdades de Odontologia oferecem uma visão meramente tecnicista da profissão, transformando o aluno, futuro profissional, em um mero "tratador de dentes", desconsiderando que o dentista deve tomar decisões que envolvem dor, medo, sofrimento ou que mexem com as aspirações das pessoas, que necessitam alívio para suas angústias e seus temores.

Como toda organização que está preocupada com a satisfação dos usuários com seus produtos e serviços, os provedores de serviços dentários estão tornando-se mais envolvidos com a satisfação do paciente. Isto é devido ao aumento da evidência de que a associação entre satisfação, 
aquiescência do paciente e sucesso do tratamento, determina a qualidade do atendimento em saúde. Em estudos recentes, a satisfação do paciente é definida como uma resposta de base afetiva e de avaliação de base cognitiva do receptor do tratamento de saúde. Newsome \& Wrigth (1999), mostraram que a satisfação é uma combinação complexa do emocional, físico e imaterial, e seus valores estão diretamente envolvidos com a qualidade.

A satisfação do paciente constitui um valioso feedback que vai contribuir para a reflexão sobre a melhoria contínua do trabalho em equipe. Assim, exige-se uma constante investigação, na busca de identificar os fatores que promovem satisfação nos pacientes atendidos nos serviços de saúde.

O envolvimento da clientela dos serviços de saúde em níveis que ultrapassam a mera utilização passiva dos mesmos é algo desejável, tendo em vista a ampliação do uso, a melhoria da qualidade de tais serviços e, principalmente, níveis mais altos de satisfação com as agências prestadoras do mesmo (Abramowicz, 1976; Malik, 1992; Martins, 1993; Trad et al., 2002).

Para se alcançar a satisfação do paciente além da qualidade do profissional e da infra-estrutura didática e operacional da clínica, é necessário que seja implantada uma política educacional que considere professores e alunos conscientes e também engajados em um processo de transformação social do homem, que revele a ética odontológica e que considere com dignidade o real compromisso que $\mathrm{o}$ profissional de Odontologia deve ter com a sociedade brasileira (ABENO, 1983/1985). 


\section{REVISÃO DA LITERATURA}

A disciplina de Clínica Integrada, que até 1970 era considerada como estágio, é hoje parte integrante do Currículo Mínimo dos Cursos de Graduação em Odontologia como matéria profissionalizante, conforme Resolução do Conselho Federal de Educação (CFE, 1982).

Segundo Tortamano et al. (1995), a literatura disponível envolvendo análises comparativas ou avaliação sobre o ensino dessa disciplina ou, mesmo sua base filosófica, é limitada. Alguns textos, na maioria institucionais, restringem-se a abordar a necessidade da disciplina no currículo, procurando estabelecer nela a responsabilidade pela formação social dos futuros profissionais da Odontologia e o aperfeiçoamento de recursos humanos (Arango, 1976; Tabacof, 1980; Ribeiro, 1987).

Outros pesquisadores como Tortamano et al. (1995); Arruda (1997), analisaram a integração curricular, a integração inter e intradisciplinar, a necessidade da formação do cirurgião-dentista clínico geral, a estrutura e os objetivos da disciplina em cursos específicos, a participação de outras disciplinas junto àclínica integrada e as propostas de avaliação sistemática de algumas instituições e concluíram nesses estudos, que a Clínica 
Integrada é a disciplina em que o aluno de graduação torna-se apto para o desempenho da Odontologia Generalista.

Essa característica torna-a, portanto, diferente das disciplinas curriculares tradicionais, em que o saber odontológico é ministrado por partes, fragmentado e desintegrado, e define seu papel como estrutura intracurricular idealmente antagônica æ̀s características e æ̀ tendências especializantes das demais disciplinas clínicas (Tortamano et al., 1995).

Perez (1993), relatou que não existe definição e consenso sobre os objetivos, conteúdos programáticos e carga horária a serem dedicadas a esta disciplina, havendo variações entre as diversas instituições de ensino odontológico.

A definição de conteúdos, objetivos de ensino e filosofia para a Clínica Integrada, deve respeitar e orientar-se pelas determinações e objetivos do currículo pleno de cada Instituição. Porém, não se deve ignorar as Resoluções do Conselho Federal de Educação (CFE, 1982) e as Recomendações da Associação Brasileira de Ensino Odontológico (ABENO, 1983/85), porque a disciplina de Clínica Integrada tem objetivos bastantes amplos dentro do processo ensino-aprendizagem. Pois ela deve promover a integração dos conhecimentos, habilidades e valores adquiridos ao longo do curso, de modo a proporcionar ao paciente o atendimento integral das necessidades evidenciadas (Tabacof, 1980; Padilha, 1994; Tortamano et al., 1995).

No que se refere a currículos nos cursos de graduação em Odontologia, o CFE recomenda que o início das atividades dos alunos na 
disciplina de Clínica Integrada deva ser precoce, com caráter progressivo, familiarizando-os com as rotinas do exame para diagnóstico, prognóstico, e do plano de tratamento (planejamento) com participação simbólica e, gradativamente, assumindo encargos de atendimento sob supervisão de tarefas, procedimentos clínicos e laboratoriais (Perez, 1993; Cruz, 1998).

O graduando de Odontologia , com base no conhecimento básico e aplicado, deverá para suas competências profissionais, desenvolver as seguintes habilidades (Padilha, 1998):

- colher, observar e interpretar dados para a construção do diagnóstico;

- identificar as afecções buco-maxilo-faciais prevalentes;

- desenvolver raciocínio lógico e análise crítica;

- propor e executar plano de tratamento adequado;

- realizar a proservação da saúde bucal;

- comunicar-se com pacientes, com profissionais da saúde e com a comunidade em geral;

- trabalhar em equipes interdisciplinares e atuar como agente de promoção de saúde;

- planejar e administrar serviços de saúde comunitária;

- acompanhar e incorporar inovações tecnológicas (informática, novos materiais, biotecnologia) no exercício da profissão. 
Na Universidade de São Paulo, desde 1970, a disciplina de Clínica Integrada, tem por finalidade permitir o aprimoramento do conhecimento obtido pelos alunos nas diversas disciplinas curriculares anteriormente cursadas, bem como trazer informações que complementem conhecimentos, de forma tal que o aluno seja capaz de diagnosticar, planejar, executar e prognosticar, de forma global os procedimentos de reabilitação em saúde bucal, adequando-os æ̀s condições sócio-econômicas da comunidade. Ainda, do ponto de vista de orientação e formação dos alunos procura também priorizar a seqüência da terapêutica odontológica nos diversos procedimentos clínicos (Tortamano et al., 1995).

O Curso de Odontologia do Centro de Ciências da Saúde da Universidade Federal do Pará (UFPA), foi criado através da Resolução no․ 105 de 03 de Julho 1972. Atualmente o Curso de Odontologia da UFPA, encontra-se em fase de implantação de um novo currículo, portanto possue 02 grades curriculares em funcionamento: A primeira com uma lamina intermediária de disciplinas constituída de Introdução, Equivalência, Modificação no Bloco e alteração de cargas horárias de disciplinas para promover a adequação do currículo as diretrizes do Ministério da Educação e Cultura (MEC) (UFPA, 2001).

Nesta lamina, a disciplina de Clínica Integrada funciona no $10^{\circ}$ semestre, com 260 horas (200 horas para adultos e 60 horas para crianças) com prática clínica e discussão de casos através de seminários, com professores das diversas disciplinas sem corpo docente específicos, o que existe é uma integração de especialidades, pois os professores das 
disciplinas são divididos por dia e por especialidades relacionadas na programação, ou seja, o paciente é o mesmo e o aluno também, mas depois do exame, diagnóstico e plano de tratamento as diferentes necessidades são executadas em conjunto com diferentes professores, mantendo uma certa integração e um atendimento integral do paciente (UFPA, 2001).

O novo Projeto pedagógico do Curso de Odontologia tem como objetivo, graduar Cirurgião-Dentista com sólida formação técnica, científica, humanística e ética, orientado para a promoção de saúde com ênfase na prevenção de doenças bucais prevalentes, e consciente da necessidade de educação continuada, interagindo com a população, capaz de alterar o perfil epidemiológico de saúde bucal da região, participando do sistema de saúde, com capacidade de liderança e sensibilidade social, com a duração de 05 anos e com 4.624 horas (UFPA, 2002).

A nova proposta para o Curso de Odontologia está de acordo com o perfil da UFPA, pois o CONSEP. através da Resolução ํㅡ. 2.891 de 2002, Art. $\mathrm{n}^{\circ} .4$, define que o Curso deverá ser composta de 05 (cinco) fases:

$1^{\text {a }}$. fase: Condições morfofuncionais e suas alterações com a variável social; 2ª . fase: Ações integradas de propedêutica e promoção de saúde; 3a․ fase: Odontologia restauradora pré-clínica; 4⿳亠丷a . e 5a . fase: Ações de atenção integral (clínica integrada) A disciplina de Clínica Integrada do Curso de Odontologia da UFPA (denominada de Clínica Odontológica) será desenvolvida em 04 semestres, em nível de complexidade crescente, com práticas clínicas em crianças e adultos, implantada pela UFPA CONSEP. Resolução nํ․ 2.811 , de 22 de 
junho de 2001 (UFPA, 2001), que no seu Art. 1ํ․ $\S 2^{\circ}$. Eqüivalência disciplinar, decide criar a disciplina de Clínica Integrada que substituirá o Estágio Supervisionado de Cirurgia, Clínica Odontológica, Prótese de Ponte Fixa, Prótese Total, Endodontia e incluirá as clínicas de Periodontia e Odontologia Preventiva e Social (Odontologia em Saúde Coletiva), situada na $4^{\underline{a}}$ fase $\left(7^{\circ}\right.$ e $8^{\circ}$ semestres) com 612 horas e na $5^{\underline{a}}$ fase $\left(9^{\circ}\right.$ e $10^{\circ}$ semestres) com 1.020 horas, assim distribuídas (UFPA, 2002; UFPA, 2000c).

a) 748 horas de clínica integrada;

b) 136 horas de atuação em saúde coletiva (estágio extramuro) que será realizado em municípios que possuam unidades interiorizadas da UFPA (CAMPUS);

c) 136 horas para realização do Trabalho de Conclusão do Curso (TCC).

O Curso de Odontologia está estruturado da seguinte maneira: 1 Coordenação e 2 Departamentos, sendo 1 de Clínica Odontológica e outro de Prótese, com 68 professores, 523 alunos, 39 disciplinas, semestral, com dupla entrada, diurno, 08:00 as 14:00 horas e das 14:00 as 20:00 horas e oferta 90 vagas por ano, com a entrada de 45 alunos por semestre divididos em 2 turnos. Possue 2 cursos de especialização, 1 em Endodontia e outro em Odontopediatria, com 7 projetos de extensão e 4 de pesquisa, 4 salas de clínicas, duas recém inauguradas de acordo com as orientações técnicas de biossegurança, central de esterilização e Comissão de Bioética. Também no Curso se realiza 1 Jornada Acadêmica anual e uma Semana de Apresentação de Trabalhos de Conclusão de Curso (UFPA, 2001). 
O curso possue um serviço de triagem composto por Assistentes Sociais e estagiários, onde são feitas as triagens sócio-econômicas dos pacientes para as clínicas, depois será feita a seleção dos pacientes para as disciplinas pelos alunos de Estomatologia, coordenados pelos professores e posteriormente haverá outra triagem para os pacientes da Clínica Integrada (UFPA, 2001).

No modelo novo em implantação a disciplina de Clínica Integrada (de adultos e crianças) será desenvolvida nas fases 4 e 5 com o nome de

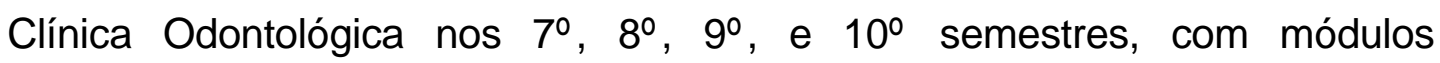
integrados de Periodontia, Cirurgia, Dentística, Endodontia, Prótese, DCM, Terapêutica, Triagem de pacientes, Urgência e Emergência em pacientes adultos e portadores de necessidades especiais (UFPA, 2002).

A Clínica Integrada do Curso de Odontologia da UFPA, é uma disciplina curricular destinada à consolidação dos conhecimentos teóricos e práticos do aluno no último semestre da graduação, vincula-se pedagógica e didaticamente à Coordenação do Curso e administrativamente aos Departamentos de Clínica e Prótese do Centro de Ciências da Saúde (UFPA, 2001).

Objetivos da Clínica integrada:

a) Integralizar o conteúdo técnico científico;

b) Integrar de modo racional e em situação real de trabalho todo o aprendizado desenvolvido durante o curso, em um sistema de discussão caso a caso, sob supervisão docente; 
c) Capacitar, técnica e cientificamente, o concluinte de Odontologia, de modo a proporcionar-Ihe a confiança e segurança indispensáveis æ̀ suas atividades profissionais;

d) Estimular atitudes éticas e humanísticas nos alunos durante o relacionamento com docentes, discentes, auxiliares e usuários.

O aluno somente poderá iniciar as suas atividades na Clínica Integrada após ter obtido aprovação em todas as disciplinas obrigatórias do ciclo básico e profissional, perfazendo o total de créditos do currículo pleno, pertinentes a esses ciclos (UFPA, 2000a).

A Clínica Integrada é constituída por atividades clínicas nas áreas de Cirurgia I e II, Dentística II e III, Endodontia I e II, Odontopediatria I e II, Ortodontia Preventiva, Periodontia, Próteses Parcial, Removível e Total, e Saúde Coletiva, com Estágio extramuro curricular em municípios do Estado (UFPA, 2000b).

Quanto ao papel da educação segundo Abrams et al., 1986, é um instrumento de transformação social - e não apenas a educação formal; mas toda ação educativa que propicie a reformulação de hábitos, a aceitação de novos valores e conceitos, e que estimule a criatividade.

Segundo Stechman (1998), à Universidade cabe educar alunos, capazes de se tornarem verdadeiras pessoas, incorporadas crítica e conscientemente à sociedade.

Esta é formação necessária para mudar e conseguir um profissional qualificado e capaz de gerar expectativas com a conseqüente satisfação nos pacientes (Cunha, 1998). 
Segundo Vargas \& Vasconcelos, 1998 a implantação das clínicas integradas nos currículos dos cursos de graduação em Odontologia, teve como objetivo promover um atendimento mais abrangente ao paciente, desenvolvendo no aluno a habilidade em realizar diagnóstico e trabalhos clínicos de forma integral.

O processo de discussão referente às clínicas integradas teve início, no Brasil, em 1976, a partir da reunião do Programa latino-americano de Inovações em Educação Odontológica, patrocinada pela Organização Mundial de Saúde (OMS) e Fundação Kellog, em Piracicaba. Nessa reunião Arango, 1976 apresentou um trabalho, no qual mostrava que a produtividade e a qualidade do tratamento prestado por uma Clínica Integrada dependiam do nível de conhecimentos adquiridos pelo aluno e da variedade dos trabalhos requeridos pelos pacientes, o que evidentemente refletia as necessidades bucais da população.

Apesar dos avanços da Odontologia, alguns pacientes ainda se sentem desconfortáveis frente ao atendimento. Nota-se que é fundamental melhorar a comunicação entre o aluno, professor e paciente, comunicação esta que deve estar associada ao carinho, e respeito ao paciente além da competência na execução dos trabalhos, para resultar no sucesso do tratamento e satisfação do usuário (Bergreen \& Maynert, 1984; Rodriguez Ousset, 1994; Ramos, 2001; Bacci et al., 2002).

A utilização dos serviços odontológicos está significativamente associada a percepções e a expectativas da comunidade em relação à prestação de serviços de saúde (Rodriguez Ousset, 1994). Programas que 
visam à melhoria da assistência médica e odontológica deveriam levar em conta as expectativas da população a respeito do que é oferecido e esperado, visto que a satisfação do paciente deve ser usada como medida do resultado do atendimento odontológico (Trad et al., 2002).

Os alunos e os professores devem esmerar-se para que o paciente não se sinta "diminuído por receber um serviço gratuito" e torná-lo capaz de entender que a qualidade de um serviço oferecido não está condicionado com a gratuidade (Vargas \& Vasconcelos, 1998).

Segundo Bacci et al., 2002 a atenção odontológica configurada em clínicas integradas deve ser um eixo, a espinha dorsal no processo de formação do aluno, e nunca uma atividade marginalizada, complementar ou terminal.

Vários pesquisadores têm direcionado seus trabalhos para estudar a qualidade da relação entre pacientes, alunos e professores, como forma de melhorar a eficácia do serviço (Marcos, 1991; Azambuja, 1994; Ramos, 2001).

No entanto, em um meio acadêmico, muitas vezes, não sabemos ou não dividimos uma mesma opinião sobre como um paciente avalia o serviço que recebe, o que considera relevante no mesmo, e, dentro de suas condições financeiras, o que o leva a escolher um serviço de saúde (Ramos, 2001).

Por sua vez, Mendes (1971) relatou que os serviços prestados existem como resposta cultural a uma necessidade básica de saúde oral e 
funcionam dentro de um sistema, que está contínua e automaticamente se ajustando, de acordo com as necessidades da sociedade.

Para estimar a qualidade dos serviços, foram identificadas três abordagens: estrutura, processo e resultado. As medidas de estrutura envolvem informações sobre recursos físicos, humanos, materiais, formas de organização e funcionamento (normas e procedimentos), tipo e especialização dos equipamentos, etc. O resultado se refere ao efeito que as ações e procedimentos tiveram sobre o estado de saúde dos pacientes, como incapacidades, desconforto e insatisfação. Já a avaliação da qualidade do processo, ou seja, as atividades realizadas pelos provedores de assistência, apresenta algumas complexidades, uma vez que pode referir-se tanto ao componente técnico, como ao de relação interpessoal, este com dificuldades maiores de mensuração (Badner et al., 1992).

Uma importante constatação da literatura sobre processo, é que a maioria dos autores adota uma perspectiva reducionista do processo de assistência, primeiro individualizando cada procedimento, e em seguida decompondo-o nas suas várias partes (Trad et al., 2002).

Pesquisadores como Abramonicz (1976); Barbisan et al., (1995) relataram que as Faculdades devem ser responsáveis por formar bons profissionais, por avanços científicos, e ainda, no atendimento a pacientes, oferecerem um bom serviço. Serviços que atualmente deixaram de ser focados em doenças para enfocar saúde. Saúde, cuja definição considera o indivíduo como um todo e envolve dimensões físicas, mentais e emocionais. 
Gerado pela grande competitividade do mundo, principalmente a partir da revolução industrial do século XVIII, o conceito de serviço de qualidade e de fabricação e comercialização de bens com qualidade, difundiu-se entre as empresas que disputam fatias de consumidores, passando a ser o fator diferencial de sucesso ou fracasso de uma instituição (Russo, 2003). Hoje fatores como confiança, atualização, competência, humanidade, presteza, pontualidade, cordialidade, preparo técnico científico e organização do ambiente de trabalho, são todos referências para a satisfação de um cliente e/ou paciente que usa um serviço.

A satisfação do paciente com um serviço de saúde, exigiu a formação de um novo profissional em saúde. Tudo mudou da Constituição de 1988 para hoje, quando as diretrizes básicas do Sistema Único de Saúde foram traçadas. Tudo se tornou novo, e necessariamente tinha de tornar-se: as instituições, a assistência, os processos de trabalho, os trabalhadores e até mesmo os usuários, que deixaram de ser "aqueles que têm carteira assinada" para serem cidadãos que detêm um direito, o de ter acesso à saúde.

Uma nova assistência á saúde (baseada na eqüidade na integralidade na universalidade e no controle social) pressupõe novos trabalhadores e novos processos de trabalho que, por sua vez, pressupõem uma nova formação profissional e um novo perfil dos usuários. Quais são os princípios, critérios e demandas desta nova formação? Qual é o seu contexto? Estaria ela vinculada a novos princípios e dimensões mundiais e locais da educação, do mercado de trabalho, das funções do Estado? Estas 
são questões a responder pelo novo profissional e pelo novo usuário através da satisfação para com o serviço de saúde.

Donabedian (1980); Deming (1990); Couto (1995) e Russo (2003), em seus estudos relataram que o paciente/cliente é um ser específico e tem exigências diferentes, por isso, a sua satisfação não pode ser garantida com soluções uniformes. Assim como estão mais exigentes, os pacientes/clientes estão mais informados, graças as novas fontes de informações. A facilidade de acesso a informação de saúde faz com que o paciente/cliente escolha um profissional de saúde com boa reputação isto não terá garantia de qualidade no resultado, mas ao menos diminui as chances de fracasso ou erro.

Em recente pesquisa Russo (2003), relata que um paciente/cliente satisfeito com o serviço de saúde recebido, tem o poder de atrair para atendimento em média pelo menos 6 novos pacientes/clientes. Já o paciente/cliente insatisfeito pode retirar 14 potenciais consumidores: mostrando que a velocidade de difusão de uma recomendação negativa é mais rápida que a recomendação positiva.

Segundo Russo (2003) em casos de insatisfação, 96\% dos pacientes/clientes insatisfeitos não se dão ao trabalho de contar ao profissional a sua insatisfação. Em conseqüência, $91 \%$ dos pacientes/clientes insatisfeitos vão procurar outro serviço e outro profissional, e $79 \%$ dos pacientes/clientes perdidos podem ser atribuídos tanto a reclamações não atendidas ou indiferença no atendimento. $O$ paciente/cliente que reclama (obtendo ou não resposta satisfatória), tem 
mais probalidade de se tornar um paciente/cliente leal do que aquele que jamais reclama.

A satisfação do cliente é geralmente definida como uma função das percepções do cliente e de suas expectativas, de modo que: Satisfação = Percepções / Expectativas, ou seja, "O cliente satisfeito é aquele que percebe que o atendimento de suas necessidades pela organização é pelo menos igual àquele que se esperava". Para isso necessitamos saber exatamente quais as expectativas do cliente e em seguida quais as sua percepções em relação ao cumprimento dessas expectativas. É aqui que nos encontramos com o primeiro desafio, porque as expectativas e as percepções são dinâmicas por serem essencialmente subjetivas e mutantes e portanto difíceis de validar (Deming, 1990; Couto, 1995; Russo, 2003).

Para satisfazer o cliente é necessário ter, primeiro uma compreensão profunda de suas necessidades e, em seguida, possuir os processos de trabalho que possam, de forma efetiva e consistente, resolver essas necessidades. Para isso, a organização deverá traduzir essas necessidades em requisitos e cumprir esses fatores, sempre, porque 0 cliente não exigirá menos. Isso exigirá a dedicação de recursos para coletar e analisar dados e informações, sistematicamente, para entender os requisitos e as percepções do cliente (Deming, 1990).

A partir do século XX, a sociedade despertou para o interesse com os serviços e produtos, pois a marca é mais que um simples nome ou símbolo. Ela deve ser uma síntese de todas as ações mercadológicas que 
se originam na satisfação de desejos ou necessidades específicos do consumidor (Russo, 2003).

Segundo Pascoe (1983); Sala (1993); Williams (1994) em seus estudos, revelaram que para avaliar satisfação de usuários são utilizados de maneira geral, escalas e questionários compostos de subitens que tratam de uma ampla gama de questões, incluindo estrutura, funcionamento e avaliação do serviço de saúde pelo usuário. Têm-se limitado, porém, à mensuração do nível de satisfação com o serviço prestado, sem um esforço de contextualização cultural.

Quando a experiência do usuário no sistema de saúde se reduz a uma pergunta dicotômica relacionada à satisfação ou insatisfação, deixam de ser contempladas considerações sobre as crenças, os modos de vida, as concepções do processo saúde-doença dos usuários do sistema de saúde, aspectos que claramente influenciam os modos de utilização dos serviços pelo usuário (Souza, 2000; Russo, 2003).

Segundo Atkinson (1993), abordar a satisfação dos usuários implica fazer um julgamento sobre características dos serviços e, portanto, sobre sua qualidade. Assim, a perspectiva do usuário fornece informação essencial para completar e equilibrar a qualidade dos serviços.

Alguns autores como Donabedian (1980); Atkinson, (1993) apontaram o quadro conceitual mais utilizado para avaliação dos serviços de saúde, que propõe estratégias para as áreas de estrutura, processo e resultado, assim entendidas: estrutura - avalia o ambiente em que se desenvolve a assistência e os instrumentos utilizados, referindo-se portanto 
æ̀ características mais estáveis e invariantes de como se estabelece a direção da atenção à saúde (pessoal, instalações e equipamentos); processo - avalia a dinâmica de assistência ao paciente, ou seja, o que fazem os profissionais da saúde do ponto de vista técnico na condução da atenção e enquanto sua intenção com os pacientes; resultado - exame do resultado da atenção ao paciente, são as conseqüências da atenção (ou falta dela) na saúde de quem a recebe.

Outros autores, como Donabedian (1980) e Pascoe (1983), consideraram que a satisfação dos usuários pode ser vista pela reação que têm diante do contexto, do processo, e do resultado global de sua experiência relativa a um serviço. Pascoe (1983), enfatizou que essa avaliação se baseia em padrões subjetivos, implicando, portanto, atividades psicológicas (no campo perceptual) de ordem cognitiva e afetiva, engajadas em um processo comparativo entre a experiência vivida e critérios subjetivos do usuário.

Os elementos contemplados pelo sujeito na avaliação de níveis de satisfação, envolvem uma ou mais combinações dos seguintes elementos: um ideal de serviço, uma noção de serviço merecido, uma média da experiência passada em situações de serviços similares, e um nível subjetivo mínimo da qualidade de serviços a alcançar para ser aceitável.

No caso da Odontologia, as situações que provocam insatisfação podem ser divididas em dois tipos: 
Insatisfações fundamentadas - são geradas por trabalhos ou serviços mal executados. Essas situações envolvem estética, função, dor, erros de atitudes no trato pessoal etc.

Insatisfações não fundamentadas - são aquelas criadas por uma expectativa exacerbada em torno de um trabalho que um cirurgião-dentista poderia executar de forma limitada. O descontentamento ocorre, por exemplo, na execução de próteses de dentes anteriores, que tecnicamente estariam perfeitas, porém não agradam ao cliente que as julga insatisfatórias.

É preciso que saibamos conduzir a clientela no caminho da saúde, em primeiro plano, para depois deixá-la fazer as opções que quiser, no âmbito do tratamento eletivo. Essa é a diferença que existe entre o comércio e a prestação de serviço em geral, e a área de saúde que gera satisfação do paciente.

O instrumento adequado para pesquisar satisfação é o questionário, pois através de perguntas e respostas, poderemos saber com detalhes como são e como agem as pessoas que até então têm procurado seus serviços. É evidente que não só dados referentes ao perfil socioeconômico são importantes, porém também é necessário saber como elas pensam, o que acham de nós, o que pensam de nosso local de trabalho, de nossos funcionários, e também o que elas gostariam que fizéssemos para que se sentissem melhor (Russo, 2003).

Estudando o assunto, Kerr (1985); Abrams et al. (1986); Fitzmaurice (1992); Barbosa, (1995), informaram que pesquisas envolvendo percepções 
de usuários agrupam alguns conceitos que levam a satisfação como: habilidade técnica do dentista, evitar que o paciente sinta dor, facilidade de acesso à clínica e ao tratamento, custo do tratamento, informações em relação ao tratamento, atitudes do professor e do aluno, estética, higiene e função dos dentes.

Mas, como a nossa sociedade carece de uma cultura de avaliação, os programas de avaliação presentes na comunidade acadêmica, ainda persistem na definição de procedimentos que induzem uma decisão e acabam por intimidar, tanto os professores, alunos e os gestores das unidades de ensino, subestimando o caráter essencial da avaliação que é o de enfatizar a discussão entre os agentes sociais-gestores, professores e alunos, já que é, a discussão, a função essencial da avaliação (Berwick, 1994; Nicodemo et al., 2001).

Diversos pesquisadores como Poi et al., 1997; Vargas \& Vasconcelos, 1998; Pinto, 2000; Nicodemo et al., 2001, relataram que a avaliação centra-se, em discutir prioritariamente alguns aspectos que merecem destaque: a) a importância do aluno no processo, mesmo que os objetivos da avaliação sejam, ainda, o centro da discussão, em sua função formativa; b) considerar que o processo de avaliação deve contar com múltiplas fontes de informações; c) considerar que a instalação de uma cultura de avaliação depende de um clima organizacional participativo.

Assim sendo a tese, satisfação do paciente como sinônimo de qualidade é defendida por muitos que lidam com a administração, 
argumentando que é através do paciente que se avalia a qualidade dos serviços prestados (Campos, 1992; Malik, 1992; Mezomo, 1993).

Segundo Stechman Neto (1998) avaliar é uma preocupação indissociável do ser humano. Processo natural, face à observação das diferenças, a avaliação permeia o nosso dia-dia como parte do contínuo e compulsivo questionamento da realidade pelo homem, vivente incansável na busca de respostas.

Com isso, a avaliação estabelecerá elos entre a teoria e a prática ou entre a realidade teórica da sala de aula e a realidade concreta do trabalho (Araújo \& Araújo, 2001).

Gallo (1996), afirmou que a avaliação compartilhada junto aos usuários, poderá ser um instrumento para a mudança das práticas de saúde nas clínicas, de maneira democrática com controle social e participação comunitária preconizada pela reforma sanitária brasileira. Então a aferição do usuário deve ser o objetivo de todo o modelo assistencial que queira ser de qualidade e humano (Souza et al., 2000).

A avaliação dos serviços pode ser um instrumento dinâmico de transformação, posto que a avaliação em si constitui-se em um processo capaz de abrigar as diferentes vozes dos diferentes atores socais que fazem do serviço o seu locus de atuação, visto que é necessário que em algum momento se inicie o processo de avaliação e que se confira sistematicidade seqüencial ao mesmo (Rocha \& Bercht, 2000).

Seguindo esta tese o envolvimento da clientela dos serviços de saúde que ultrapassem a mera utilização passiva dos mesmos, é algo 
desejável, tendo em vista a ampliação do uso, a melhoria da qualidade de tais serviços e, principalmente, níveis mais altos de satisfação com as agências prestadoras do mesmo (Martins, 1993; Perez, 1993; Bittar, 2001).

Segundo Bittar (2001), "as percepções dos pacientes são vitais e é por isso que elas devem ser pesquisadas com instrumentos adequados", visto que delas dependem a análise sobre qualidade de serviços. Portanto, tratando-se de avaliação de qualidade e satisfação, deve-se conhecer as necessidades e os desejos do paciente, núcleo central do sistema de saúde (Padilha et al., 1995).

Por outro, lado é possível constatar uma ampliação na conceituação de efetividade, resultado e qualidade, que não deve limitar-se a uma perspectiva clínica biológica, e de doença, mas incluir dimensões da subjetividade e historicidade, o que significa pensar também em saúde e qualidade de vida, e ser capaz de captar os processos diagnósticos e terapêuticos da forma mais ampliada (Chaves, 1986; Guyatt et al., 1993; Pope \& Mays, 1993; Orchard, 1994).

Para Bacci et al. (2002), a qualidade da assistência nos serviços de saúde pode ser defendida como satisfação das necessidades dos pacientes. É para eles que devem ser dirigidas as estratégias na busca da qualidade. Os pacientes devem ser ouvidos acerca da avaliação sistemática das atividades dos professores e alunos das Clínicas Integradas das Faculdades, como também a respeito do impacto dos processos de tratamento sobre sua saúde e o seu perfil de risco (Costa \& Formigli, 2001). 
O enfoque de risco tem sido muito utilizado na dimensão individual, principalmente para a descrição da etiologia. É necessário resgatá-lo para a dimensão do coletivo. Trad et al. (2002), sustentaram que "avaliar o processo-saúde-doença em sua dimensão coletiva não pode ser feito somente com a dimensão da epidemiologia tradicional (tempo-lugar-pessoa), se não se busca a essência do processo".

Embora não se trate aqui de uma instância do processo saúdedoença foi-se buscar a essência do tratamento odontológico e neste, as múltiplas normas que o complementam na orientação do que é uma assistência desejável. Afinal, as normas técnicas representam um conhecimento científico acumulado, um saber reconhecido e aceito nos meios científicos, ainda que nem sempre sejam atualizadas na velocidade em que progride esse conhecimento (Poi \& Tagliavini, 1999).

Por outro lado, é possível constatar uma ampliação na conceituação de satisfação, resultado e qualidade, que não deve limitar-se a uma perspectiva clínica biológica, e de doença, mas incluir dimensões da subjetividade e historicidade, o que significa pensar também em saúde e qualidade de vida, e ser capaz de captar os processos diagnósticos e terapêuticos da forma mais ampliada (Guyatt et al., 1993; Orchard, 1994; Pope \& Mays, 1993; Nicodemo et al., 2002).

Segundo Bittar (2001) indicadores de qualidade e quantidade em saúde, produzem informações para medir produção de programas e serviços, bem como estabelecer metas a serem alcançadas e permitem formar um banco de dados simples, ágil e de baixo custo, além da 
montagem de séries históricas que permitam a comparação com outras instituições ou consigo mesma, quando analisadas no tempo.

A instituição que possui uma equipe de trabalho que demonstra interesse e atenção aos pacientes, considerando-os como prioridade nas ações de saúde, caminha para alcançar a qualidade pela satisfação das necessidades e das expectativas do paciente (Azambuja, 1994; Loureiro et al., 2000).

A partir desses procedimentos cria-se um relacionamento de amizade e de confiança que contribui sensivelmente na relação com o usuário. Mas o desafio na busca da qualidade não termina com a satisfação do paciente, é preciso buscar também satisfação nos atores do processo (Neves, 1995; Butters \& Willis, 2000).

Assim sendo, a disciplina de Clínica Integrada pode ser avaliada de acordo com as seguintes proposições (CFE, 1982).

- na integração, quando a intenção da disciplina se norteia pela expectativa de aproximar, reunir conhecimentos, práticas, setores ou partes relacionadas aos processos de ensino como um todo e não necessariamente especificadas;

- $\quad$ no progmatismo, quando a intenção que orienta a disciplina é dar conta das atividades, a ela atribuída, da melhor maneira possível, sem, no entanto ultrapassar este referencial;

- $\quad$ na prevenção, quando a orientação principal da disciplina envolve valores e procedimentos relacionados com a manutenção da saúde. 
- no humanismo, quando a orientação principal envolve uma preocupação com o desenvolvimento do homem, atingindo uma amplitude que ultrapassa sua formação profissional;

Portanto, podemos afirmar que a aglutinação e homogeneização dos conhecimentos já adquiridos nas diversas disciplinas básicas e clínicas do currículo, acabam refletindo a própria filosofia de ensino da Instituição (Veiga et al., 2000).

Do ponto de vista moderno, a avaliação foi o meio de que se valeu a escola para saber se os objetivos do ensino, tal como planejados, foram atingidos em relação ao aluno (Perez, 1993).

Portanto, o sistema de ensino tem na avaliação seu motor processual, isto é, o elemento dinâmico que garante, nas duas pontas, a entrada e a saída do sistema e, no meio o fluxo entre suas fases. As notas, reprovação, aprovação, a evasão, são fenômenos resultantes da avaliação que alivia o sistema de seus excessos de carga, permitindo a renovação e ocupação de suas vagas (Poi et al., 1997).

A participação situa-se como elemento central de uma avaliação, pois, onde não há participação popular, não há qualidade (Narvai, 1993; Nuto \& Nations, 1999).

Em Porto Alegre (RS), Barbisan et al. (1995) realizaram um estudo chamado de "Parecer dos pacientes sobre a eficácia no atendimento recebido na Faculdade de Odontologia da UFRGS", com o objetivo de verificar a qualidade de atendimento do paciente na FO-UFRGS, desde o ingresso no setor de triagem, até o encaminhamento aos ambulatórios e 
atendimentos pelos alunos, e sua avaliação ao final deste processo. Com os resultados alcançados, observou-se que o paciente estava satisfeito com o atendimento e ambiente físico da Faculdade, acreditavam na competência do aluno e indicariam o serviço para outras pessoas.

Resultados observados por Barbosa (1995) relataram que um dos ambientes mais propícios para avaliar satisfação dos pacientes com 0 serviço de uma Faculdade de Odontologia, deve ser a clínica, por ser o retrato do trabalho de uma equipe de professores e alunos no exercício da prática odontológica em todos os níveis de atenção, portanto capaz de refletir a eficácia social da Instituição (Leão \& Dias, 2001).

Todo e qualquer tipo de avaliação de saúde não pode encerrar-se em si mesmo. Ao apontar deficiências, ao analisar a satisfação, ao medir o grau de eficiência, apenas inicia-se sua principal função e objetivo de confirmar ou reformular o processo (Carvalho et al., 2000).

Para isto podemos utilizar a Epidemiologia que é um instrumento de estudo das condições de saúde-doença das populações, dos principais fatores causais associados, e de avaliação da eficácia dos serviços, programas e políticas de saúde (Brasil, 2000; Brasil, 2001).

Ao se proceder a uma efetiva avaliação institucional, consegue-se demonstrar a seriedade e a consistência dessa Instituição, especialmente pelo fato de ser um órgão público e portanto, sujeito ao controle social da população (Pinheiro \& Silva, 2002; Newsone \& Wright, 1999; Nuto \& Nations, 1999). 
Para Mezomo (1994), é preciso que a universidade deixe a prisão da "certeza" e entre na liberdade da "dúvida" para poder, pelo questionamento, vislumbrar a "verdade" que ela sempre buscou. Que ela se avalie, rotineiramente, não apenas quanto aos aspectos quantitativos de sua estrutura e de sua produção, mas, sobretudo, quanto aos aspectos qualitativos de seus processos e de seus resultados.

A impressão generalizada da opinião pública e dos usuários sobre o desempenho dos serviços públicos de saúde é de que o sistema é deficiente, com os seguintes problemas: cobertura insuficiente, desigualdade no atendimento, baixa quantidade dos serviços oferecidos em termos de equipamentos e serviços profissionais, baixa capacidade resolutiva e reduzido grau de satisfação por parte dos usuários (Santana, 1996).

A qualidade pode existir a nível dos fatos e na percepção das pessoas. A primeira diz respeito à visão do profissional que utiliza indicadores para quantificá-la. Já a qualidade na percepção das pessoas é a visão empírica dos fatos, um julgamento individual, subjetivo, sem critério técnico. Essa forma de observar e julgar são utilizadas pelo usuário (Masseto, 1997).

Segundo Hirata et al. (2001) a formação do aluno e a preparação do futuro profissional não se completa exclusivamente com atividades curriculares dentro da sala de aula, do laboratório e de clínicas. Currículos plenos, com carga horária extremamente excessiva impedem que o aluno freqüente a biblioteca, e tenha vivência universitária extra classe. 
Segundo Pinto (2000), permanece o eterno dilema: se tanto a preferência subjetiva quanto æ̀s abordagens profissionais são suspeitas para determinar quais são as necessidades e como elas são medidas, quem vai decidir sobre os indicadores sociais apropriados e como? A resposta consensual é a participação. A participação bem informada da população cujas necessidades estão sendo avaliadas é essencial.

Para que se alcance uma avaliação mais realista das necessidades, haveria que alcançar uma noção mais precisa acerca do potencial (tendência) do indivíduo, para responder positivamente aos cuidados de saúde que lhe serão proporcionados (Leão \& Dias, 2001; Poi et al., 1997).

Sendo assim, se vamos avaliar a satisfação com serviços nas Faculdades de Odontologia, é preciso definir bem que a Clínica Integrada é a disciplina em que o aluno de graduação torna-se apto para o desempenho da clínica geral, de acordo com os fatores cognitivos, afetivos e psicomotores, com capacidade para exame, diagnóstico, planejamento e pela conseqüente execução do plano de tratamento, objetivando a resolução do caso clínico, interagindo os conhecimentos, habilidades e atitudes (valores) adquiridos ao longo do curso, de modo a proporcionar ao paciente o atendimento integral das necessidades evidenciadas (Barros, 1981; Brasil, 1982a; Stechman, 1998).

Avaliar a importância da disciplina de Clínica Integrada na rede de atividades curriculares do Projeto Pedagógico do Curso de Odontologia da Universidade Federal do Pará, e seu papel integrador e de transdisciplinaridade, indicará uma integração das disciplinas de um campo 
particular sobre uma base compartilhada, cuja coordenação é assegurada por conhecimentos comuns, capaz de desenvolver uma autonomia teórica e metodológica perante as disciplinas que a originaram (Brasil, 1982b).

A exemplo do ocorrido com a moderna ecologia oriunda da biologia evolucionista em sua interface com as geociências, a disciplina de Clínica Integrada é, diferente das demais disciplinas curriculares tradicionais, em que o saber odontológico é ministrado por partes, fragmentado e desintegrado, pois tem seu papel definido como estrutura intracurricular idealmente antagônica æ̀s características e æ̀s tendências especializantes das demais disciplinas clínicas (Brasil, 1996; Couto et al., 1997; Garcia, 2002).

Porém, segundo Almeida \& Padilha (2001) em um trabalho realizado na Disciplina de Clínica Integrada da Universidade Federal da Paraíba (DCI/UFPB), foi observado que a DCI/UFPB não é capaz de promover saúde bucal nos pacientes, só atendimento curativo em nível de ambulatório, o que provocou uma insatisfação nos usuários.

Em outro trabalho, segundo Weyne (1997) no nível psicossocial, uma boca sadia garante a manutenção da boa aparência, da expressão e da comunicação interpessoal, sendo assim, um fator de avaliação na preservação da auto-estima.

Contudo, Kramer et al. (2000) relataram que as decisões de tratamento e avaliação dependem, entre outros fatores, do que o paciente é capaz de aceitar e manter e que permite um resultado que o paciente considere satisfatório. 
Segundo Alvesalo \& Uusi-Heikkilä (1984) em um estudo sobre o uso de serviço, características comportamentais, suas intercorrelações e satisfação, realizado através de uma amostragem aleatória de 94 pacientes das clínicas dentárias de 03 especialidades, Periodontia, Dentística Restauradora e de Ortodontia e uma de Odontologia Familiar para os moradores adstritos da Universidade de Connecticut (USA), cujos dados foram coletados em uma entrevista e registros dos pacientes, observou-se que na procura de tratamento o percentual mais alto (34\%) dos pacientes, confiaram nas indicações de amigos, parentes ou vizinhos.

Neste trabalho, as seguintes dimensões de satisfação foram mensuradas: dificuldades para conseguir uma consulta, satisfação geral com o tratamento, custo do tratamento em geral, conveniência do tratamento e satisfação com a saúde oral. Os resultados mostraram que as opiniões com relação ao tratamento e a saúde oral são dominantemente positivas variando de 60 a $94 \%$ de todas as respostas. Os custos foram considerados como altos por $54 \%$ dos pacientes. Houve uma correlação positiva e significante entre grau de utilização e satisfação com o tratamento. A maioria dos pacientes, $82 \%$ estava satisfeita com o tratamento dentário nas clínicas.

Os resultados relacionados à variedade similar de serviços na Clínica de Odontologia Familiar e das outras clínicas, mostraram que suas realizações estão de acordo com os objetivos do programa educacional daquela clínica. Uma descoberta inesperada, foi segundo os autores que as opiniões sobre a Clínica de Odontologia Familiar nos custos dentários foram mais negativas e sobre a duração do tratamento foram mais positivas do que 
das outras clínicas. Provavelmente as pessoas que procuraram tratamento em uma Clínica de Odontologia Familiar, valorizaram especialmente os custos moderados relacionados ao tratamento amplo. Diferenças de opinião sobre o tempo de tratamento devem ser devido ao papel das clínicas especiais, como as de ensino, por exemplo, onde os tratamentos levaram mais tempo do que a média.

Em 1986, Davis et al., relataram que na Faculdade de Odontologia da Universidade de Nova York em Búfalo, após à aplicação de um questionário para mensurar em 81 pacientes a expectativa e satisfação com as próteses utilizadas, que a maioria dos pacientes procurou o tratamento em prótese esperando que as próteses sejam comparáveis a dentição natural, tanto funcional quanto esteticamente e a satisfação alta pode representar além disto, os meios pelos quais os pacientes justificaram as despesas de seus tratamentos odontológicos.

Handelman et al. (1990) relataram em um trabalho para avaliar a satisfação do paciente em quatro tipos de clínica dentária, que houve um crescimento significativo em tipos alternativos de clínica dentária. Para determinar a satisfação, os pacientes foram examinados em clínicas privadas urbanas, em uma clínica odontológica hospitalar, um centro de saúde do bairro e uma grande clínica privada situada em um shopping center, usando-se um questionário com 14 itens e uma escala de classificação de 5 pontos.

A satisfação do paciente foi relacionada aos seguintes fatores em ordem decrescente: dentista, equipe, eficiência, tempo-custo e acesso. Os 
pacientes avaliaram mais favoravelmente as clínicas privadas em todos os fatores com exceção do acesso, que foi avaliado de forma mais positiva nas clínicas no shopping center. Os pacientes avaliaram menos favoravelmente o hospital em todos os fatores, com exceção do dentista, que teve a avaliação menos favorável na clínica no shopping center. Embora as clínicas privadas tenham sido avaliadas mais favoravelmente, tipos alternativos de clínicas também foram avaliados positivamente e atenderam as necessidades específicas dos pacientes. A satisfação foi maior para paciente mais velhos, para pacientes com pouca escolaridade e para pacientes brancos comparados com pacientes negros e hispânicos.

Segundo Barbisan et al. (1995) no trabalho, parecer dos pacientes sobre eficácia no atendimento na Faculdade de Odontologia da Universidade Federal do Rio Grande do Sul (FOUFRGS), onde realizaram entrevistas com 61 pacientes que estavam retornando para atendimento. A partir disso, observou-se que os pacientes estavam satisfeitos com o atendimento e ambiente físico da Faculdade, acreditavam na competência do aluno e indicariam o atendimento recebido para outras pessoas. E a maioria dos pacientes (66.57\%) atribuiu nota 10 aos atendimentos recebidos e a média aritmética dos graus atribuídos pelos pacientes para o atendimento recebido foi de 9.24 numa escala de 0 a 10.

Segundo Lahti et al. (1996) no estudo de expectativas dos pacientes sobre um dentista ideal, as expectativas dos pacientes foram atendidas em todas as outras características do dentista exceto comunicação e assistência regular. Não ocorreram muitas diferenças entre os subgrupos de pacientes. 
Segundo Handelman et al. (1996) no trabalho sobre satisfação do paciente em uma clínica dentária regular e uma clínica noturna, relataram que as respostas dos usuários através de um questionário com 14 itens, de uma amostra selecionada aleatoriamente, não apresentaram diferença significante, apesar de os profissionais da clínica noturna receberem mais uma taxa de serviços por atendimento como incentivo. Os itens mais mencionados com notas baixas foram números de consultas para o tratamento completo, dor, cortesia das recepcionistas, e este estudo demonstrou que o pagamento de incentivos financeiros não reduz e não garante postura do profissional diferenciada para a satisfação do paciente.

Segundo Franco \& Campos em (1998), estudou-se o ambulatório de Pediatria do Hospital das Clínicas da Universidade de Campinas (UNICAMP), um serviço didático assistencial que, inserido no Sistema Único de Saúde (SUS), presta assistência secundária e terciária para crianças de 0 a 18 anos. Foram aplicados 221 questionários entre clientes do ambulatório geral de pediatria e de uma de suas especialidades, permitindo comparar diversos indicadores de qualidade da assistência médica prestada. Evidenciou-se um bom nível de conhecimento dos responsáveis pelos pacientes sobre seus problemas de saúde. Encontrou-se alto grau de satisfação dos mesmos, embora houvesse baixíssima vinculação entre médico e usuário. Com relação ao atendimento, 43.4\% relataram problemas, mas apenas $17.6 \%$ propuseram sugestões para melhorá-lo. O tempo de espera nas consultas foi bastante longo. 
Na reunião da Câmara dos Delegados em 1997 foi discutido, "Competências para o novo dentista", estas competências incorporam compreensão, habilidades e valores em uma resposta integrada a variação normal de problemas e desafios no exercício da Odontologia , que permitirão ao graduado um exercício seguro e independente. Sendo que, o nível de desempenho requer algum grau de rapidez e adequação para a qualidade na prestação de serviço e satisfação do paciente (House of Delegates, 2002).

Em um estudo realizado sobre o significado de uma clínica odontológica para seus usuários, Ramos et al. (1999), realizaram cerca de 30 entrevistas com os pacientes da clínica extramuro da Faculdade Federal de Odontologia de Diamantina de Senador Mourão, relatando sua importância para a população do Distrito e da Região, uma vez que como prestadora de serviços odontológicos vem cumprindo satisfatoriamente com sua missão social, pois a qualidade técnica do serviço é perfeitamente confundida com o grau de satisfação do paciente ao ser tratado com afetividade.

Em 1999, Chu \& Lo em sua pesquisa sobre satisfação dos pacientes com serviços dentários oferecidos pela clínica dentária da Universidade de Hong Kong, relataram que o estudo foi uma avaliação da satisfação sobre o tratamento dentário para estudantes universitários, funcionários da Universidade e seus dependentes.

Os objetivos deste estudo foram: estudar a satisfação dos usuários com os serviços dentários, identificar as razões por não usarem os serviços 
dentários e comparar as opiniões dos estudantes com as dos funcionários da Universidade e suas esposas. Um total de 140 estudantes e 180 funcionários da Universidade e suas esposas foram aleatoriamente selecionadas para este estudo, com as taxas de resposta de $100 \%$ para os alunos e $77 \%$ para os funcionários e suas esposas. Os resultados mostraram que ambos os grupos de pacientes estavam satisfeitos com a qualidade dos serviços oferecidos pela clínica dentária da Universidade. Entretanto, eles não estavam satisfeitos com o longo tempo de espera para uma consulta. Os estudantes que não foram atendidos na clínica dentária universitária afirmaram que eles estavam ocupados e não tinham tempo para uma consulta dentária. De modo, inverso os funcionários da Universidade e suas esposas não procuraram o tratamento da clínica porque achavam que as taxas eram altas. Embora os escores do Índice de Satisfação Dentária (ISD) para os estudantes (64.5\%) e funcionários e suas esposas $(65.1 \%)$ fossem similares, havia diferença nos aspectos dos serviços com os quais os dois grupos estavam, satisfeitos ou insatisfeitos.

Segundo uma pesquisa realizada por Unfer \& Saliba (2000) os programas de saúde devem considerar os aspectos relativos ao conhecimento e as práticas em saúde bucal, para viabilizar o processo de capacitação da população e promover a responsabilização coletiva da promoção da saúde, em todos os níveis da sociedade.

Os autores relataram neste trabalho que, $66.6 \%$ dos pacientes responderam afirmativamente quando foi perguntado se tinham cárie, $29.8 \%$ mencionaram não ter a doença e $65.8 \%$ consideraram que a cárie dentária 
pode ser evitada por meio do autocuidado, enquanto para $36.5 \%$ o dentista tem um papel significativo neste processo.

Em um recente trabalho que objetivou analisar o abandono do tratamento odontológico (como forma de insatisfação) no Centro de Saúde de Murialdo, em Porto Alegre, Rio Grande do Sul (RS), Rocha \& Bertch (2000) relataram que 29 pacientes (30\%) dos 100 que foram ao Centro de Saúde, citaram como causa do abandono, a impossibilidade de faltar ao trabalho, o tempo de duração do tratamento (muito longo), doenças, gravidez e mudança de domicílio. Sendo que até o momento do abandono, o tratamento oferecido pela instituição foi considerado bom.

Segundo Butters \& Willis (2000) a satisfação do paciente está tornando-se um indicador cada vez mais importante de qualidade no tratamento dentário. Entretanto, a maioria dos levantamentos de satisfação do paciente, tem como público alvo apenas os pacientes atuais das clínicas dentárias das Universidades ou de Instituições, o que pode resultar em uma estimativa aumentada da satisfação com o tratamento, já que os pacientes insatisfeitos provavelmente já deixaram a clínica ou a Instituição. Neste trabalho, os autores fizeram um levantamento telefônico de 291 pacientes, sistematicamente selecionados das listagens do computador da Faculdade de Odontologia de pacientes atuais, os avaliados periodicamente e os antigos, sendo que foram pesquisados onze (11) aspectos de qualidade de tratamento oferecido pela Faculdade de Odontologia. Os resultados indicaram que a satisfação do paciente com o tratamento recebido foi alta e 
que nenhuma das médias para qualquer categoria de paciente atingiu a variação de insatisfação.

Os sujeitos que tinham abandonado o tratamento estavam menos satisfeitos do que os pacientes atuais ou chamados para o estudo em cinco (5) áreas: qualidade do tratamento, duração e número de consultas, explicação do tipo de tratamento e taxas. Os resultados tem implicações para os administradores das Faculdades de Odontologia e educadores, em seus esforços para oferecer ao paciente tratamento de alta qualidade e manter um número adequado de pacientes, para garantir ótimas experiências clínicas para os alunos.

Foram observadas, três (3) razões principais citadas pelos pacientes como justificativa pela procura dos serviços da Faculdade: o custo baixo dos serviços, a recomendação de amigo ou familiar, e a qualidade percebida do tratamento recebido (satisfação), (Butters \& Willis, 2000).

Em 2000, Gürdal et al., realizaram uma pesquisa sobre a satisfação com o tratamento dentário entre os pacientes de uma clínica ambulatorial da Faculdade de Odontologia da Universidade de Izmir, Turquia. O estudo foi realizado em 1001 pacientes dos quais 674 preencheram o questionário para determinar os fatores de (in) satisfação. A maioria dos pacientes tinha escolaridade alta (74.7\%), renda alta $(48.7 \%)$ e era de jovens ou de meia idade (73.1\%). Dos 1001 pacientes, 38.6\% estavam satisfeitos com 0 tratamento dentário que receberam, $23.8 \%$ estavam tanto satisfeitos quanto insatisfeitos, 5\% estavam insatisfeitos e 33.7\% não fizeram comentários. 
Em um estudo realizado por Moysés \& Watt em 2000, observou-se que a insatisfação dos paciente estava relacionada com o inadequado modelo operatório de muitas intervenções, falta de definição de estratégias e avaliação distorcida dos efeitos dos programas desenvolvidos.

Segundo Mascarenhas (2001), que realizou um levantamento em 235 pacientes, sendo 119 entrevistados em 1997 e 116 em 1998, com 95\% dos pacientes respondendo os questionários, onde o eixo da questão era 0 nível de satisfação de pacientes atendidos pelo modelo tradicional (procura espontânea e casual), e pelo modelo de tratamento completo, nenhuma diferença significante foi observada nas características de satisfação dos pacientes atendidos nos dois (2) tipos de sistema clínico. O fato que chamou atenção foi que os pacientes, em alguns casos, estavam menos satisfeitos com o modelo de tratamento completo, porque demorava mais, que o tradicional onde o caso "era resolvido mais rapidamente" e não existia referência de complexidade, pois o aluno era de série mais adiantada e no modelo completo o paciente começava na triagem, adequação para diagnóstico e planejamento ascendente por complexidade e era referenciado para outros alunos o que gerava um nível de insatisfação com este modelo.

No trabalho "Avaliação dos serviços de saúde prestados por Faculdades de Odontologia: A visão do usuário", Leão \& Dias (2001), relataram que a avaliação da qualidade do atendimento recebido é importante, já que a procura do serviço está relacionada com a satisfação decorrente do mesmo. O objetivo do trabalho foi o de conhecer a avaliação do paciente em relação ao serviço oferecido por duas (2) instituições de 
ensino. Um questionário sobre qualidade do serviço odontológico foi entregue a pacientes das 2 Faculdades de Odontologia (A e B) e uma análise descritiva dos dados foi realizada. Mais de $50 \%$ dos pacientes da Faculdade "A" relataram estar satisfeitos com todos os itens abordados no questionário. Na Faculdade "B", itens como "satisfação com restaurações estéticas" e "custos do tratamento" apresentaram menos de $50 \%$ de satisfação. Através deste tipo de informação é importante que uma Faculdade de Odontologia, além de ensino, considere também o paciente, não como um "material de ensino", mas como um usuário de um serviço que ela oferece (avaliando suas necessidades e oferecendo um serviço de qualidade).

Chu et al. (2001) monitoraram a satisfação dos usuários (funcionários, dependentes e alunos) dos serviços dentários de uma Universidade de Hong Kong através de dois (2) sistemas de pagamentos de taxas e outros itens de satisfação, de 1996 a 2000. Em resumo, a satisfação total dos pacientes com a clínica dentária do Serviço de Saúde da Universidade (SSU) em 1996 e em 2000 com dois (2) sistemas diferentes de pagamento de taxas foi similar. Entretanto os pacientes em 2000 estavam menos satisfeitos com o custo do serviço dentário, eles estavam mais satisfeitos com os aspectos de "acesso", "conveniência", "qualidade" e o "relacionamento" do serviço do que os pacientes em 1996. Em 2000 verificou-se um percentual significativamente menor de estudantes e usuários que rejeitavam o serviço e ocorreu um nível de satisfação maior que em 1996 por parte dos pacientes. 
Segundo Ramos (2001) no trabalho, como o paciente se sente ao ser atendido por um aluno de Odontologia, aplicou um questionário em 31 pacientes das clínicas do Curso de Odontologia da Faculdade Federal de Odontologia de Diamantina (FAFEOD), para identificar o sentimento dos pacientes das clínicas ao serem atendidos por alunos, apresentando uma justificativa para a opinião emitida. Os principais resultados apontaram que, apesar dos avanços da Odontologia, alguns pacientes ainda se sentem desconfortáveis frente ao atendimento. Nota-se que é fundamental melhor comunicação entre aluno e paciente, comunicação esta que deve estar associada ao carinho, ao respeito ao paciente e àcompetência na execução dos trabalhos, para resultar no sucesso do tratamento e satisfação do paciente, sendo que o alívio da dor, a reparação do aspecto estético e a gratuidade do tratamento foram fatores que fizeram com que os pacientes procurassem as clínicas da Faculdade.

Segundo Padilha et al. (2001) no trabalho realizado com 98 pacientes da Clínica Integrada da Faculdade de Odontologia da Universidade Federal Fluminense, sobre saúde bucal e nível sócioeconômico, observaram que o perfil do paciente da CIFOUFF, apresentou predomínio de escolaridade e poder aquisitivo baixos, e a análise da saúde bucal indicou a necessidade de maior ênfase para o diagnóstico e tratamento da doença gengival, e não foi encontrado associação estatística entre os níveis sócio-econômico e os índices de saúde bucal referentes a cárie e a higiene bucal. 
De acordo com Almeida et al. (2001) no estudo da avaliação do ensino odontológico na Clínica Integrada da Universidade Federal da Paraíba (CIUFPB), que esta disciplina diferentemente das demais disciplinas do currículo, estava preparada para atender todas as necessidades dos pacientes, sejam elas curativas, educativas ou preventivas. Porém os resultados de tal estudo mostraram que a qualidade dos equipamentos e conteúdos programáticos, não são transferidos de modo direto e linear para a prática clínica, pois foi percebido falta de qualidade no serviço e um nível de insatisfação no paciente.

Segundo Wanderley et al. (2002) no estudo da efetividade dos serviços odontológicos oferecidos pela Disciplina de Clínica Integrada da Universidade Federal da Paraíba, os autores concluíram que a efetividade foi crítica, com predomínio da atenção curativa, índice de abandono preocupante e deficiência no registro dos planejamentos. Entretanto, é oferecida a atenção integral, abrangendo as diversas áreas da Odontologia, caracterizando a alta complexidade do serviço prestado ao paciente, sem grandes interferências no processo causal da doença, aspecto este já referido por Almeida \& Padilha (2001), em outro estudo realizado na referida clínica sobre promoção de saúde.

Matos et al. (2002) no trabalho Projeto Bambuí: Avaliação de serviços odontológicos privados, públicos e de sindicatos, informaram que os resultados mostraram a existência de importantes diferenças em relação à saúde bucal e ao tipo de tratamento recebido entre os usuários dos diferentes tipos de serviços odontológicos. De maneira geral, os usuários de 
serviços públicos estavam em grande desvantagem em relação aos usuários do serviço do sindicato. Esse achado é preocupante, uma vez que um dos objetivos dos serviços públicos odontológicos é a redução das desigualdades, propiciando melhoria da qualidade de vida relacionada à saúde para os indivíduos com menor nível sócio-econômico, que são mais vulneráveis æ̀s doenças bucais.

Pinheiro et al. (2002) com base nas informações obtidas em recente trabalho, onde $94.09 \%$ dos pacientes submetidos a uma pesquisa, informaram ter preferência em serem atendidos por cirurgiões-dentistas que utilizavam óculos, máscaras, luvas e gorro, concluíram que grande parte dos entrevistados estava consciente da funcionalidade da indumentária utilizada pelo cirurgião-dentista na prevenção de doenças infecto-contagiosas.

Assim, a avaliação do que é realizado, é um dos componentes fundamentais para a programação dos serviços com garantia de qualidade e satisfação, Organização Mundial da Saúde (OMS) (WHO, 1997).

Em um estudo de Garcia \& Contreras (2002) foi relatado, que a satisfação dos pacientes, estava ligada a qualidade do atendimento e a um sistema de retorno eficiente, simples e prático, com intervalos regulares bem definidos. E segundo os autores, a orientação direta ao paciente, por meio de fotos, radiografias, macro modelos, espelho de mão e conversa individual é o método mais adequado para a motivação e satisfação dos pacientes.

A despeito das variações significativas entre as estruturas culturais e étnicas de sociedades diferentes, pode-se observar que as interações 
pessoais, têm prioridades no estabelecimento da satisfação com os serviços odontológicos prestados nas clínicas integradas.

Portanto, diante de toda essa revisão e das diversas experiências relatadas, é de nosso interesse fazer o seguinte questionamento: a qualidade dos serviços prestados pela Clínica Integrada do Curso de Odontologia da Universidade Federal do Pará (CICOUFPA) conduz à satisfação nos pacientes?

Motivados por esta questão foi proposto como fundamento para este estudo, identificar e pesquisar, os itens que os pacientes poderiam identificar como fatores de satisfação ao avaliarem os serviços recebidos e a percepção dos usuários quanto aos fatores, que determinaram a satisfação com a qualidade dos procedimentos realizados na CICOUFPA. 


\section{PROPOSIÇÃO}

Constitui objetivo do presente estudo:

Avaliar a satisfação dos pacientes atendidos na Disciplina de Clínica Integrada do Curso de Odontologia da Universidade Federal do Pará (CICOUFPA), em relação aos seguintes aspectos: dor, medo, informações sobre o tratamento curativo e procedimentos preventivos, indumentária, relação com o professor, aluno e serviço de triagem, motivo da procura do serviço, notas para o atendimento, satisfação com o serviço, e organização da CICOUFPA. 


\section{MATERIAL E MÉTODOS}

Este estudo foi realizado na Clínica Integrada do Curso de Odontologia da Universidade Federal do Pará, nos meses de Maio e Junho de 2002.

\subsection{Material}

Para este trabalho foram utilizados os seguintes materiais:

- Questionário elaborado de acordo com o objetivo da pesquisa (Apêndice 1);

- Autorização impressa dos pesquisados para a participação na pesquisa de acordo com as normas da Comissão de Bioética do Curso de Odontologia da UFPA/CNE/CNS/M. da Saúde (Apêndice 2).

\subsection{Métodos}

Este trabalho foi realizado na CICOUFPA que tem finalidades acadêmicas, de pesquisa e atendimento à comunidade. Atende as especialidades de Dentística, Endodontia, Prótese, Odontopediatria, 
Cirurgia, Periodontia, Saúde Coletiva, e está localizada dentro do Campus Universitário.

A pesquisa foi realizada na sala de espera da Clínica Integrada do Curso de Odontologia da UFPA. (CICOUFPA), um serviço didáticoassistencial do qual participam docentes de diversas disciplinas, pois a clinica não tem corpo docente específico e alunos do $10^{\circ}$ semestre do curso.

O trabalho será caracterizado pelo estudo descritivo realizado com base no método qualitativo. Optou-se por essa abordagem, uma vez que esse tipo de pesquisa tem como propósito observar e descrever, os aspectos característicos de uma determinada população e avaliar a satisfação dos pacientes em relação ao atendimento oferecido por serviços odontológicos de Clínicas Integradas (Gil, 1991).

Para ajustar o instrumento de coleta foi realizado um estudo piloto junto a vinte (20) pacientes. O questionário foi aplicado, preliminarmente em 10 indivíduos para avaliar seu entendimento em relação æ̀ perguntas. Nesta avaliação, os pacientes, deram sugestões em relação à elaboração das perguntas e sobre o conhecimento das palavras utilizadas e em alguns casos informaram que o vocabulário estava difícil e foram sugeridas outras palavras.

De acordo com o resultado obtido, algumas perguntas foram modificadas quando necessário. Duas semanas mais tarde, outros 10 pacientes responderam o questionário, e novos ajustes foram realizados para conferir confiabilidade ao instrumento de coleta (Leão \& Dias, 2001). 
O estudo foi desenvolvido dentre 600 pacientes da Clínica Integrada do Curso de Odontologia da Universidade Federal do Pará em uma amostra de 200 usuários, com representatividade de 33\%. Para participar da pesquisa o paciente precisava estar em condição de responder ao questionário, sendo observado os seguintes critérios:

- ter sido atendido pelo menos três vezes na CICOUFPA e aceitar a participar da pesquisa;

- ter idade mínima de 18 anos.

Para cálculo da amostra foi utilizado um nível de confiança de 95\% e o erro amostral de 0,05. A técnica de amostragem utilizada foi amostra aleatória simples. Trata-se de um estudo transversal cujo desfecho é avaliar a satisfação do paciente (Leão \& Dias, 2001).

Para a coleta de dados foi utilizado um questionário, onde se procurou captar a opinião dos pacientes em relação aos diversos aspectos dos procedimentos recebidos e da relação entre os usuários, alunos, professores, serviço de triagem e pessoal de apoio. O questionário (Apêndice 1), foi aplicado durante os meses de Maio e Junho de 2002, com 19 questões fechadas, onde foram abordadas itens sobre qualidade da estrutura física (conforto, limpeza e iluminação), organização, atendimento e orientações recebidas do professor, aluno e triagem, e uma questão aberta tipo depoimento, onde o entrevistado poderia discorrer livremente sobre o tema que Ihe foi proposto.

O questionário foi aplicado pelo autor do trabalho, eliminando-se assim problemas relativos a padronizações de perguntas e respostas, na 
sala de espera da Clínica Integrada em um clima de cordialidade, sem forçar a situação, não fazendo deste instante um episódio constrangedor e nem de caráter obrigatório para o paciente, que foi informado do propósito e autorizou através do consentimento livre e esclarecido a aplicação do instrumento de pesquisa. Foi destacado o fato de que seriam preservados, integralmente, os dados de identificação dos pacientes.

Foram consideradas nesta avaliação as seguintes dimensões: cognitivas, relacional, organizacional e profissional, e para estimar a qualidade dos serviços, foram identificados três abordagens: estrutura, processo e resultados (Trad et al., 2002).

Foi também levado em consideração as críticas apontadas pela literatura quanto æ̀s limitações metodológicas em estudos que avaliaram a satisfação de pacientes, notadamente vieses ligados àdesejabilidade social ou àredução do processo subjetivo de avaliação a respostas do tipo sim/não em questionários fechados.

Portanto foi avaliado como os pacientes expressaram sua percepção sobre o atendimento na CICOUFPA, e os serviços oferecidos pelos alunos e professores e ao mesmo tempo o que revelaram sobre suas necessidades e expectativas de satisfação (Trad et al., 2002).

Este estudo se enquadra na modalidade de pesquisa de risco mínimo e, de acordo com a resolução 196/96 do Conselho Nacional de Saúde, relativa a pesquisa em seres humanos, se torna necessária à aprovação do protocolo de pesquisa por uma CEP (Comitê de Ética em Pesquisa ou de Bioética) Institucional. Além disso, tal procedimento 
pressupõe a utilização do consentimento livre e esclarecido, conforme explicitado no capítulo IV da Resolução CSN 196/96 (Brasil, 2002).

Para tabulação e análise dos dados foi utilizado o software epidemiológico Epi Info 604.d. E o nível de significância para avaliação dos dados obtidos foi de $5 \%(P<0,05)$.

Foi utilizado o teste Qui-Quadrado para identificar a associação entre os sexos em relação à dor durante 0 tratamento e o medo do tratamento na sala de clínica.

Para identificar se existem diferenças entre as idades dos pacientes em relação às informações recebidas sobre o tratamento dentário e as informações recebidas sobre procedimentos de prevenção da cárie, foi utilizada o Teste "t" (de student) ao nível de $5 \%$ de significância $(P<0,05)$. 


\section{RESULTADOS E DISCUSSÃO}

A saúde bucal é uma medida de avaliação dos serviços odontológicos. O Departamento de Saúde do Reino Unido define saúde bucal como "um padrão de saúde que permite ao indivíduo comer, falar e socializar-se sem doença ativa, desconforto ou embaraço e que contribui para o seu bem-estar geral". Dessa forma, a avaliação de serviços de saúde bucal deve incluir a satisfação com a aparência dos dentes, satisfação com a capacidade de mastigação, percepção da necessidade de tratamento dentário, presença de dor de dente e tipo de tratamento recebido (Matos et al., 2002).

Em 1998, Padilha relatou que o Projeto Pedagógico Inovado, também chamado de Odontologia Comunitária, divulgado e defendido por Mendes (1985) teve como objetivo superar o modelo educacional tradicional que representava a Odontologia científica, e incorporar o componente investigacional ao já existente modelo da integração docente-assistencial, incluindo na atividade dita de extensão a própria essência do projeto.

Assim o projeto modelo-tradicional passa a ser reconhecido como modelo inovado (Clínica Integrada como disciplina), base do novo projeto pedagógico, e objetivo a ser alcançado nas Faculdades de Odontologia, 
para adequar a graduação do aluno de acordo com as normas das instituições, das necessidades de inclusão social, e promover qualidade e satisfação nos pacientes usuários dos serviços dessas clínicas.

Mas como avaliar esta satisfação nos pacientes e que critérios seriam utilizados neste processo, e como seria feito a seleção dos itens que expressariam esta satisfação pelos usuário. Foram estes questionamentos e necessidade de respostas, que nos levaram a propor este trabalho de avaliar esta satisfação dos pacientes atendidos na CICOUFPA.

Portanto para a obtenção dos resultados desta pesquisa, foram aplicados 200 questionários nos meses de Maio e Junho de 2002, representando 33\% dos 600 usuários inscritos para serem atendidos na Clínica Integrada do Curso de Odontologia da Universidade Federal do Pará (CICOUFPA), durante o $1^{\circ}$ semestre de 2002.

A partir da estatística descritiva, foi possível identificar e agrupar as diversas variáveis por afinidade. Por exemplo: variáveis relacionadas a informações sobre higiene, uniformização dos alunos e professores, dor no tratamento, qualidade do atendimento, informações sobre os procedimentos, motivo da procura da CICOUFPA, constrangimento por ser atendido em local coletivo, indicação da clínica para outras pessoas, avaliação por nota e informações sobre a organização em geral (Santos \& Lacerda, 1999).

Os resultados da pesquisa, são avaliados e discutidos de acordo com os itens dos questionários e das variáveis agrupadas para esse trabalho, interagindo com a literatura existente e com os testes estatísticos indicados, de acordo com as características deste estudo. 
Tabela 5.1 - Distribuição dos pacientes quanto ao sexo na Clínica Integrada. COUFPA, Belém, 2002

\begin{tabular}{c|c|c|c|c}
\hline Sexo & № de pacientes & $\%$ & Média & Desvio Padrão \\
\hline Masc & 65 & 32,5 & 33,75 & 13,61 \\
Fem & 135 & 67,5 & 35,27 & 13,05 \\
\hline Total & 200 & 100,0 & & \\
\hline
\end{tabular}

Dos 600 usuários inscritos foi selecionada uma amostra de 200 pacientes para serem entrevistados, 65 (32.5\%) foram do sexo masculino e $135(67.5 \%)$ do sexo feminino. A maioria dos pacientes que freqüentam a Clínica Integrada do COUFPA são do sexo feminino, razão pela qual justifica-se um percentual maior de entrevistados deste sexo (Tabela 5.1).

O fato de as mulheres estarem mais presentes nos consultórios odontológicos se dá pela importância que elas atribuem àestética, ou ainda, ao indicativo de que podem dispor, em geral, de maior tempo em relação aos homens, por não estarem vinculadas a tipo de ocupação com horários rígidos (Carvalho et al., 2000).

Segundo Martins et al. (1999), a imposição cultural e econômica não faculta ao homem definir-se como doente, adiando, tanto quanto possível, a procura do médico ou do dentista.

De acordo com Ramos (2001), a ida ao dentista é um momento de grande significado emocional para o paciente, pois, afinal, o fato de permitir que alguém trate de sua boca, transforma-se em um ato de grande intimidade. Daí, a importância da consciência do trabalho do dentista ser 
revestida de um caráter muito maior e muito mais profundo do que somente recuperar a função e a estética, ou aliviar a dor daquele paciente (Ramos et al., 1999).

“... Fico preocupada quando vou ao dentista pois pode doer, e o meu problema ser grave e como não tenho estudo, não sei a gravidade da doença. E quais são os meus direitos para tratar na clínica integrada ..."

(A. N. C., 38 anos, sexo feminino).

Tabela 5.2 - Distribuição dos pacientes da amostra por faixa etária e sexo. CICOUFPA, Belém, 2002

\begin{tabular}{c|c|c|c|c|c|c}
\hline Idade/Sexo & Mas & $\%$ & Fem & $\%$ & Total & $\%$ \\
\hline 18 a 20 & 8 & 12,3 & 16 & 11,9 & 25 & 12,5 \\
31 a 30 & 23 & 35,4 & 37 & 27,4 & 60 & 30,0 \\
41 a 50 & 18 & 27,7 & 47 & 34,8 & 65 & 32,5 \\
51 a 60 & 3 & 4,6 & 15 & 11,1 & 18 & 9,0 \\
61 a 70 & 4 & 6,2 & 5 & 3,7 & 9 & 4,5 \\
Mais de 70 & 1 & 1,5 & 0 & 0,0 & 1 & 0,5 \\
\hline Total & 65 & 100,0 & 135 & 100,0 & 200 & 100,0 \\
\hline
\end{tabular}

Os resultados sobre faixa etária e o sexo observados na Tabela 5.2, indicam que no sexo feminino a faixa etária de 31 a 40 anos é a mais freqüente na clínica com 47 mulheres (34.8\%) e no masculino fica na faixa 
de 21 a 30 anos, com 23 homens (35.4\%), observa-se baixa demanda de idosos com mais de 61 anos a 70 e acima de 70 anos. Na faixa etária de 18 a 20 anos em ambos os sexos, onde as necessidades são menos complexas só temos $12.5 \%$ dos pacientes, o que provocará uma procura tardia para tratamento e com maior complexidade.

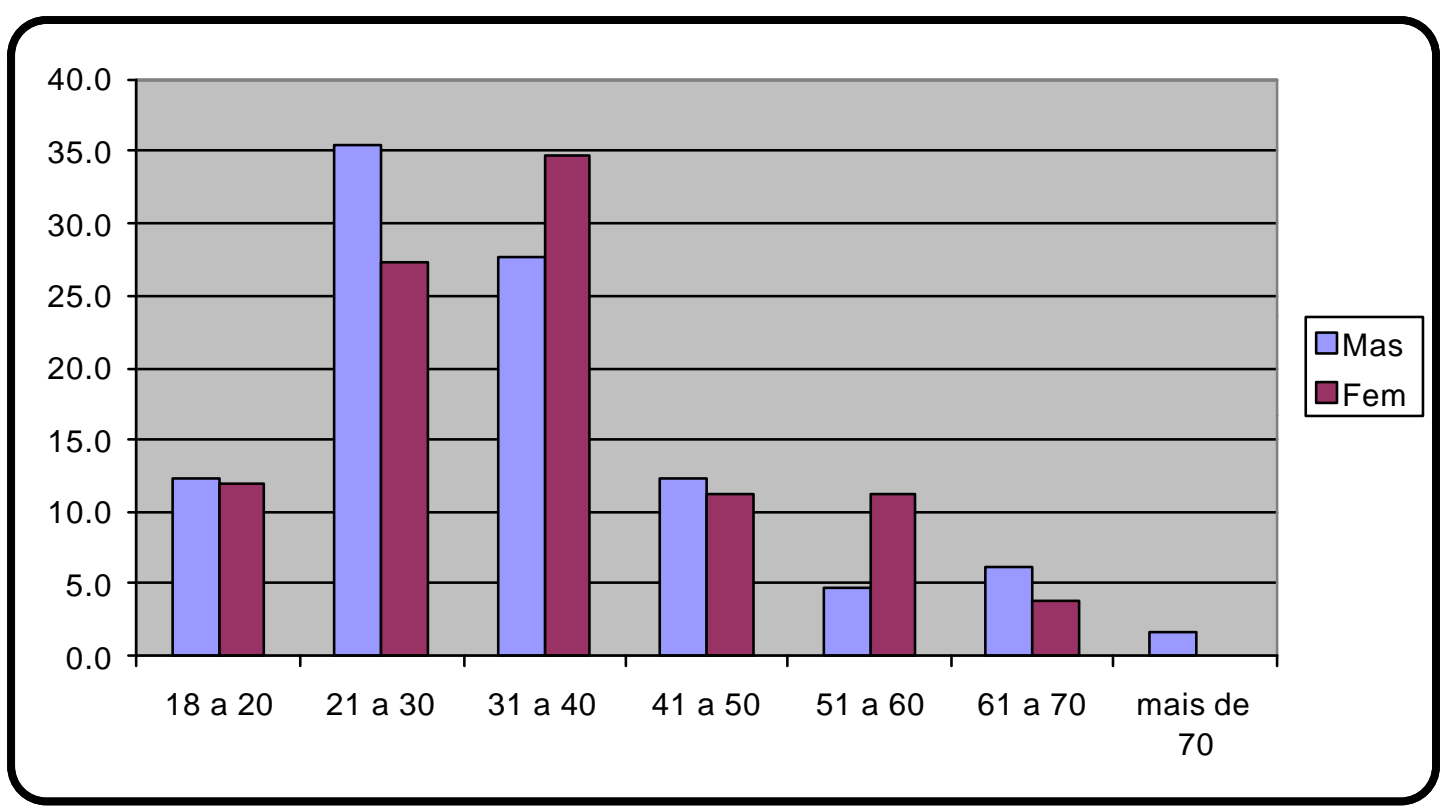

Gráfico 5.1 - Distribuição (\%) dos pacientes da amostra por faixa etária e sexo. CICOUFPA, Belém, 2002

Observa-se no Gráfico 5.1, que as faixas etárias que mais freqüentam a CICOUFPA estão polarizadas entre 21 a 30 e 31 a 40 anos, portanto adulto e já portador de várias patologias em estado de complexidade, tipo de pacientes de acordo com o perfil da Clínica Integrada. Neste quadro segundo Kramer et al. (2000) a (in) satisfação dos pacientes estará relacionada com o modelo operatório de muitas intervenções, falta de 
definição de estratégias e avaliação distorcida dos efeitos dos programas desenvolvidos.

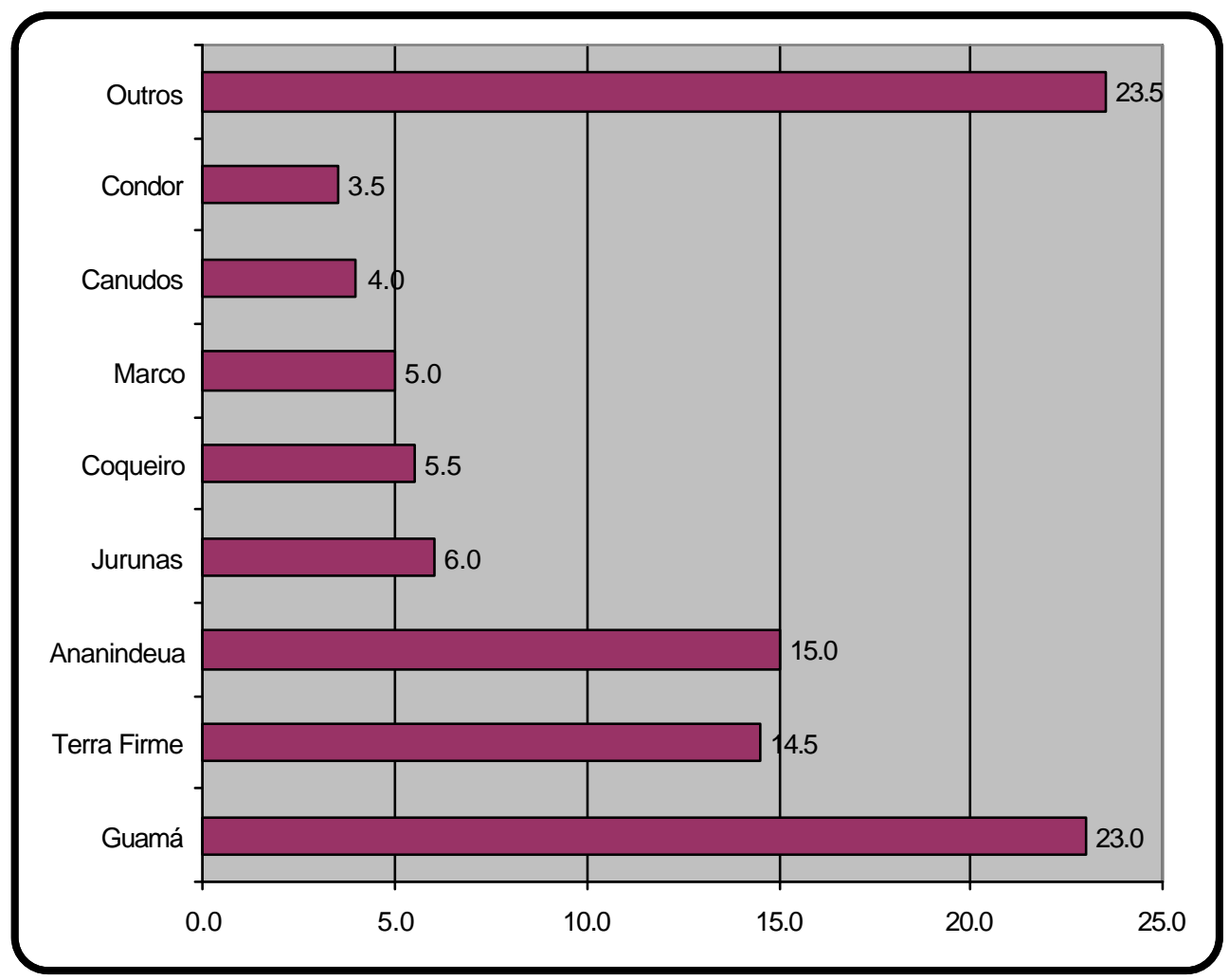

Gráfico 5.2 - Análise (\%) da origem por bairros dos pacientes da CICOUFPA, Belém, 2002

No Gráfico 5.2 observa-se que os pacientes da CICOUFPA procedem dos bairros mais próximos (Terra Firme e Guamá) que representam $37.5 \%$ da clientela, porém existe a presença de pacientes de bairros distantes (Jurunas e Coqueiro), e até de outros municípios como Ananindeua que faz parte da região metropolitana da grande Belém com 26.5\%, que significa o uso da CICOUFPA como referência e contra referência do Sistema Único de Saúde (SUS) em todos os níveis de atenção 
na área odontológico para tratamento especializado, não existente na rede básica de saúde.

Tabela 5.3 - Situação do vínculo de trabalho dos pacientes da Clínica Integrada. COUFPA, Belém, 2002

\begin{tabular}{c|c|c}
\hline Situação de Emprego & № de pacientes & $\%$ \\
\hline Desempregado & 106 & 53,0 \\
Empregado & 87 & 43,5 \\
Aposentado & 5 & 2,5 \\
Aposentado e empregado & 2 & 1,0 \\
\hline Total & 200 & 100,0 \\
\hline
\end{tabular}

Na Tabela 5.3, sobre vínculo de trabalho, observa-se que 53\% dos pacientes estão desempregados, $43.5 \%$ trabalham formalmente, com um percentual mínimo de aposentados de $2.5 \%$, com $1 \%$ dos pacientes na situação de aposentados e empregados, perfazendo um total de $47 \%$ dos usuários com renda fixa através de contratos de trabalho diversos.

Este enfoque é característico da clientela de Clínicas Integradas das Faculdades de Odontologia das Instituições de Ensino Superior no Brasil, sendo que os pacientes que trabalham possuem um elevado nível de faltas, pois eles não conseguem dispensas para freqüentarem regularmente os serviços de saúde, problema este que dificulta ao aluno a integralização de seus procedimentos em saúde bucal, além do fato que indivíduos de classes 
baixas terem maiores dificuldades de promoverem saúde, participarem de campanhas de prevenção, e por isto tem maiores prevalência de alterações no seu estado de saúde.

Tabela 5.4 - Análise da renda mensal familiar dos pacientes da Clínica Integrada. COUFPA, Belém, 2002

\begin{tabular}{c|c|c}
\hline Renda Mensal & № de pacientes & $\%$ \\
\hline Nenhuma & 3 & 1,5 \\
1 a 2 sm & 123 & 61,5 \\
2 a 3 sm & 38 & 19,0 \\
3 a 5 sm & 30 & 15,0 \\
5 a 10 sm & 4 & 2,0 \\
Mais de 10 sm & 2 & 1,0 \\
\hline Total & 200 & 100,0 \\
\hline
\end{tabular}

Quanto à renda familiar expressa na Tabela 5.4 e antevista no Gráfico 5.3, observa-se que a grande maioria dos pacientes $61.5 \%$ está situada na faixa de 1 a 2 salários, 19\% com 2 a 3 salários e $15 \%$ dos paciente recebem de 3 a 5 salários. 


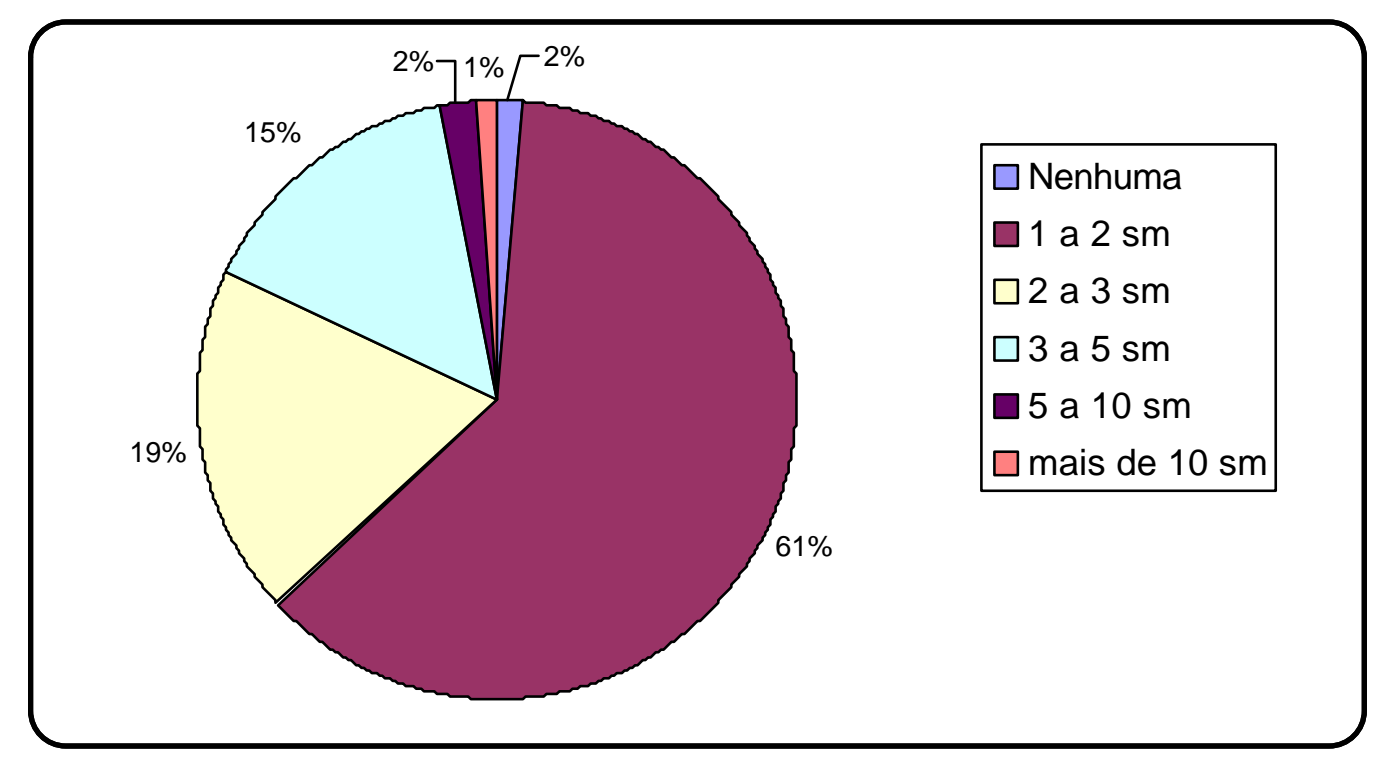

Gráfico 5.3 - Estudo da renda familiar mensal dos pacientes da Clínica Integrada. COUFPA, Belém

Segundo Padilha et al. (2001) no trabalho realizado em 98 pacientes da Clínica Integrada da Faculdade de Odontologia da Universidade Federal Fluminense, sobre saúde bucal e nível sócio-econômico, observou-se que o perfil do paciente da CIFOUFF, apresentou predomínio de escolaridade e poder aquisitivo baixos, perfil que não é muito diferente deste da CICOUFPA.

Portanto, os pacientes da CICOUFPA possuem baixo poder aquisitivo, o que dificulta o trabalho dos alunos quando precisam da colaboração deles para serviços protéticos, sendo o pagamento de taxas, um fator de insatisfação do usuário, Gráfico 5.3.

Pois segundo Butters \& Willis (2000) o pagamento de taxas altas é proporcional ao abandono do tratamento e isto dificulta manter o paciente, podendo ser um indicador para melhorar a seleção e retenção do usuário, 
melhorando a qualidade e satisfação dos pacientes para áreas que precisam de pagamento.

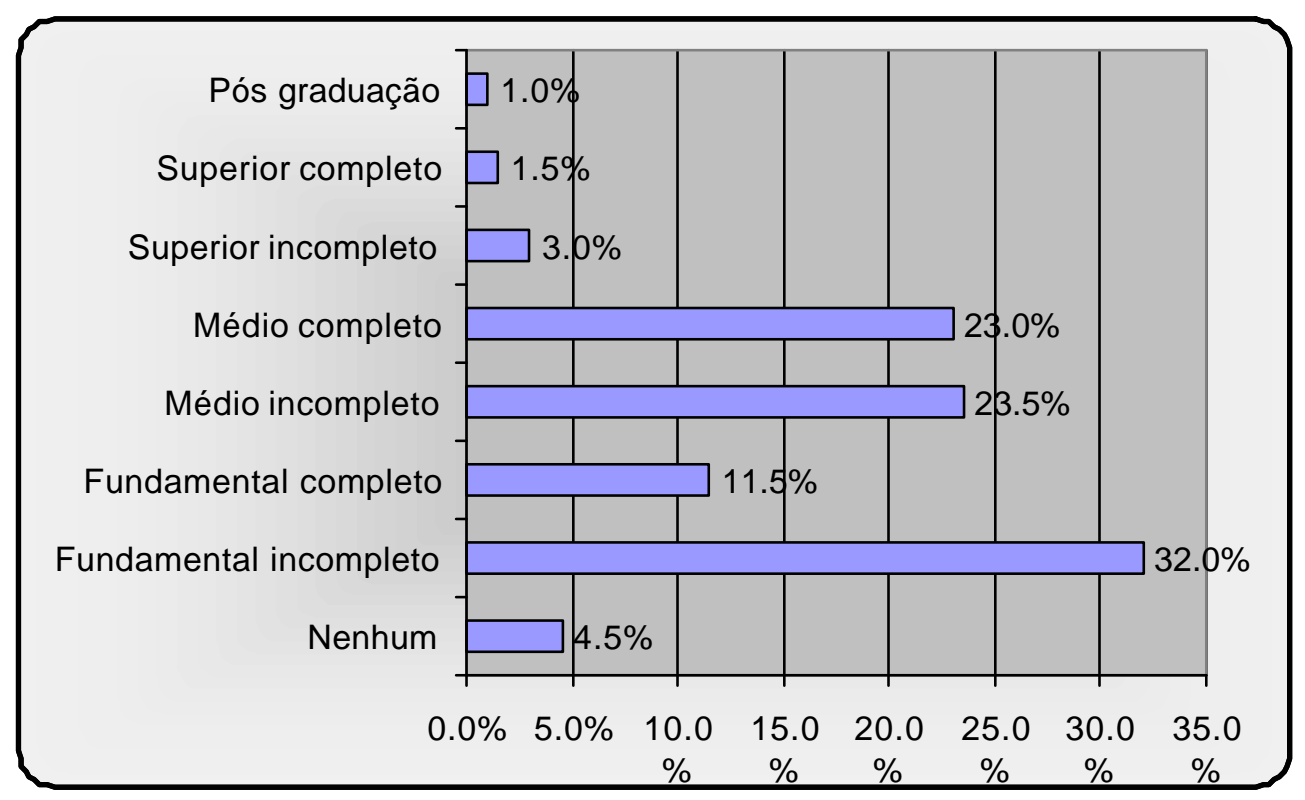

Gráfico 5.4 - Análise dos níveis de escolaridade dos pacientes da Clínica Integrada. COUFPA, Belém, 2002

No Gráfico 5.4 observa-se que apenas $5.5 \%$ dos pacientes apresentaram nível superior, sendo 1\% com pós-graduação, este se justifica pela localização do curso dentro do Campus da UFPA. Destaca-se também o percentual de $46.5 \%$ para pacientes com nível médio completo e incompleto e de $43.5 \%$ com nível fundamental completo e incompleto.

Segundo Barbisan et al. (1995); Ramos (1997); Leão \& Dias (2001); Matos et al. (2002), os estudos da área de saúde têm demonstrado que os indivíduos das classes sociais mais baixas são os que apresentam maiores dificuldades para prevenção e o tratamento de certas doenças, ou por não terem condições de alterarem as condições sociais e ambientais que as 
geram, ou porque sua situação de classe não lhes permite acesso a certas práticas curativas.

Segundo Leão \& Dias (2001) e Ramos (2001), quanto mais tempo demora o tratamento, mais o paciente gasta dinheiro nas diversas idas e vindas, portanto favorece ao abandono e dificulta o atendimento.

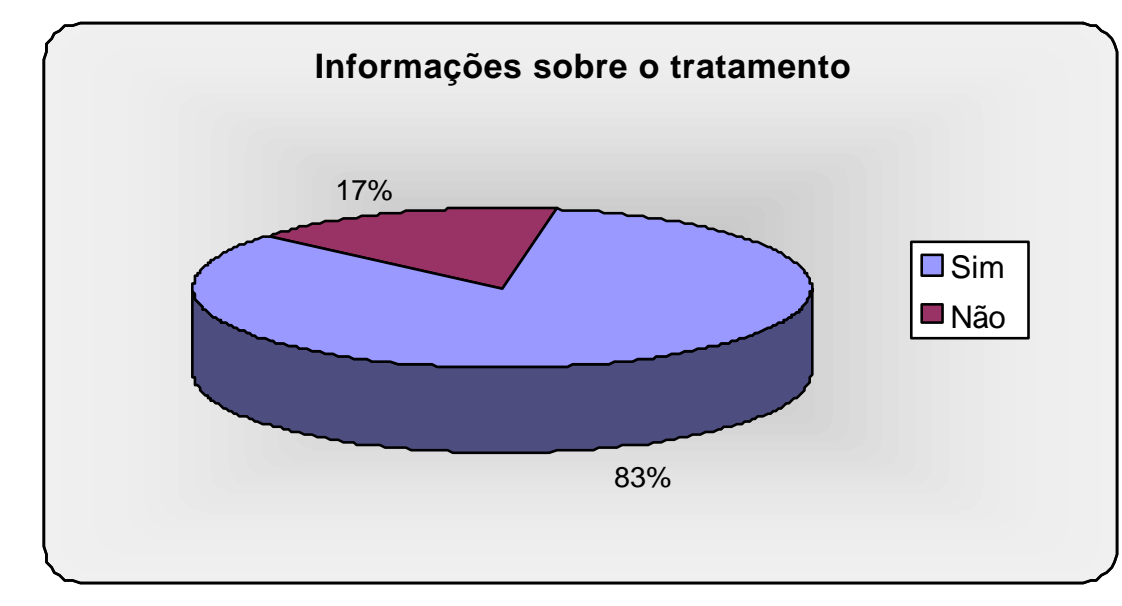

Gráfico 5.5 - Análise das Informações recebidas pelos pacientes sobre 0 tratamento odontológico na CICOUFPA, Belém, 2002

Observa-se no Gráfico 5.5, que $83 \%$ dos pacientes receberam informações sobre procedimentos curativos e $17 \%$ não receberam informações sobre tratamentos curativos, destacando o interesse do aluno pela especialidade. 


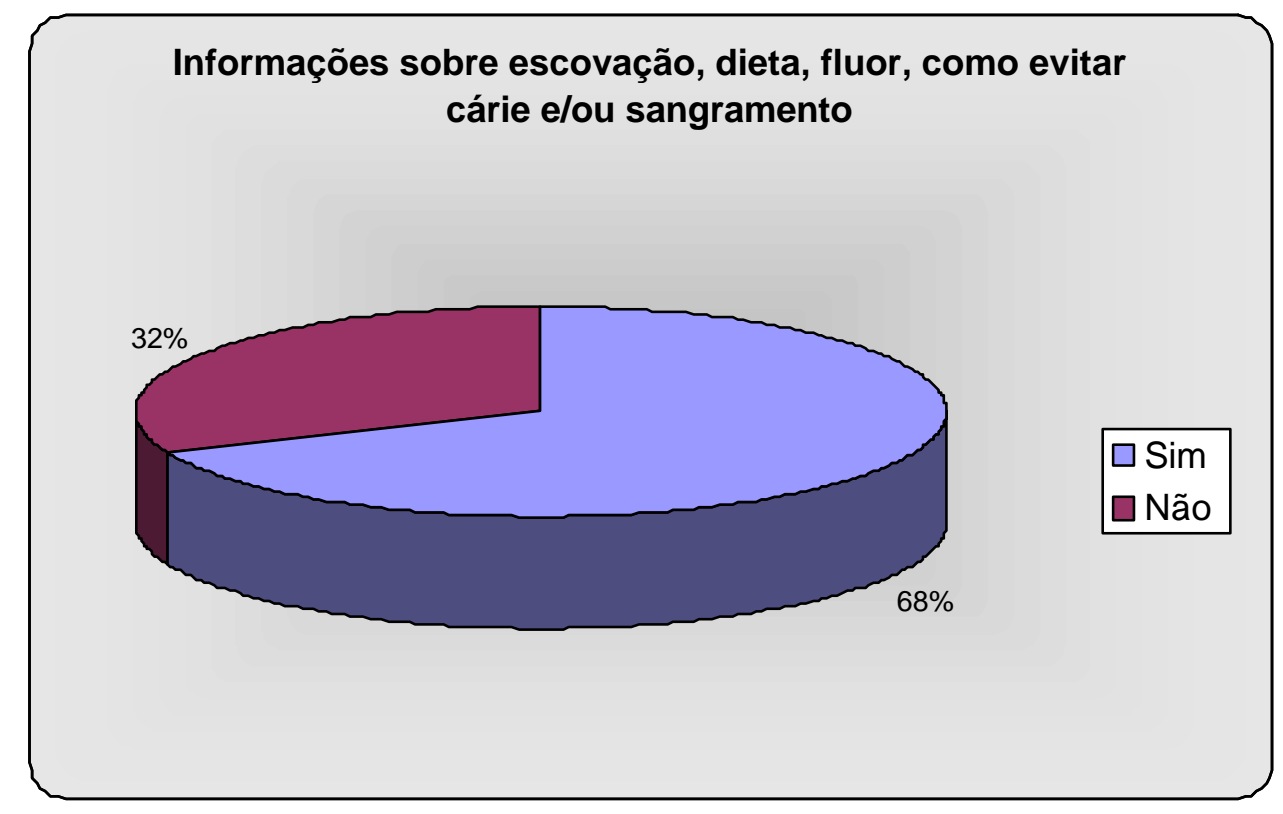

Gráfico 5.6 - Análise das Informações recebidas pelos pacientes sobre procedimentos preventivos na CICOUFPA, Belém, 2002

Observa-se no Gráfico 5.6, que 68\% dos entrevistados receberam informações sobre procedimentos preventivos, sendo isso um dado positivo para motivação do paciente em prevenção domiciliar e também sobre as necessidades de tratamento e procedimentos que seriam desenvolvidos (Gráfico 5.5) de acordo com os princípios da Bioética (consentimento livre e esclarecido).

Porem segundo Unfer \& Saliba (2000) os programas de saúde deveriam considerar os aspectos relativos ao conhecimento e as práticas em saúde bucal para viabilizar o processo de informação da população e promover a responsabilização coletiva de promoção da saúde em todos os segmentos populacionais. 
No trabalho de Unfer \& Saliba (2000), realizado sobre responsabilidade coletiva, $66.6 \%$ responderam afirmativamente quando foi perguntado se tinham cárie e 29.8\% mencionaram não terem a doença e $65.8 \%$ consideraram que a cárie dentária poderia ser evitada por meio do autocuidado, enquanto para $36.5 \%$ o dentista tem um papel significativo neste processo. Por isto receber informações preventivas e curativas é um fator de satisfação que o paciente percebe durante o atendimento, evento também comprovado nesta pesquisa na CICOUFPA.

Tabela 5.5 - Análise das Informações recebidas pelos pacientes sobre o tratamento por faixa etária na CICOUFPA, Belém, 2002

\begin{tabular}{c|c|c|c|c|c|c}
\hline Idade & Sim & $\%$ & Não & $\%$ & Total & $\%$ \\
\hline 18 a 20 & 22 & 13,2 & 3 & 9,1 & 25 & 12,5 \\
31 a 30 & 43 & 25,7 & 17 & 51,5 & 60 & 30,0 \\
41 a 50 & 57 & 34,1 & 7 & 21,2 & 65 & 32,5 \\
51 a 60 & 16 & 9,6 & 2 & 6,1 & 18 & 9,0 \\
61 a 70 & 7 & 4,2 & 1 & 3,0 & 9 & 4,5 \\
Mais de 70 & 2 & 1,2 & 0 & 0,0 & 1 & 0,5 \\
\hline Total & 167 & 100,0 & 33 & 100,0 & 200 & 100,0 \\
\hline
\end{tabular}


Tabela 5.6 - Análise das Informações recebidas pelos pacientes sobre procedimentos preventivos por faixa etária na CICOUFPA, Belém, 2002

\begin{tabular}{c|c|c|c|c|c|c}
\hline Idade & Sim & $\%$ & Não & $\%$ & Total & $\%$ \\
\hline 18 a 20 & 17 & 12,4 & 8 & 12,7 & 25 & 12,5 \\
31 a 30 & 38 & 27,7 & 22 & 34,9 & 60 & 30,0 \\
41 a 50 & 47 & 34,3 & 17 & 27,0 & 64 & 32,0 \\
51 a 60 & 16 & 11,7 & 2 & 3,2 & 18 & 9,0 \\
61 a 70 & 5 & 3,6 & 3 & 4,8 & 8 & 4,0 \\
Mais de 70 & 2 & 1,5 & 0 & 0,0 & 2 & 1,0 \\
\hline Total & 137 & 100,0 & 63 & 100,0 & 200 & 100,0 \\
\hline
\end{tabular}

Nos Gráficos 5.5 e 5.6, observa-se que $83 \%$ dos pacientes receberam informações sobre os tipos de tratamento e $68 \%$, sobre procedimentos preventivos. Porém quando relaciona-se as informações dos Gráficos 5.5 e 5.6, com a idade observa-se na Tabela 5.5 que as informações sobre tratamento, na faixa de 21 a 30 anos (60 dos 200), 43 receberam e 17 não receberam o que é estatisticamente significante nesta faixa, e no geral 167 (83\%) pacientes receberam e 33 (17\%) dos pacientes não receberam as informações.

Para identificar se existe diferença entre as idades dos pacientes que receberam informações sobre o tratamento e aqueles que não 
receberam, foi utilizado o teste $\mathrm{t}$ - student, com um nível de significância de $p<0,05$.

A idade média dos que receberam informações sobre o tratamento foi de 35.2 e o desvio padrão de 13.4 e dos que não receberam foi de 32.0 e desvio padrão de 12.4 .

O teste indicou que não houve nenhuma diferença estatisticamente significante entre as idades dos pacientes que receberam e dos que não receberam informações sobre o tratamento, com $p=0,19$.

Na Tabela 5.6 sobre informações preventivas por faixa etária, na faixa de 21 a 40 (124 dos 200) observa-se que 85 pessoas receberam e 39 não receberam informações, e no geral 137 receberam e 63 não receberam informações preventivas o que é estatisticamente significante.

Para identificar se existe diferença entre as idades dos pacientes que receberam informações sobre prevenção de cárie e aqueles que não receberam foi utilizado o $\mathrm{t}$ - student, com um nível de significância de $\mathrm{p}<$ 0,05 .

A idade média dos que receberam, informações sobre prevenção de cárie e foi de 35.3 e desvio de 13.6 e dos que não receberam foi de 33.2 e desvio padrão de 12.5 .

O teste indicou que não houve nenhuma diferença entre as idades dos pacientes que receberam e dos que não receberam informações sobre procedimentos preventivos, com $\mathrm{p}=0.27$.

Observa-se que na Tabela 5.5, 167 receberam informações sobre o tratamento e 33 não, e na Tabela 5.6, 137 receberam informações 
preventivas e 63 não, indicando que o aluno da CICOUFPA está mais interessado em explicar os tratamentos curativos que os procedimentos preventivos.

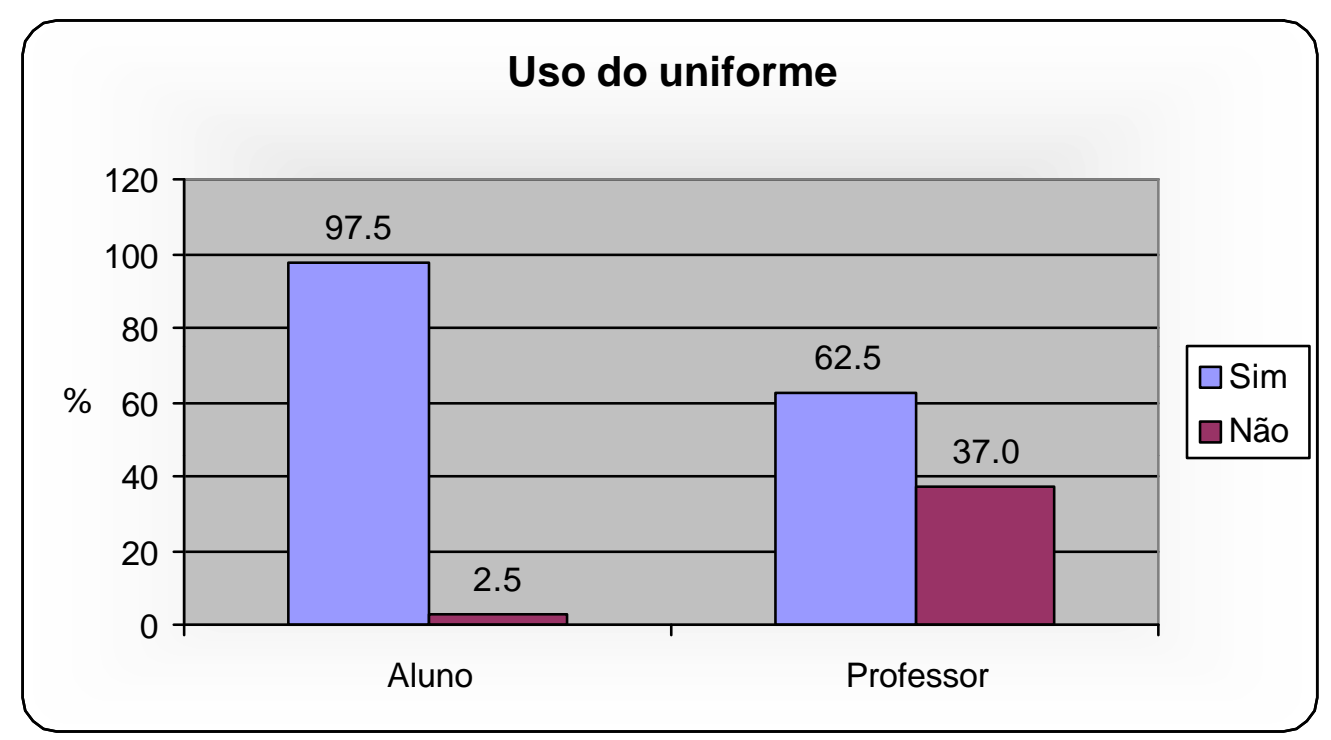

Gráfico 5.7 - Estudo das respostas dos pacientes sobre a utilização do traje adequado pelo aluno e professor na CICOUFPA, Belém, 2002

Em função dos riscos de contaminação por doenças infecciosas ao qual estão expostos os profissionais da Odontologia e os usuários, a utilização dos equipamentos de proteção individual (EPI) vem sendo colocados em prática, pela grande maioria dos prestadores de serviços, fato este também executado na CICOUFPA.

Assim sendo, no presente trabalho, quanto àutilização do uniforme, percebe-se que $97.5 \%$ dos alunos estavam com o traje adequado e somente $62.5 \%$ dos professores, segundo informações do pacientes, estavam completamente uniformizados na CICOUFPA, Gráfico 5.7. 
Analisando os dados encontrados no trabalho, constata-se que tanto o sexo feminino quanto o sexo masculino coincidem em suas respostas. A impressão que ambos têm do uso de máscara, luvas e óculos de proteção pelo cirurgião-dentista é a de, principalmente, defendê-los de infecções, seguindo da alternativa de que tal aparato Ihes propicia segurança. Esses achados são concordantes com o existente na literatura.

Pinheiro et al. (2002) com base nas informações obtidas em recente trabalho, onde $94.09 \%$ dos pacientes submetidos a uma pesquisa, informaram preferência em serem atendidos por cirurgiões-dentistas que utilizavam óculos, máscaras, luvas e gorros, concluíram que grande parte dos entrevistados está consciente da funcionalidade da indumentária utilizada pelo cirurgião-dentista na prevenção de doenças infectocontagiosas.

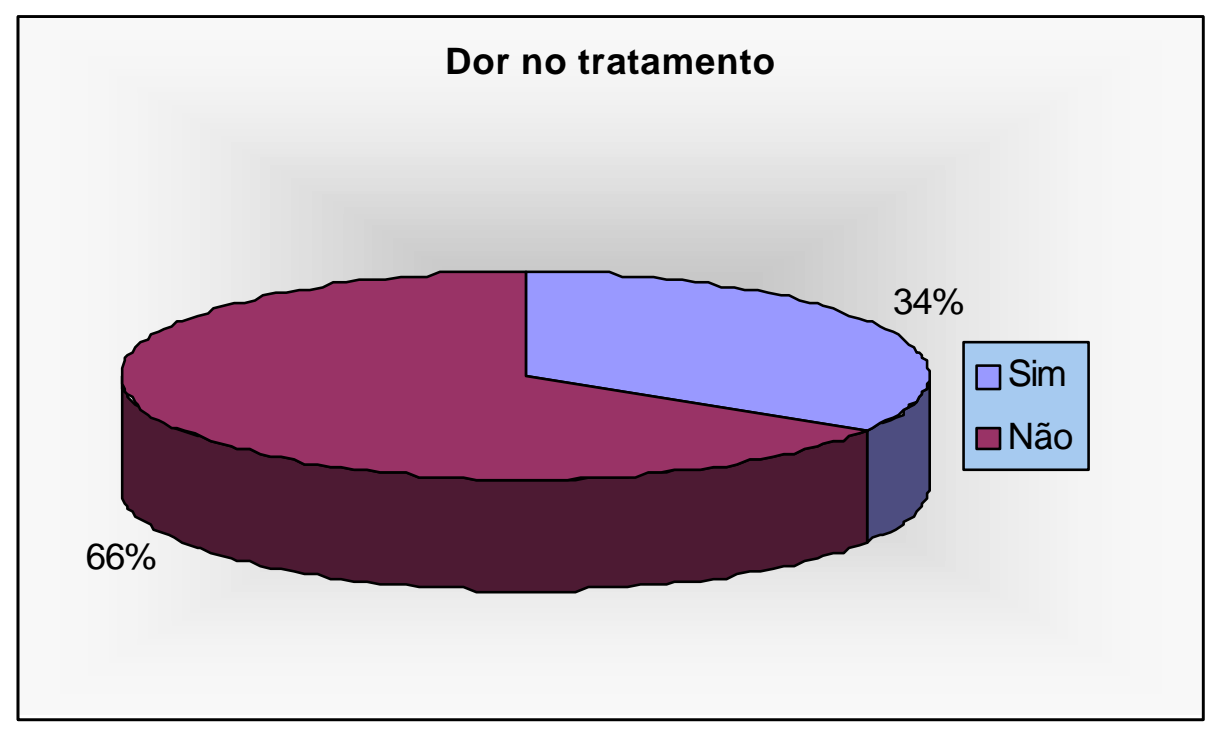

Gráfico 5.8 - Opinião dos paciente quanto à sensação de dor no tratamento ao ser atendido na CICOUFPA, Belém, 2002 
No Gráfico 5.8, observa-se que quando foi perguntado aos pacientes se sentiram dor durante o atendimento, que $34 \%$ responderam que sim e $66 \%$ responderam que não sentiram nenhuma dor durante o tratamento odontológico.

Segundo Leão \& Dias (2001), em um trabalho realizado sobre satisfação do paciente, relataram que a dor é um fator considerável, que gera insatisfação quando sentida durante os procedimento odontológicos principalmente de alta complexidade (tratamento de canal e cirurgias), pois a satisfação com a prática odontológica continua sendo muito associada a dor.

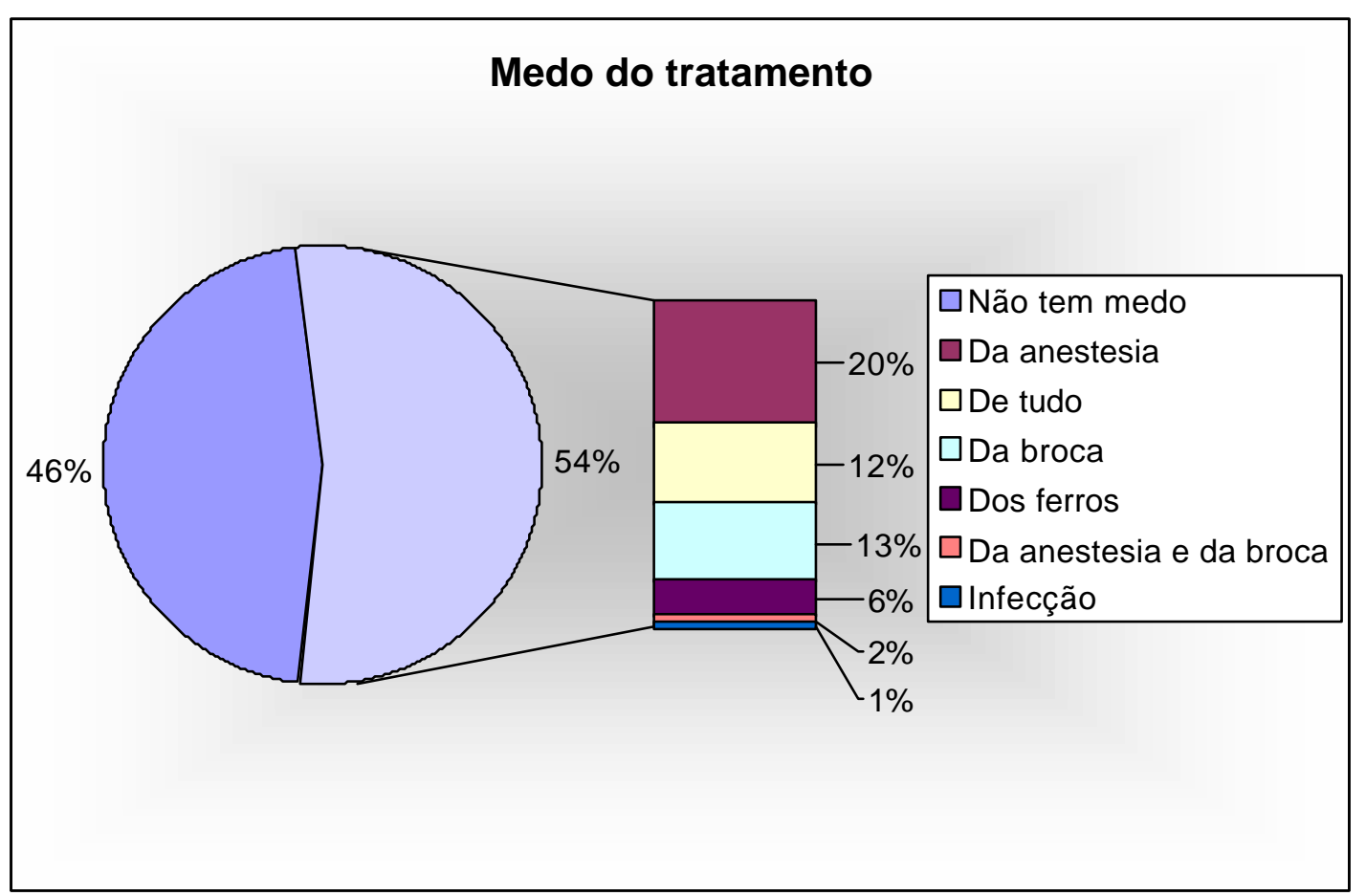

Gráfico 5.9 - Opinião dos pacientes quanto à sensação de medo no tratamento odontológico na CICOUFPA, Belém, 2002 
No Gráfico 5.9 , observa-se que $46 \%$ dos pacientes não tem medo do tratamento e dos 54\% que referenciaram medo do tratamento odontológico, $20 \%$ tem medo da anestesia e $13 \%$ tem medo da broca.

Ramos (2001) em seu trabalho como o paciente se sente ao ser atendido por um aluno de Odontologia, aplicou um questionário em 31 pacientes das clínicas do Curso de Odontologia da Faculdade Federal de Odontologia de Diamantina (FAFEOD), para identificar o sentimento dos pacientes das clínicas ao serem atendidos por alunos. Os principais resultados apontaram que, apesar dos avanços da Odontologia, alguns pacientes ainda se sentem desconfortáveis frente ao atendimento. Nota-se que é fundamental melhorar a comunicação entre aluno e paciente, comunicação esta que deve estar associada ao carinho, e respeito ao usuário e à competência na execução dos trabalhos, para resultar no sucesso do tratamento e satisfação do paciente, sendo que o alívio da dor, a reparação do aspecto estético e a gratuidade do tratamento, foram fatores que fizeram com que os pacientes procurassem as clínicas da Faculdade.

Observa-se que o paciente, procurou o serviço da CICOUFPA por necessidades sentidas específicas: dor, cárie e dentes fraturados, buscou tratamento eletivo; portanto salienta-se que são pacientes de baixo poder aquisitivo, cujo história de vida está relacionada a dor e sofrimento, assim sendo associam a dor e o medo como fatores de (in) ou satisfação quando durante o atendimento ocorrem episódios dolorosos, que com certeza concorrem para respostas de insatisfação durante o tratamento ou até mesmo de abandono. 
Tabela 5.7 - Opinião dos pacientes sobre à sensação de dor durante o tratamento relacionando com o sexo dos pacientes na CICOUFPA, Belém, 2002

\begin{tabular}{c|c|c|c|c|c|c}
\hline Dor/Sexo & Mas & $\%$ & Fem & $\%$ & Total & $\%$ \\
\hline Sim & 19 & 29,2 & 49 & 36,3 & 68 & 34,0 \\
Não & 46 & 70,8 & 86 & 63,7 & 132 & 66,0 \\
\hline Total & 65 & 100,0 & 135 & 100,0 & 200 & 100,0 \\
\hline
\end{tabular}

Utilizou-se o teste do Qui-Quadrado para identificar a associação entre a dor durante o tratamento e o sexo do paciente, foi utilizado o nível de significância de 95\% $(P<0,05)$. Assim sendo observa-se que não há diferença estatisticamente significante entre os sexos em relação à dor durante o tratamento, com $p=0,41$.

Segundo Ramos (1997), quanto a opinião dos pacientes da Clínica Integrada da Faculdade Federal Odontologia de Diamantina FAFEOD, a respeito do que mais temiam no tratamento odontológico, $48.97 \%$ não tiveram medo de nada e $52.03 \%$ sentiram medo por diversas causas.

Neste estudo na CICOUFPA, confirmou-se pelo (Gráfico 5.9) o estudo de Ramos (1997), pois 46\% dos pacientes não sentiram medo de nada e 54\% responderam que sentiram medo por vários motivos.

Ainda que a Odontologia através de uma visível evolução nós últimos anos, tenha se caracterizado por oferecer aos pacientes um tratamento rápido e indolor, ela ainda é vista como uma especialidade que 
provoca, como resposta dos pacientes, a ansiedade, o medo, a dor e o desconforto (Ramos, 1997).

Em estudos realizados por Bergreen \& Maynert (1984); Gonçalves (1993), em 160 adultos com diferentes temores em relação ao tratamento odontológico, observou-se que tanto homens quanto mulheres apresentaram, em ordem decrescente, medo da alta-rotação, da anestesia, da extração e da preparação da anestesia. Kleiman (1982) constatou que o medo do tratamento odontológico é um dos maiores impedimentos do tratamento em si, associado ao stress do paciente. Boltanski (1989) informou que os membros das classes populares se utilizam de categorias como leve ou pesado, para distinguir o bom do mal profissional. A "mão leve" ou a "mão pesada" do Cirurgião-Dentista, segundo Gonçalves (1993), juntamente com os instrumentais, mobiliza sentimentos, de se estar sendo acariciado ou de estar sendo violado durante a prática odontológica.

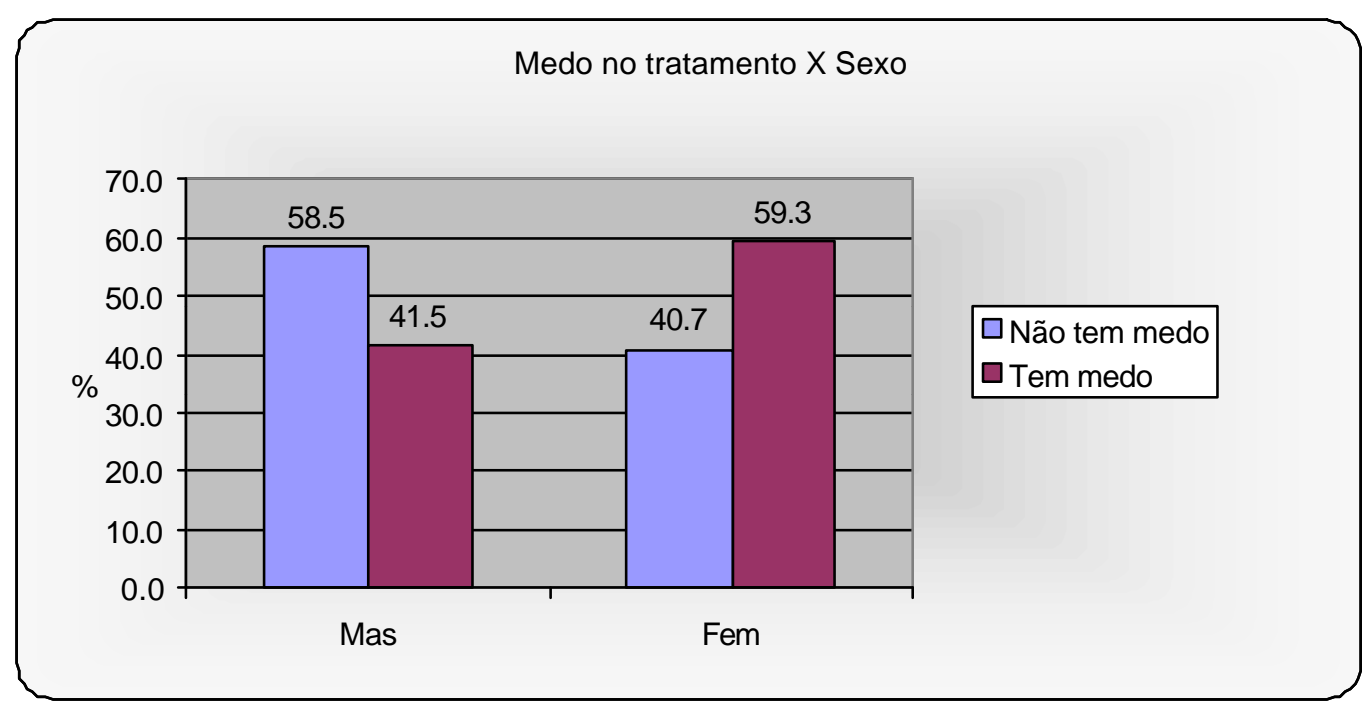

Gráfico 5.10 - Estudo da opinião dos pacientes analisando medo e sexo durante o tratamento odontológico na CICOUFPA, Belém, 2002 
No Gráfico 5.10 , observa-se que $58.5 \%$ dos homens não sentiram medo durante o tratamento e nas mulheres $40.7 \%$ disseram também não terem medo durante o atendimento.

Foi utilizado o teste do Qui-Quadrado para identificar a associação entre o medo do tratamento e o sexo, com o nível de significância de $95 \%$ $(P<0,05)$. Também foi identificado que as mulheres tiveram mais medo do tratamento que os homens com $p=0,03$, resultado que não é estatisticamente significante.

Segundo Chaves (1986), o fato de um serviço ser gratuito não exclui a obrigatoriedade de uma atenção individual ao paciente. O profissional deve esmerar-se para que o paciente não se sinta "diminuído" por receber um serviço gratuito.

Com relação à impressão dos pacientes a respeito do atendimento recebido do professor, aluno e do serviço de triagem, observa-se nos gráficos abaixo as seguintes informações

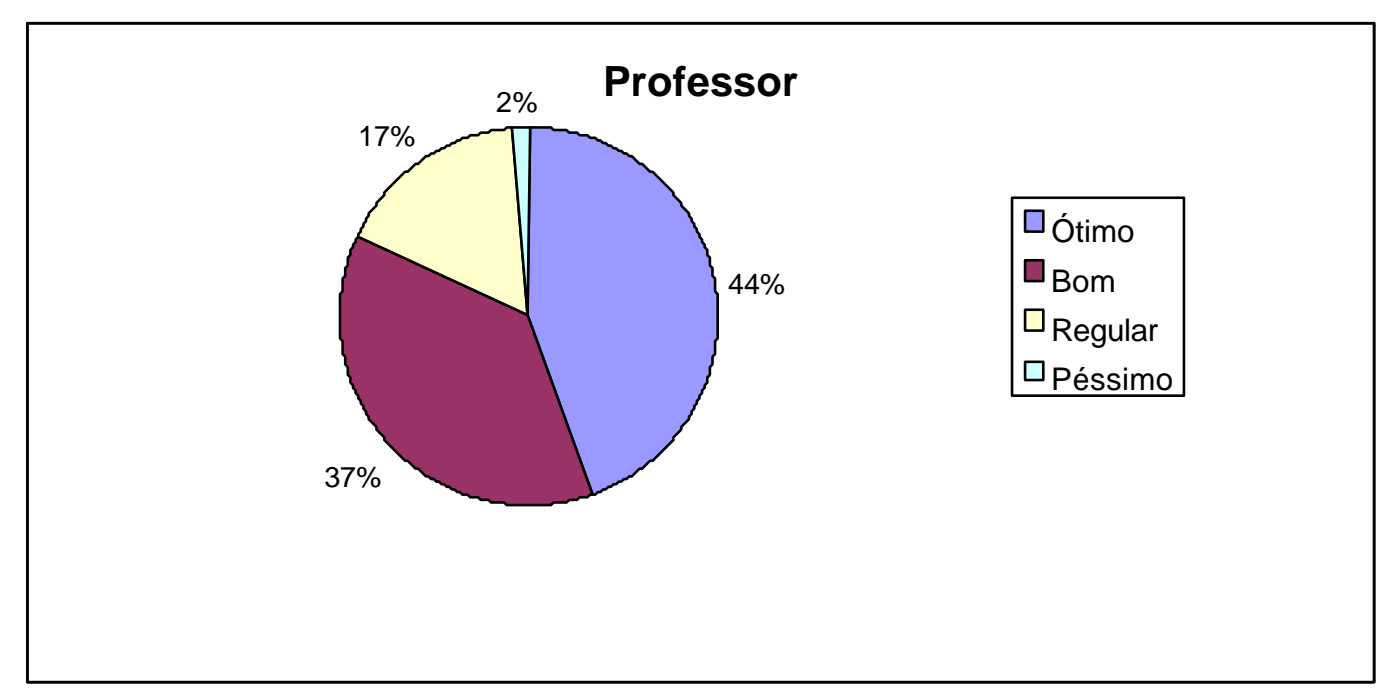

Gráfico 5.11 - Análise da opinião dos pacientes quanto ao atendimento prestado pelo professor da CICOUFPA, Belém, 2002 


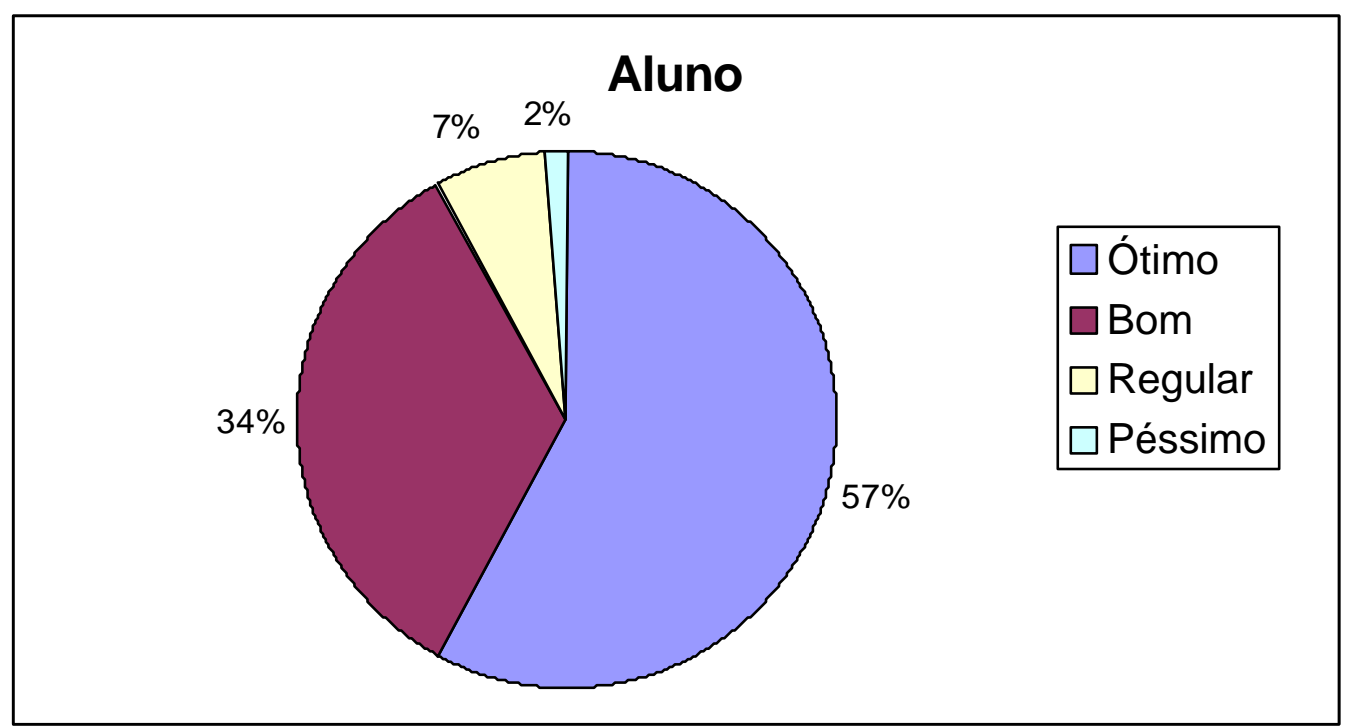

Gráfico 5.12 - Análise da opinião dos pacientes quanto ao atendimento prestado pelo aluno da CICOUFPA, Belém, 2002

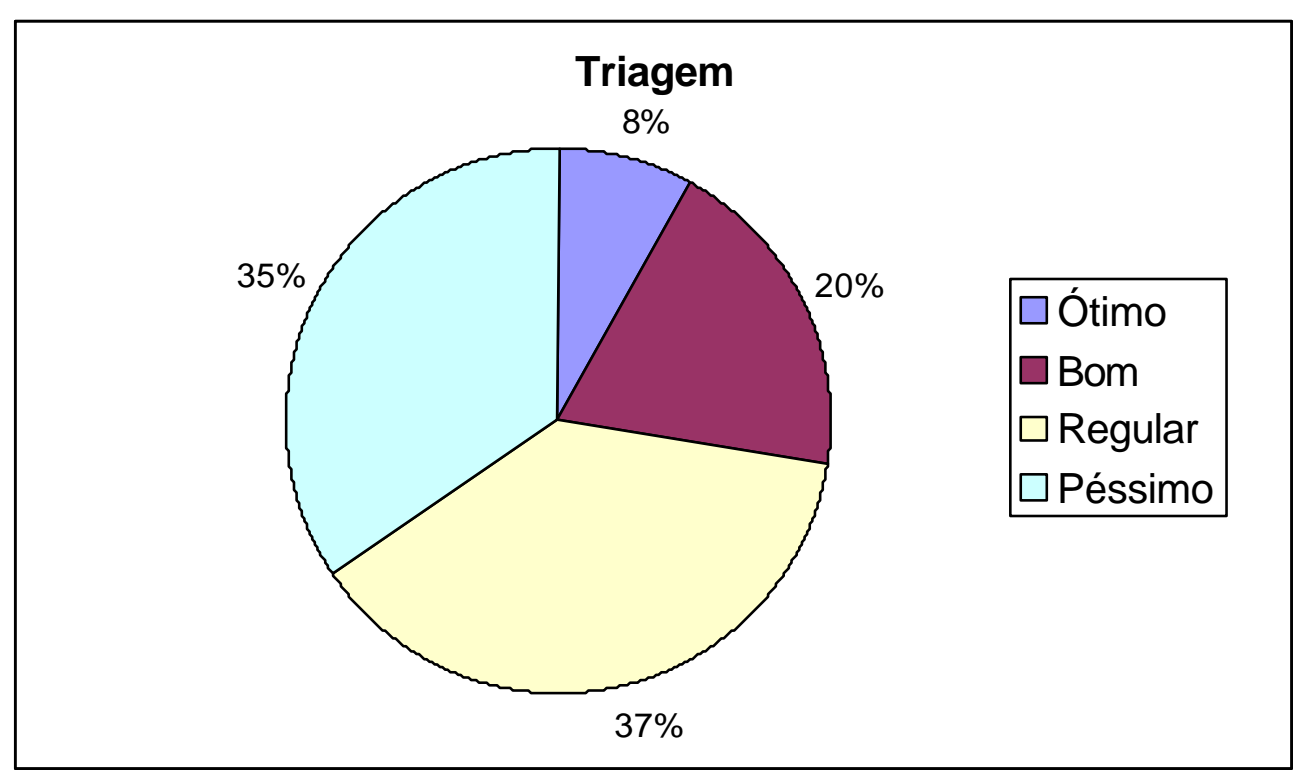

Gráfico 5.13 - Análise da opinião dos pacientes quanto ao atendimento prestado pelo serviço de triagem da CICOUFPA, Belém, 2002 
No Gráfico 5.11 observa-se que o atendimento por parte dos professores recebeu aprovação dos pacientes com 81\% (ótimo e bom), sendo que $1.5 \%$ dos pacientes considerou péssimo o atendimento do professor. No Gráfico 5.12 percebeu-se que $91 \%$ dos alunos receberam aprovação com (ótimo e bom) e 1.5\% dos pacientes achou péssimo 0 atendimento dos alunos e no Gráfico 5.13 sobre a triagem, o percentual de aceitação foi de $65 \%$ com um percentual de $35 \%$ de péssimo. Este resultado do serviço de triagem, sinaliza que será preciso realizar reuniões com os recursos humanos da área, a fim de elucidar os pontos negativos referenciados pelos pacientes como: demora no atendimento, maus tratos, triagem errada de pacientes para a Clínica Integrada, falta de agendamento e local inadequado para a triagem.

Segundo Wanderley et al. (2002) no estudo da efetividade dos serviços odontológicos oferecidos pela Disciplina de Clínica Integrada da Universidade Federal da Paraíba, relataram que a efetividade foi crítica, com predomínio da atenção curativa, índice de abandono preocupante e deficiência no registro dos planejamentos. Entretanto, é oferecido atenção integral, abrangendo as diversas áreas da Odontologia, caracterizando a alta complexidade do serviço prestado ao paciente sem grandes interferências no processo causal da doença, aspecto já referido por Almeida \& Padilha (2001) em outro estudo realizado na referida clínica sobre promoção de saúde na DCIUFPB.

Em relação à satisfação, Koslowsky et al. (1974) informaram como resultado de seu trabalho, que existe um número muito baixo de pacientes 
descontentes com seus "dentistas"; Barbisan et al. (1995) afirmaram que $90 \%$ dos pacientes estavam satisfeitos com 0 atendimento recebido e relataram que na FOUFRGS, existe uma aprovação de $90.17 \%$ quanto ao atendimento prestado pelo aluno.

De modo geral, o paciente não possui critérios objetivos que the permitam avaliar a qualidade do tratamento odontológico recebido, baseando-se para seu julgamento em critérios difusos como rapidez, organização, amabilidade e resolutividade do "problema" que o aflige (cárie, dor, estética, tratamento endodôntico, periodontal e/ou protético, etc.) (Leão \& Dias, 2001).

Segundo Ramos (2001), a prática odontológica na Clínica Integrada está baseada em um modelo de atenção ainda voltado para a prática sintomática e curativa, tratando a doença até que surja nova doença. Está voltada para o ato tecnicista tornado-se acrítica, não havendo, até então, nenhuma reflexão sobre os resultados alcançados. O fato de termos hoje, no Brasil, 173.520 Cirurgiões-Dentistas e 152 Faculdades de Odontologia, formando anualmente 11.500 novos profissionais (CFO, 2002), acirra a concorrência e o jovem formando encontra um mercado de trabalho altamente competitivo, para o qual deverá estar bem preparado.

Segundo Ramos (1997) em um estudo realizado na Clínica Integrada da FAFEOD, em Diamantina, os pacientes, consideraram $97.92 \%$ ótimo e bom o atendimento do aluno ao usuário. Analisando tais dados e comparando-os com os obtidos nesta pesquisa, confirmou-se a satisfação, 
pois $91 \%$ dos pacientes consideram ótimo e bom o atendimento prestado pelos alunos da CICOUFPA.

Os pacientes da Clínica Integrada do COUFPA, quando estimulados a responderem o porque da consideração do atendimento recebido ter sido "ótimo ou bom", responderam, de forma espontânea, com vocábulos tais como: capacidade, educação, responsabilidade, pontualidade, dedicação, interesse, atenção, eficiência, tranqüilidade, delicadeza, simplicidade, inteligência e amizade. Por outro lado, aqueles que fizeram queixas ao atendimento colocaram especialmente, a morosidade dos alunos, a presença de poucos professores para supervisão, e o funcionamento do serviço de triagem como entraves do atendimento.

A totalidade dos docentes da Clínica Integrada do COUFPA, de acordo com informações colhidas nos Departamentos de Clínica e de Prótese do Curso de Odontologia, são especialistas em suas respectivas áreas de atuações (Dentística, Endodontia, Periodontia, Prótese, Cirurgia), e formados no modelo tradicional, com visão mais curativa. Para Ramos (2001), ainda mais importante do que enfatizar o treinamento do aluno em tecnologia recente e sofisticada, é o professor oferecer-Ihe uma sólida formação, preparando-o para se adequar àrealidade em que atuará e com espírito crítico e aberto para eventual absorção de tecnologias. O padrão de excelência de uma Instituição de Ensino Superior, repousa substancialmente na qualidade de ter seu corpo docente em continuada dedicação ao ensino (Ramos, 2001). 
De acordo com Ramos (1997), em um estudo realizado na Clínica Integrada da FAFEOD, Diamantina, sobre atendimento, observa-se que os pacientes consideraram $94.79 \%$ ótimo e bom o atendimento odontológico prestado pelos professores e alunos.

Analisando tais dados e comparando-os com os obtidos por Leão \& Dias (2001) com 92\% de aceitação e com os dados obtidos por este trabalho na recente pesquisa, onde $81 \%$ dos pacientes da CICOUFPA estão satisfeitos com o atendimento recebido por parte dos professores, os mesmo tem um papel importante como referência pela atenção prestada e percebida pelo paciente, conferindo um imagem de segurança e satisfação, confirmando-se assim a satisfação dos pacientes com o tratamento recebido nas clínicas integradas. Quanto aos resultados positivos da avaliação dos pacientes (conceitos "ótimo" e "bom"), referentes aos professores, as palavras mais citadas foram: dedicação, transmissão do saber, assistência ao aluno, responsabilidade, humanismo, são educados, competentes e atualizados. Os pacientes que apontaram algum problema, informaram que alguns professores se atrasavam em demasia, saiam muito da sala, não usavam o vestuário completo, e em determinadas ocasiões, haviam divergência de opiniões entre eles, o que deverá ser motivo de avaliação por parte dos docentes da CICOUFPA.

Quanto à opinião dos pacientes, se consideravam o aluno da CICOUFPA apto a desempenhar o mesmo nível de atendimento de um profissional já formado, $91 \%$ dos pacientes concordaram, estes resultados superaram os de Ramos (1997) na CIFAFEOD (Diamantina) cujo resultado 
foi de $84.38 \%$ e os achados de Barbisan et al. (1995) em trabalho semelhante na Faculdade de Odontologia da UFRGS, com $65.57 \%$ de respostas positivas.

Quanto àavaliação do serviço de triagem da CICOUFPA, de acordo com o Gráfico 5.13, somente $28 \%$ dos pacientes responderam com conceitos, "ótimo" e "bom", resultado estatisticamente significante, que demonstrou a insatisfação com o serviço, sendo que entre os fatores citados ressaltaram: demora no atendimento, demora da marcação da consulta, desorganização no setor, falta de humanidade, ambiente inadequado para atendimento, provocando revolta nos pacientes, resultados estes que servirão com certeza para reflexão dos profissionais do setor de triagem e dos Administradores do Curso de Odontologia da UFPA.

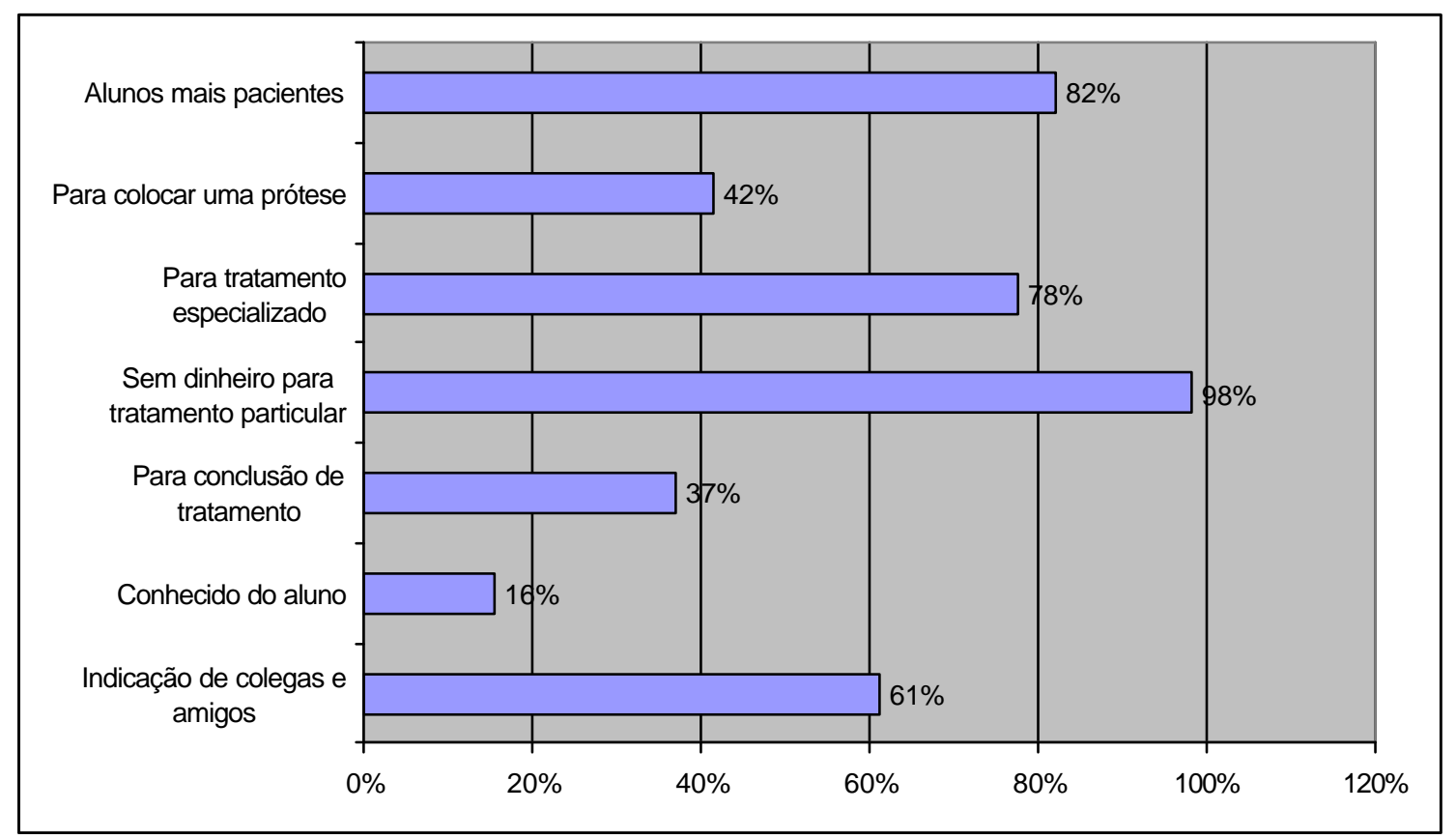

Gráfico 5.14 - Distribuição dos pacientes quanto ao motivo da procura de atendimento CICOUFPA, Belém, 2002 
Quanto aos motivos da procura pela CICOUFPA para tratamento, no Gráfico 5.14, destacamos os itens; os alunos tem mais paciência no atendimento com $82 \%$, procura por tratamento especializado com $78 \%$, sem dinheiro para tratamento $98 \%$ e um referencial de recomendações de colegas e amigos de $61 \%$.

Por isso, a qualidade dos serviços de saúde tem que ser analisada no contexto mais amplo, envolvendo os fatores sócio-econômicos em que vive a população, as diferenças culturais e os distintos modelos de interpretação das enfermidades, sendo apropriadas em cada contexto específico (Nuto \& Nations, 1999).

Mas além do problema sócio-econômico dos pacientes, neste trabalho observa-se a qualidade do atendimento, a existência de especialidades e a recomendação de amigos como fatores importantes da procura dos usuários pela CICOUFPA.

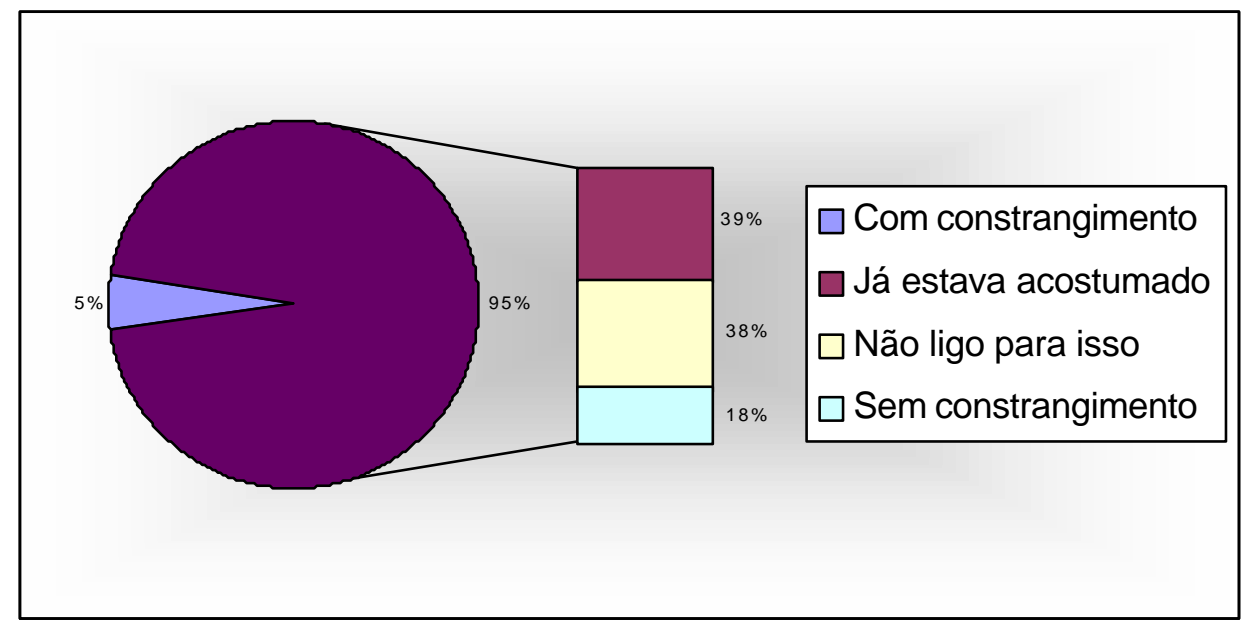

Gráfico 5.15 - Análise da opinião dos pacientes quanto ao fato de ser atendido em um ambiente coletivo, como a CICOUFPA, Belém, 2002 
Segundo Ramos (2001) no trabalho, como o paciente se sentiu ao ser atendido por um aluno de Odontologia em ambiente público, relatou que aplicando um questionário em 31 pacientes das clínicas da Faculdade Federal de Odontologia de Diamantina (FAFEOD), para identificar o sentimento dos pacientes, os resultados apontaram que alguns pacientes ainda se sentiam desconfortáveis durante o tratamento.

Nesta pesquisa da CICOUFPA, o fato do atendimento ser em um ambiente coletivo, ao lado de muitas pessoas, não desagradou à maioria dos pacientes (95\%), que afirmaram não se importar com isso, uma vez que já estavam acostumados com este tipo de ambiente, conforme ilustra o Gráfico 5. 15, porém o ambiente deixou $5 \%$ dos pacientes constrangidos, porque gostariam de ter um local de atendimento individualizado.

Ramos (1997) em outra pesquisa, relatou que $90.62 \%$ dos pacientes pesquisados na Clínica Integrada da FAFEOD, Diamantina, não se incomodaram em serem atendidos em local coletivo, porque já estavam acostumados.

Porém, mesmo com este alto índice relatado sem constrangimento, com referência ao ambiente em si, devem ter surgido marcas, atitudes e significados, ligados à emotividade de quem ali estava participando, fosse como prestador ou como usuário do serviço (Ramos, 1997). Daí poderia surgir um certo desejo de privacidade na atenção odontológica, o que de fato não ocorreu (Leão \& Dias, 2001).

Matos et al. (2002), no trabalho Projeto Bambuí: que avaliou serviços odontológicos privados, públicos e de sindicatos, admitiram que os 
resultados mostraram a existência de importantes contrastes em relação à saúde bucal e ao tipo de atenção recebida entre os usuários dos diferentes tipos de serviços odontológicos. De maneira geral, os usuários de serviços públicos estavam em grande desvantagem em relação aos usuários do sindicato. Esse achado é preocupante, uma vez que um dos objetivos dos serviços públicos odontológicos é a redução das desigualdades, propiciando melhoria da qualidade de vida relacionada à saúde para os indivíduos com menor nível sócio-econômico, que são mais vulneráveis às doenças bucais.

Tabela 5.8 - Análise da distribuição dos pacientes referenciados para tratamento por especialidades na CICOUFPA, Belém, 2002

\begin{tabular}{c|c|c}
\hline Trat. Especializados & № de Pacientes & $\%$ \\
\hline Prótese & 83 & $41,5 \%$ \\
Endodontia & 62 & $31,0 \%$ \\
Dentística & 43 & $21,5 \%$ \\
Periodontia & 31 & $15,5 \%$ \\
Cirurgia & 24 & $12,0 \%$ \\
Ortodontia & 6 & $3,0 \%$ \\
\hline
\end{tabular}

$\mathrm{Na}$ Tabela 5.8 observa-se pelos resultados sobre especialidades, que $41.5 \%$ dos pacientes procuraram por Prótese, 31\% por Endodontia, 21.5\% por Dentística, 15.5\% por Periodontia, 12\% por Cirurgia e 3\% por Ortodontia. 
Esta procura por especialidades justifica-se porque a CICOUFPA é uma unidade de referência secundária e terciária do SUS e também para as demais disciplinas do Curso.

Diversos trabalhos relataram que em outros Estados e Países este perfil da Clínica Integrada é o mesmo, devido a proposta dos modelos pedagógicos, que estabelecem nível de complexidade crescente para colocar a disciplina de Clínica Integrada como necessária para o adestramento das habilidades adquiridas durante o Curso. E essa formação seguramente, acompanhando o alto padrão científico-tecnológico da própria Odontologia, deverá ultrapassar limites, indo de encontro, também, æ̀ necessidades humanísticas e sociais dos pacientes que freqüentam a CICOUFPA.

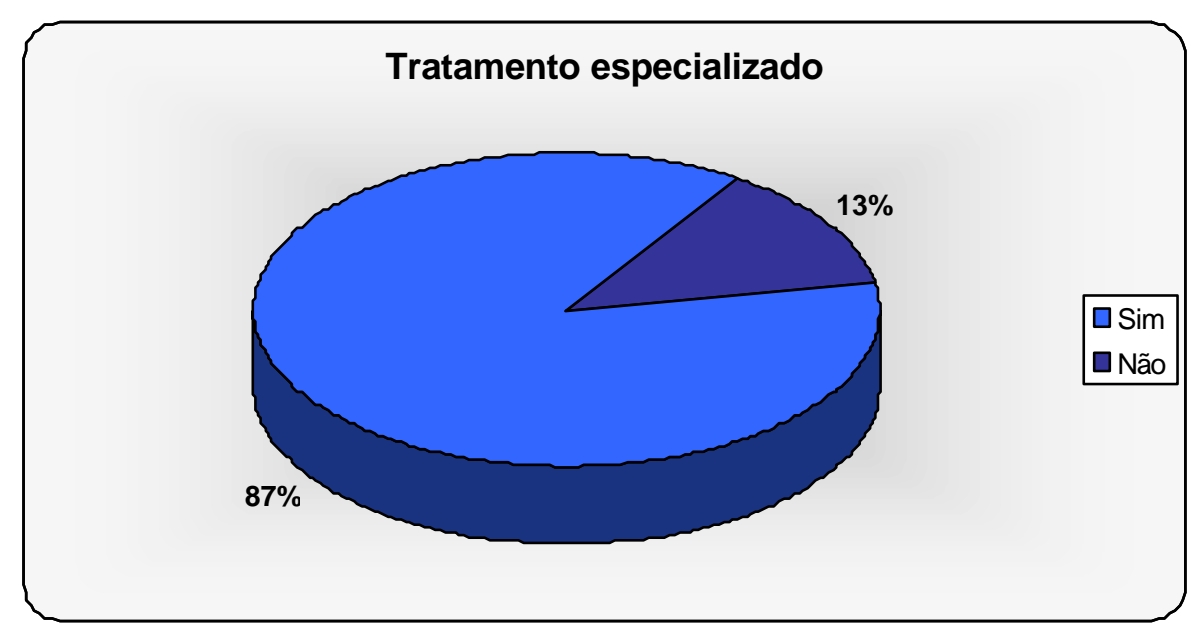

Gráfico 5.16 - Distribuição dos pacientes por atendimentos especializados na CICOUFPA, Belém, 2002

No Gráfico 5.16 observa-se que dos 200 pacientes, 87\% procuraram o tratamento especializado e $13 \%$ procuraram o atendimento clínico por 
demanda expontânea. Isto demonstra que a CICOUFPA, funcionou como referência para o SUS, justificando sua proposta de disciplina que provoca integração de conhecimentos e habilidades que foram desenvolvidas nos conteúdos programáticos das diversas disciplinas da Faculdade.

Tabela 5.9 - Estudo da opinião dos pacientes quanto ao ambiente da CICOUFPA, Belém, 2002

\begin{tabular}{l|c|c|c|c|c|c|c|c|c|c}
\hline Itens/Conceitos & Ótimo & $\%$ & Boa & $\%$ & Regular & $\%$ & Péssima & $\%$ & Total & $\%$ \\
\hline Organização & 68 & 34,0 & 87 & 43,5 & 41 & 20,5 & 4 & 2,0 & 200 & 100,0 \\
Conforto & 60 & 30,0 & 86 & 43,0 & 50 & 25,0 & 4 & 2,0 & 200 & 100,0 \\
Limpeza & 68 & 34,0 & 90 & 45,0 & 36 & 18,0 & 6 & 3,0 & 200 & 100,0 \\
Iluminação & 74 & 37,0 & 101 & 50,5 & 22 & 11,0 & 3 & 1,5 & 200 & 100,0 \\
Pontualidade & & & & & & & & & & \\
do aluno
\end{tabular}

Observação: Nesta questão foi permitida mais de uma resposta, de maneira que o número de respostas superou o número de entrevistados e no item pontualidade do aluno um entrevistado não respondeu, portanto ficaram 199 respostas.

$\mathrm{Na}$ Tabela 5.9 uma observação de caráter geral refere-se à perspectiva das mulheres como avaliadoras de serviços de saúde, caracterizada pelo conhecimento ímpar do cotidiano, experiência de vida e pelo fato de serem as principais agentes de saúde no contexto doméstico. Observa-se que as mulheres são capazes de identificar com clareza 
indicadores de qualidade de vida e satisfação. A pontualidade do aluno na CICOUFPA, foi um item em que 16 pacientes sinalizaram como um dos fatores que precisavam de melhorias para evitar longas esperas.

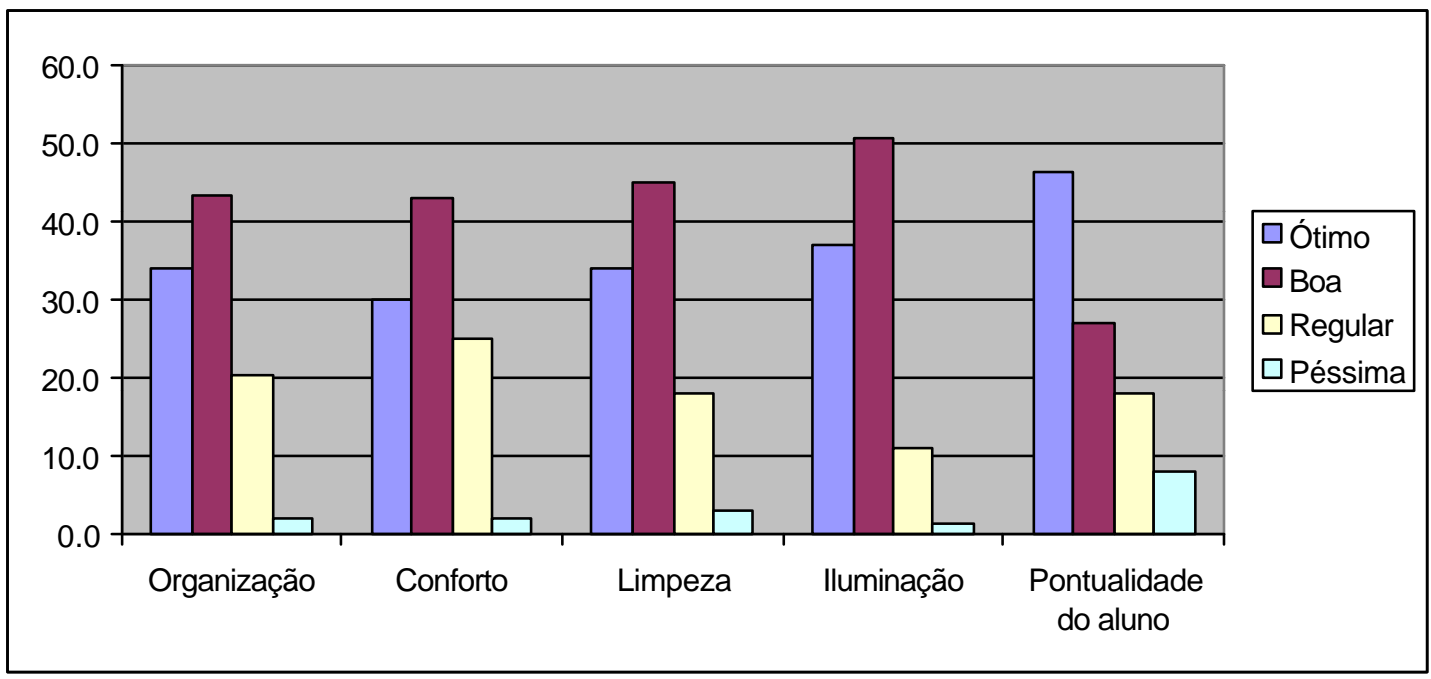

Gráfico 5.17 - Análise da opinião dos pacientes quanto o ambiente da CICOUFPA, Belém, 2002

Segundo Chaves (1986), o ambiente se traduz como um elemento que determina a satisfação do paciente, em relação ao atendimento odontológico e Barbisan et al. (1995); Leão \& Dias (2001); Ramos (1997) e Ramos (2001), em seus respectivos trabalhos relataram que os pacientes atendidos manifestaram, na sua grande maioria, uma opinião positiva a respeito da organização, limpeza, conforto e iluminação das clínicas.

Garcia \& Contreras (2002) relataram que a satisfação dos pacientes está ligada à qualidade do atendimento, a um sistema de retorno eficiente, simples e prático, com intervalos regulares. 
Estes dados comparados com os resultados desta pesquisa, confirmaram que uma grande maioria (Tabela 5.9 e Gráfico 5.17), tem opinião positiva sobre o ambiente na Clínica Integrada do COUFPA, através dos conceitos ótimo, bom e regular, observou-se também que os percentuais dos que não aprovaram o ambiente não foram estatisticamente significantes.

Tabela 5.10 - Avaliação das nota, em escala de 0 a 10, para o atendimento odontológico recebido pelos pacientes da CICOUFPA, Belém, 2002

\begin{tabular}{c|c|c}
\hline Nota & № de pacientes & $\%$ \\
\hline 2 & 1 & 0,5 \\
5 & 7 & 3,5 \\
7 & 9 & 4,5 \\
8 & 24 & 12 \\
9 & 69 & 34,5 \\
10 & 45 & 22,5 \\
\hline Total & 45 & 22,5 \\
\hline Média= 8.33 e & Desvio= 1.35 & 100 \\
\hline
\end{tabular}




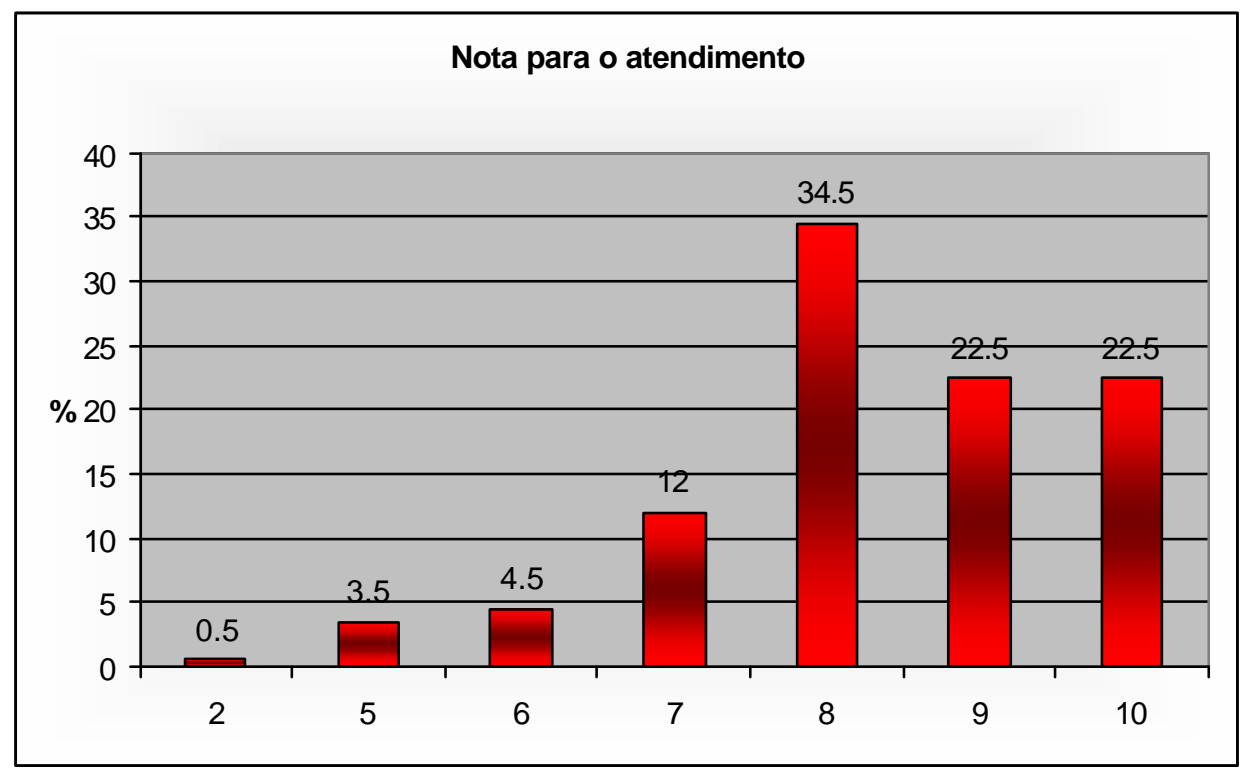

Gráfico 5.18 - Avaliação por nota, em escala de 0 a 10, para o atendimento odontológico recebido pelos pacientes da CICOUFPA, Belém, 2002

Barbisan et al. (1995) relataram em seu trabalho sobre avaliação da satisfação dos pacientes atendidos na UFRGS, que $78.68 \%$ dos pacientes conferiram notas 9 e 10 para a CIUFRGS. Ramos (1997), descreveu que na Faculdade de Odontologia de Diamantina (MG) $81.26 \%$ dos pacientes deram notas 9 e 10 para a CIFAFEOD e outros relatos informaram que o nível das notas 9 e 10 tiveram um alto percentual de referência. Porém neste trabalho, apesar do grau de satisfação, somente $45 \%$ dos pacientes aferiram notas 9 e 10 para a CICOUFPA de acordo com a Tabela 5.10 e Gráfico 5.18.

Os resultados obtidos são altamente expressivos. Mas, concordando com Mezomo (1994), é preciso que a Universidade se avalie, rotineiramente, não apenas nos aspectos quantitativos de sua estrutura e de sua produção, 
mas, sobretudo, quanto aos aspectos qualitativos de seus processos e de seus resultados

Em todos os estudos realizados observou-se um elevado nível de satisfação dos pacientes com os tratamentos recebidos, e que nenhuma das médias para qualquer categoria de paciente, atingiu a variação de insatisfação.

Segundo Butters \& Willis (2000), a satisfação do paciente está tornando-se um indicador cada vez mais importante de qualidade. Entretanto, a maioria dos levantamentos de satisfação do paciente, tem como público alvo apenas os pacientes atuais da clínica dentária ou da instituição (Faculdade de Odontologia), o que pode resultar em uma estimativa aumentada da satisfação com o tratamento, já que os pacientes insatisfeitos provavelmente já deixaram a clínica ou a instituição.

As diferenças nos níveis de satisfação podem esclarecer porque as pessoas abandonaram o tratamento na Faculdade de Odontologia e podem dar idéia valiosa para melhorar a seleção do paciente, retenção e qualidade do serviço nas clínicas.

Como pode ser observado, há três (3) razões principais citadas pelos pacientes como justificativa pela procura dos serviços da faculdade: 0 custo baixo dos serviços, a recomendação de amigo ou familiar, e a qualidade percebida do tratamento recebido (satisfação), (Butters \& Willis, 2000).

O serviço como espaço no qual se desenrola dimensões da vida, o processo saúde-doença está integrado ao dia-dia dos pacientes e 
teoricamente deve ajudá-los em relação as ações de saúde (Gallo, 1996; Ramos, 1997; Stechman, 1998).

Apesar dos resultados francamente favoráveis e positivos, somos de opinião que os professores responsáveis pela Clínica Integrada, jamais deveriam se acomodar em seu saber e em sua dedicação. Pelo contrário, devem sentir-se responsáveis, ano a ano, pelo controle da qualidade, pela angústia do que muito ainda resta a fazer, pelo aprimoramento da própria clínica, em seus aspectos organizacionais, filosóficos, administrativos e técnicos-científicos .

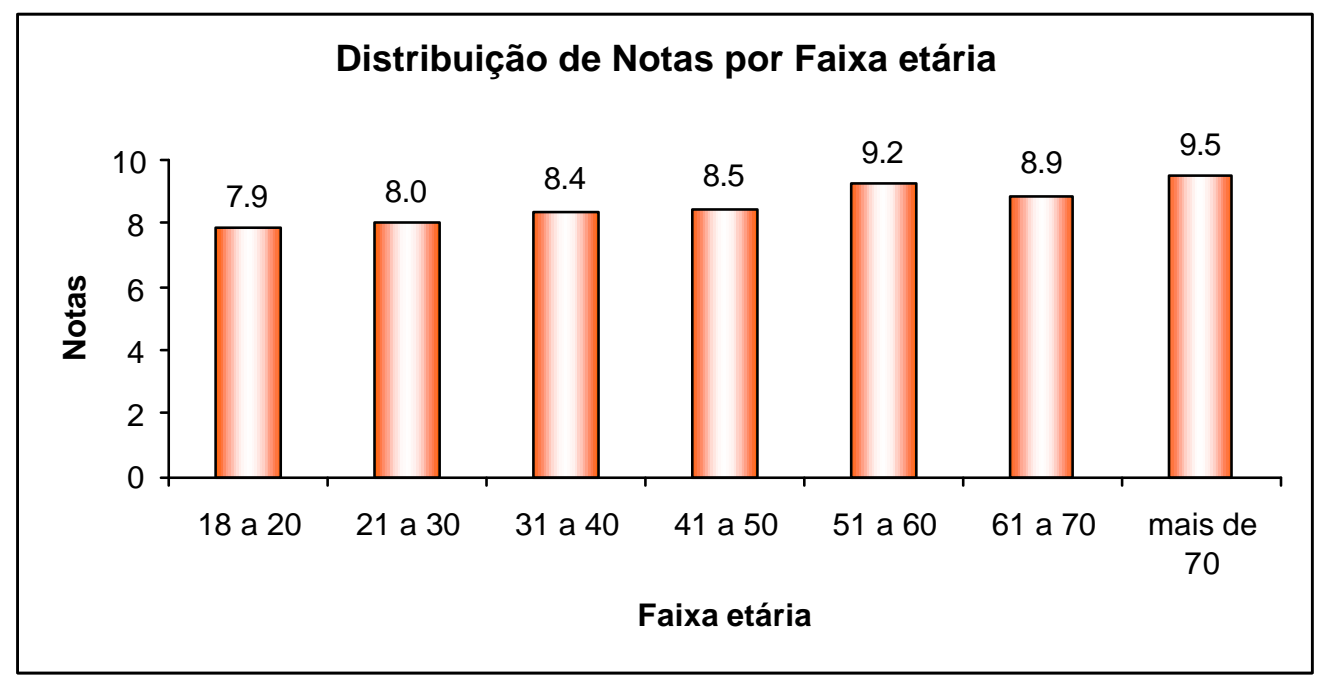

Gráfico 5.19 - Análise da distribuição das médias das notas por faixa etária, atribuídas pelos pacientes da CICOUFPA, Belém, 2002

Analisando o Gráfico 5.19, percebe-se que a faixa etária que atribuiu média mais alta foi a de mais de 70 anos e a média mais baixa foi na faixa de 18 a 20 anos, no grupo de idosos devido ao tratamento protético 
satisfatório e no grupo de jovens, devido a falta de tratamento completado no semestre pelo mesmo aluno.

Garcia \& Contreras (2002) relataram que a satisfação dos pacientes, está ligada àqualidade do atendimento, e a um planejamento de agenda em datas devidamente aprazadas. E que a orientação direta ao paciente, por meio de recursos audio-visuais e convencimentos é o método mais adequado para a motivação e satisfação dos pacientes nas clínicas.

Tabela 5.11 - Distribuição das notas para o atendimento por nível de escolaridade dos pacientes da CICOUFPA, Belém, 2002

\begin{tabular}{|c|c|c|c|c|c|c|c|c|}
\hline \multirow[t]{2}{*}{ Escolaridade } & \multicolumn{7}{|c|}{ Notas para 0 atendimento } & \multirow[t]{2}{*}{ Total } \\
\hline & 2 & 5 & 6 & 7 & 8 & 9 & 10 & \\
\hline Nenhum & 0 & 0 & 0 & 0 & 3 & 3 & 3 & 9 \\
\hline $\begin{array}{l}\text { Fundamental } \\
\text { Incompleto }\end{array}$ & 0 & 2 & 2 & 7 & 22 & 8 & 23 & 64 \\
\hline $\begin{array}{l}\text { Fundamental } \\
\text { Completo }\end{array}$ & 0 & 1 & 4 & 2 & 6 & 3 & 7 & 23 \\
\hline $\begin{array}{l}\text { Médio } \\
\text { Incompleto }\end{array}$ & 0 & 1 & 1 & 9 & 19 & 12 & 5 & 47 \\
\hline $\begin{array}{l}\text { Médio } \\
\text { Completo }\end{array}$ & 0 & 3 & 1 & 6 & 16 & 14 & 6 & 46 \\
\hline $\begin{array}{l}\text { Superior } \\
\text { Incompleto }\end{array}$ & 0 & 0 & 1 & 0 & 2 & 3 & 0 & 6 \\
\hline $\begin{array}{l}\text { Superior } \\
\text { Completo }\end{array}$ & 0 & 0 & 0 & 0 & 0 & 2 & 1 & 3 \\
\hline $\begin{array}{l}\text { Pós- } \\
\text { Graduação }\end{array}$ & 1 & 0 & 0 & 0 & 1 & 0 & 0 & 2 \\
\hline Total & 1 & 7 & 9 & 24 & 69 & 45 & 45 & 200 \\
\hline
\end{tabular}


$\mathrm{Na}$ Tabela 5.11. Percebe-se que a nota 8 foi atribuída 22 vezes pelos pacientes de escolaridade fundamental incompleta, 19 vezes pelos pacientes de escolaridade médio incompleto e 16 vezes pelos pacientes com o nível médio completo, quanto a nota 9 esta foi atribuída por 12 vezes pelos pacientes com nível médio incompleto e 14 vezes pelos pacientes com nível médio completo e a nota 10 foi atribuída 23 vezes pelos pacientes com nível fundamental incompleto.

Tabela 5. 12 - Distribuição das notas para o atendimento por idade dos pacientes da CICOUFPA, Belém, 2002

\begin{tabular}{c|c|c|c|c|c|c|c|c|c}
\hline \multirow{2}{*}{ Idade } & \multicolumn{7}{|c|}{ Notas para o atendimento } & \multirow{2}{*}{ Total } & Nota \\
\cline { 2 - 7 } & $\mathbf{2}$ & $\mathbf{5}$ & $\mathbf{6}$ & $\mathbf{7}$ & $\mathbf{8}$ & $\mathbf{9}$ & $\mathbf{1 0}$ & & Média \\
\hline 18 a 20 & 0 & 3 & 1 & 1 & 13 & 5 & 2 & 25 & 7.9 \\
21 a 30 & 1 & 1 & 3 & 13 & 21 & 13 & 8 & 60 & 8.0 \\
31 a 40 & 0 & 2 & 4 & 8 & 19 & 15 & 16 & 64 & 8.4 \\
41 a 50 & 0 & 1 & 1 & 1 & 9 & 5 & 6 & 23 & 8.5 \\
51 a 60 & 0 & 0 & 0 & 1 & 3 & 5 & 9 & 18 & 9.2 \\
61 a 70 & 0 & 0 & 0 & 0 & 4 & 1 & 3 & 8 & 8.9 \\
Mais de 70 & 0 & 0 & 0 & 0 & 0 & 1 & 1 & 2 & 9.5 \\
\hline Total & 1 & 7 & 9 & 24 & 69 & 45 & 45 & 200 & 8.3 \\
\hline
\end{tabular}

$\mathrm{Na}$ Tabela 5.12. Observa-se que as faixas etárias que atribuíram maior número de notas 10 foram as de 21 a 30 anos, 31 a 40 e 51 a 60 anos, contribuindo para a média de 8.33 de satisfação para com o atendimento na CICOUFPA. Porém, a nota 10 teve menor média entre os 
pacientes da faixa etária entre 18 a 20 anos, sendo que foram atribuídas, no total, 17 notas abaixo de 7 , significando que alguns pacientes não estão plenamente satisfeitos com o atendimento odontológico na Clínica Integrada.

Tabela 5. 13 - Distribuição das notas para o atendimento por faixa salarial dos pacientes da CICOUFPA, Belém, 2002

\begin{tabular}{c|c|c|c|c|c|c|c|c}
\hline \multirow{2}{*}{ Renda } & \multicolumn{7}{|c|}{ Notas para o atendimento } & \multirow{2}{*}{ Total } \\
\cline { 2 - 7 } Nenhuma & 2 & 5 & 6 & 7 & 8 & 9 & $\mathbf{1 0}$ & \\
\hline 1 A 2 SM & 0 & 0 & 0 & 0 & 1 & 0 & 2 & 3 \\
2 A 3 SM & 0 & 2 & 6 & 15 & 44 & 25 & 31 & 123 \\
3 A 5 SM & 0 & 3 & 2 & 6 & 13 & 6 & 8 & 38 \\
5 A 10 SM & 0 & 2 & 1 & 2 & 9 & 12 & 4 & 30 \\
Mais de 10 SM & 0 & 0 & 0 & 1 & 1 & 2 & 0 & 4 \\
\hline Total & 1 & 0 & 0 & 0 & 1 & 0 & 0 & 2 \\
\hline
\end{tabular}

Na Tabela 5.13 a nota 10, atribuída por 45 usuários predomina na faixa salarial de 1 a 2 SM, sendo que a nota 8 atribuída por 69 pacientes predomina nas faixas de 1 a 2 SM e de 2 a 3 SM, nos 123 pacientes da faixa de 1 a 2 SM estão concentradas as notas 7 (15), 8 (44), 9 (25) e 10 (31) pacientes.

Segundo Padilha et al. (2001), no trabalho realizado com 98 pacientes da Clínica Integrada da Faculdade de Odontologia da 
Universidade Federal Fluminense, sobre saúde bucal e nível sócioeconômico, observou-se que o perfil do paciente da CIFOUFF, apresentou predomínio de escolaridade e poder aquisitivo baixos, e a análise da saúde bucal indicou a necessidade de maior ênfase para o diagnóstico e tratamento da doença gengival, e não foi encontrado associação estatística entre os níveis sócio-econômico e os índices de saúde bucal referentes a cárie e a higiene bucal.

Para Martins (1993), o paciente percebe a diferença qualitativa da forma, do tipo de atendimento que recebe e a distância que o separa do profissional.

A Clínica Integrada do COUFPA é um local de docência, onde o aluno está em franco processo de formação. Cada procedimento, por isso mesmo, é acompanhado e avaliado pelo professor onde se discutem os casos clínicos. Além de tudo segundo Ramos (1997), o trabalho é individualizado, há especificidade de tratamento (mais rápidos ou mais demorados, dependendo do caso e da especialidade). Porém Carvalho et al. (2000) defende que, na Clínica Integrada, o aluno deve ser cada vez mais estimulado para atuar com responsabilidade individual, a fim de se evitar futuras dependências e inseguranças. 


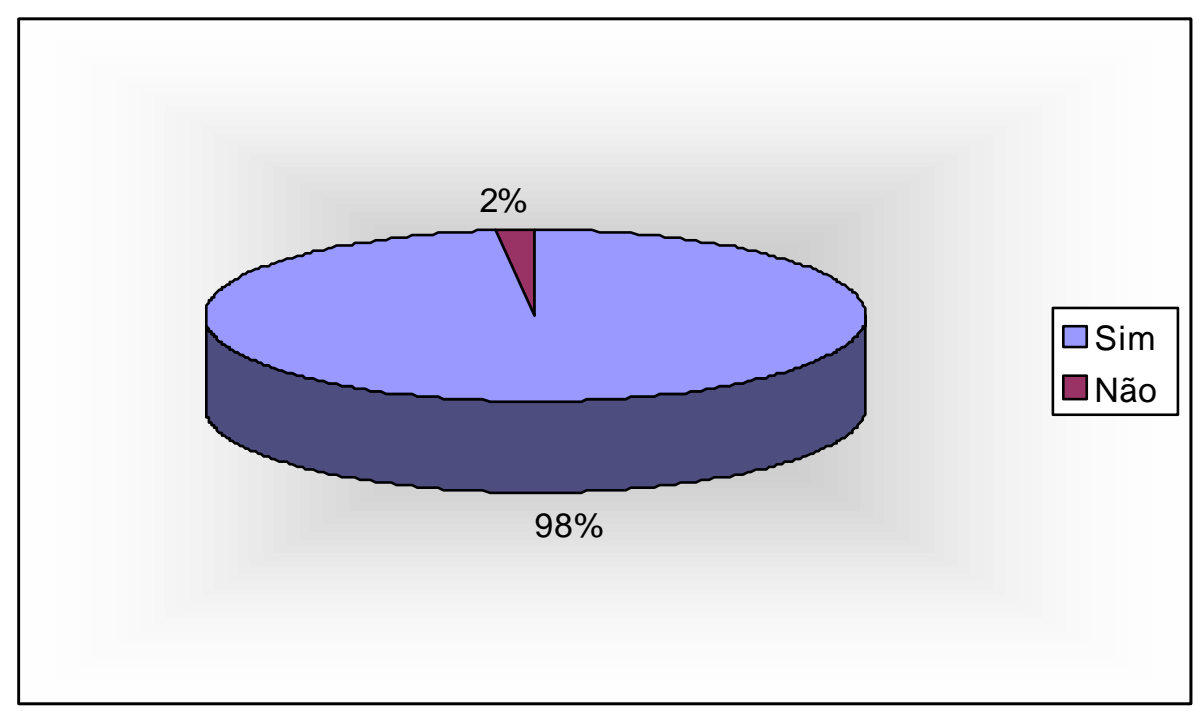

Gráfico 5.20 - Opinião dos pacientes atendidos na Clínica Integrada se indicariam ou não os serviços para outras pessoas. CICOUFPA, Belém, 2002

Segundo Barbisan et al. (1995), em sua pesquisa na FOUFRGS, relataram que os pacientes indicariam a Clínica Integrada a outras pessoas. Leão \& Dias (2001) em outro trabalho no Rio de Janeiro, relataram que a maioria dos pacientes recomendaram as clínicas. Sendo que Ramos (1997) informou que $95.83 \%$ dos pacientes da CIFAFEOD indicariam a outras pessoas o serviço, e nesta pesquisa, 98\% dos pacientes indicariam a CICOUFPA para outras pessoas Gráfico 5.20, demonstrando com isto que, em todas as Clínicas Integradas existe um elevado nível de satisfação com os serviços recebidos. Isto comprova que a CICOUFPA, como prestadora de serviços odontológicos, vem cumprindo satisfatoriamente com sua missão 
social, pois a qualidade técnica do serviço é perfeitamente confundida com o grau de satisfação do paciente ao ser atendido.

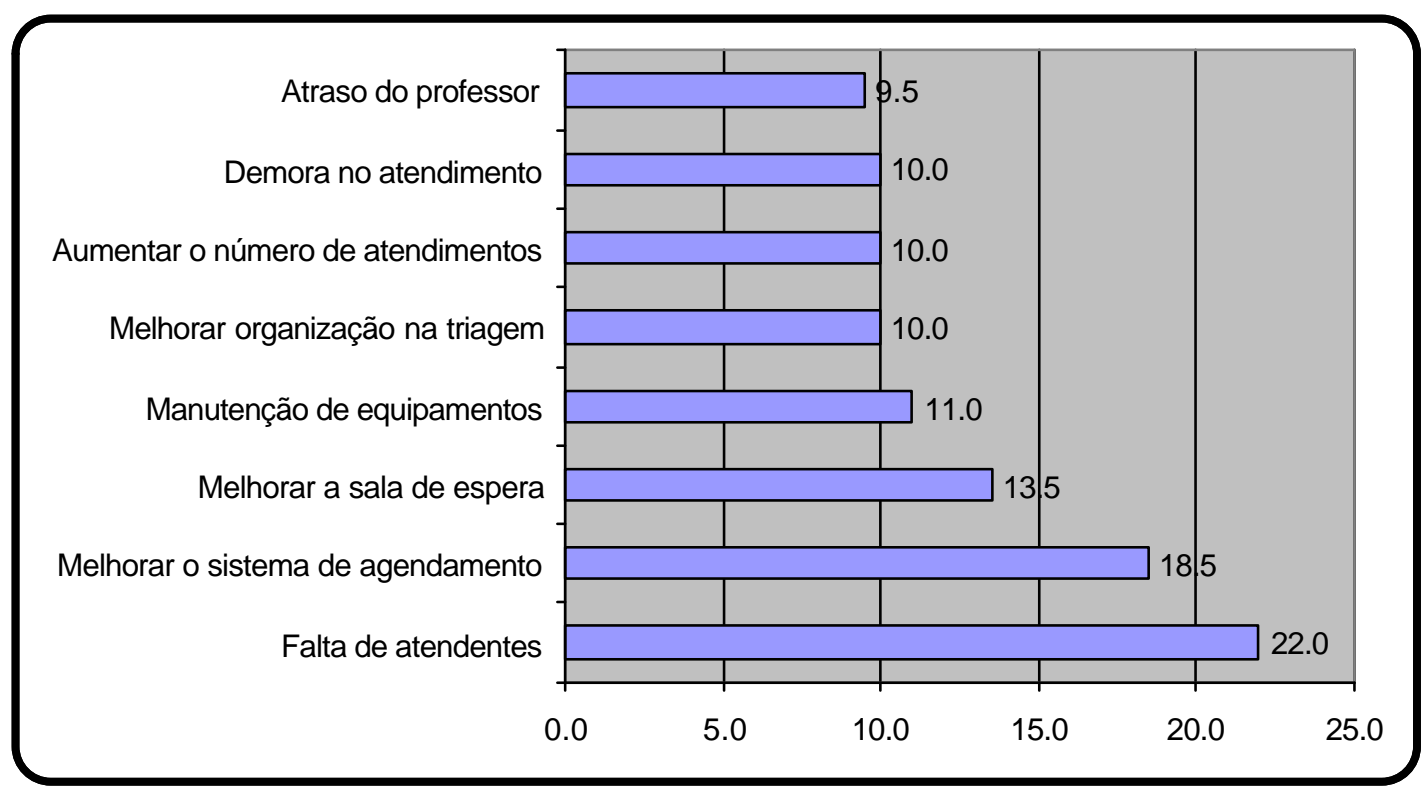

Gráfico 5. 21 - Análise das sugestões dos pacientes da Clínica Integrada do para melhoria do atendimento. CICOUFPA, Belém, 2002

No Gráfico 5.21 observamos que as sugestões dos pacientes estão centradas em problemas organizacionais e administrativos, confirmando o que é citado na literatura e reafirmando os resultados de que os pacientes estão satisfeitos com o atendimento prestado pela CICOUFPA na área técnica dentro da sala de clínica e com a qualidade dos procedimentos prestados pelos alunos e professores. Porem existem grandes problemas como: falta de atendentes $22 \%$, melhorar o sistema de agendamento $18.5 \%$, melhorar o ambiente da sala de espera 13.5\%, aumentar o número de atendimentos $10 \%$ e capacitação do serviço de triagem com 10\%. 
Para Franco \& Campos (1998), o conceito de qualidade é historicamente produzido e pressupõe uma análise processual, uma dinâmica a respeito das condições conjunturais, cujos princípios deveriam se corporificar em um conjunto de procedimentos capazes de garantir a excelência dos resultados e dos serviços. Quando comparamos os resultados de Ramos (1997) na Clínica Integrada da FAFDEOD, Barbisan et al. (1995) na Clínica Integrada da UFRGS; Leão \& Dias (2001) nas Faculdades A e B do Rio de Janeiro e os resultados desta pesquisa realizada na Clínica Integrada do COUFPA, o nível de satisfação foi altamente significativos. Sobre a análise das sugestões dos pacientes, Ramos (1997) indicou que 35.42\% disseram para deixar como está, Barbisan et al. (1995) sinalizaram que $28.8 \%$ dos pacientes disseram que esta tudo bem e Leão \& Dias (2001); Pereira (2000), informaram que os pacientes não teriam grandes sugestões, enquanto na CICOUFPA, somente $8 \%$ não apresentaram qualquer sugestão, portanto tivemos uma quantidade significante de pacientes que fizeram sugestões para melhorar o atendimento na CICOUFPA.

Segundo Nuto \& Nations, (1999); Almeida et al. (2001); Emmerich et al. (2000), a avaliação qualitativa dos serviços como processo de construção de cidadania, se faz a partir da consideração central da avaliação, sobre proporcionar opções que permitam o alcance dos objetivos esperados nos projetos sociais e não somente apreciação de metas alcançadas acriticamente. 
O cenário das Instituições de Ensino Odontológico com a globalização, permite uma troca mais rápida de experiências e percebe-se a educação em saúde como mecanismo e estratégia de transformação da realidade, onde sua prática, na relação paciente-profissional no mundo, deve ser transformadora, facilitadora e libertadora:

- Transformadora na medida em que ao desenvolver uma consciência crítica e estar comprometido com a população à qual assiste, visa a promoção da saúde associada àidéia de saúde àtransformação social.

- $\quad$ Facilitadora à medida que proporciona ações participativas que levem ao planejamento, fiscalização, acompanhamento e avaliação do serviço de saúde, questionando inclusive o próprio papel da Universidade na comunidade em que a mesma está inserida.

- Libertadora à medida que tal profissional de saúde é capaz de reconhecer sua prática como dialógica, numa relação sujeito-sujeito, num processo onde sujeito e objeto se confundem, transformando ao mesmo tempo em que é transformado.

Refletir sobre inovações pedagógicas no ensino superior, necessariamente nos encaminha à questão do projeto político-pedagógico, como aquele que enfatiza a organização curricular, confere-lhe organicidade e permite que suas ações adquiram relevância. O projeto políticopedagógico de um curso (qualquer que seja) terá que fazer opções, definir intencionalidade e perfis profissionais, decidir sobre os focus decisórios do currículo (objetivos, conteúdos, metodologia, recursos didáticos e avaliações), analisar as condições reais e objetivas de trabalho, otimizar 
recursos humanos, físicos e financeiros, estabelecer e administrar o tempo para o desenvolvimento das ações, enfim, coordenar os esforços em direção a objetivos e compromissos futuros.

Portanto, avaliar a satisfação dos usuários da CICOUFPA foi um ato extremamente complexo, cuja responsabilidade não é competência única do usuário, do professor ou do aluno, mas sim de todos os elementos integrantes do processo educacional, espera-se que a Clínica Integrada corrija algumas distorções no ensino odontológico, como a especialização precoce e o uso desnecessário de tecnologia.

Destacamos alguns itens necessários para a Clínica Integrada do COUFPA no momento: implementar as ações de promoção e prevenção, estimular no aluno a importância do tratamento clínico integrado como estratégia fundamental para uma graduação adequada, discutir com os alunos os direitos do paciente, as normas de biossegurança, o papel do serviço de triagem, informar ao aluno que ele, neste momento, assessorado pelo professor e posteriormente sozinho, tem o direito de discordar das posições do paciente em relação às escolhas deste, sobre os tratamento recomendados.

Entende-se que as Faculdades não são obrigatoriamente prestadoras de serviços e que as prioridades máximas devem ser o ensino, a pesquisa e a extensão, sendo a disciplina de Clínica Integrada indispensável no currículo mínimo do Curso de Odontologia, com corpo docente próprio e seguindo as normas do Projeto Pedagógico do Curso e as Diretrizes do Ministério da Educação. 
A literatura comprova que na maioria das vezes, percebe-se um corpo docente improvisado por especialistas, sem serem formados como clínicos gerais, com enfoque de Clínica Integrada, provocando uma prática de especialidades na Clínica (Vargas \& Vasconcelos, 1998).

$\mathrm{Na}$ clínica integrada, o educador passa a ser o educador problematizador, que desafia os educandos que são agora investigadores críticos, permeados por constantes diálogos, pois a educação como prática de liberdade deve negar o conceito de isolamento e abstração do ser humano, assim como tornar o mundo uma presença constante em seu diálogo (Franco \& Campos, 1998).

Os pacientes, assim como quaisquer outros consumidores, criam expectativas em relação ao atendimento que irão receber. Os níveis de expectativa em serviços podem ir de desejado, que é o tipo que os pacientes esperam receber, e serviços adequados, que é o mínimo aceitável para que não se sintam insatisfeitos. Fatores como o medo e a insegurança, no caso de tratamentos odontológicos, podem ser amenizados se o paciente perceber que os benefícios superam o seu nível de expectativa, desenvolvendo o ponto crucial, empatia (Carvalho et al., 2000).

Assim sendo, após a discussão e avaliação dos indicadores de qualidade da atenção prestada na CICOUFPA, podemos afirmar que de maneira geral, os procedimentos realizados nos pacientes, são identificados pelos mesmos, como bastante satisfatórios, sendo a falta de integração entre a coordenação da clínica, serviço de triagem, pacientes e a lógica ainda fragmentada de sua organização os principais problemas 
apresentados. As soluções propostas para enfrentá-los são relativamente simples, não requerem o investimento de verbas e certamente produzirão melhorias na qualidade da assistência e portanto, satisfação dos pacientes com o tratamento recebido na disciplina de Clínica Integrada do Curso de Odontologia da Universidade Federal do Pará. 


\section{CONCLUSÕES}

A partir dos resultados obtidos, julga-se lícito afirmar que os pacientes da CICOUFPA estão satisfeitos com o atendimento recebido, pois analisando os respostas que indicam qualidade e satisfação concluimos que:

* O ambiente da CICOUFPA foi considerado organizado por $98 \%$ dos usuários, sendo que $34 \%$ dos pacientes consideram ótimo, $43.5 \%$ consideram bom e $20.5 \%$ consideraram regular.

* Dos pacientes atendidos, 66\% ficaram satisfeitos, por não sentirem dor durante os procedimentos realizados.

* Quanto a questão medo no tratamento $46 \%$ não tiveram medo e $54 \%$ sentiram medo, sendo que destes $20 \%$ tiveram medo da anestesia e $13 \%$ sentiram medo da broca, além de outros itens.

* Os pacientes responderam que $97.5 \%$ dos alunos e $62.5 \%$ dos professores estavam trajados com a indumentária completa.

* O serviço de triagem recebeu aprovação por parte de (55\%) dos pacientes, pois $8 \%$ acharam ótimo, $20 \%$ bom e $37 \%$ regular.

* O atendimento odontológico prestado pelo aluno foi aprovado por (98\%) dos pacientes, pois $57 \%$ achou ótimo, $34 \%$ bom e $7 \%$ regular. A 
assistência prestada pelos professores foi considerada por $44 \%$ dos usuários como ótima, $37 \%$ boa e por $17 \%$ como regular.

* Dos pacientes atendidos na CICOUFPA, 83\% receberam informações sobre os procedimentos curativos e $17 \%$ não receberam informações.

* Cerca de $68 \%$ dos pacientes receberam informações sobre os procedimentos preventivos e $32 \%$ não receberam informações de prevenção e promoção da saúde bucal.

* A maioria dos usuários 91.5\%, aprovou com notas 10 (22.5\%), 9 (22.5\%), 8 (34.5\%) e 7 (12\%) o atendimento recebido na CICOUFPA, e a média das notas foi de 8.33 numa escala de 0 a 10 com o desvio padrão de 1.35 .

* Analisando o cruzamento nível de escolaridade e as notas para o atendimento verificamos que as notas 8,9 e 10 foram mais prevalentes nos níveis de escolaridade: fundamental incompleto, médio incompleto e médio completo.

* No cruzamento entre faixa etária e notas para o atendimento as notas 8, 9 e 10 foram mais prevalentes nas faixas etárias de 21 a 30 anos, 31 a 40 anos e 41 a 50 anos.

* Analisando o cruzamento faixa salarial e notas para o atendimento as notas 8,9 e 10 foram mais prevalentes nas faixas salariais de 1 a $2 \mathrm{SM}$, 2 a 3 SM e 3 a 5 SM.

* A quase totalidade dos pacientes (98\%), afirmou que estão satisfeitos com os atendimentos recebidos e responderam que indicariam os serviços para outras pessoas. Sendo que a maioria já indicou, pois dos 
entrevistadas na CICOUFPA $61 \%$ ali estavam indicados por pacientes já atendidos anteriormente, confirmando portanto os $95 \%$ de pacientes que não sentem constrangimentos em serem atendidos na CICOUFPA. 
ANEXO 


\section{ANEXO 1 - Parecer da Comissão de Bioética}

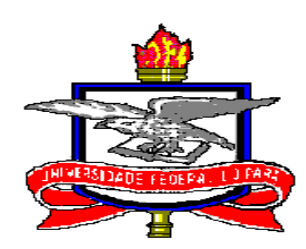

\section{UNIVERSIDADE FEDERAL DO PARÁ CENTRO DE CIÊNCIAS DA SAÚDE CURSO DE ODONTOLOGIA COMISSÃO DE BIOÉTICA}

A Comissão de Bioética do Curso de Odontologia da Universidade Federal do Pará, usando dos direitos a ela conferida pelo seu Regimento Interno, aprovado pelo Colegiado do Curso de Odontologia, e analisando os autos do processo em questão,

\section{RESOLVE:}

Que o Projeto "Avaliação da satisfação dos pacientes atendidos na clínica integrada do Curso de Odontologia da Universidade Federal do Pará" apresentado pelo aluno do Curso de Mestrado Interinstitucional em Clínica Integrada USP-FO/UFPA-CCS-CO Izamir Carnevali de Araújo , Orientado pelo Prof ${ }^{\circ}$. Dr. Rodney Garcia Rocha e Co-orientado pela Prof ${ }^{a}$. Dra. Regina Fátima Feio Barroso, depois de analisado pelos membros desta Comissão, considerando a legislação vigente e seguindo orientação das portarias do Conselho Nacional de Saúde e da Comissão Nacional de Ética do Ministério da Saúde, preenche todos os requesitos necessários para que seja desenvolvido como suporte técnico para o referido trabalho.

Assim sendo esta Comissão reconhece a validade do trabalho e que sua metodologia tem suporte técnico, legal e ético, e por isso concorda com a sua realização e autoriza o desenvolvimento do mesmo.

Belém, 04 Março de 2002.

\author{
Prof $^{a}$. Alda França Costa \\ Membro
}

\author{
Prof $^{\circ}$. Helder Antonio Rabelo Pontes \\ Membro
}




\section{REFERÊNCIAS ${ }^{1}$}

ABRAMOWICZ, M. Contribuição para o estudo dos pacientes que freqüentam as clínicas da FO. da USP. Rev Fac Odontol Univ São Paulo, São Paulo, v. 14, n. 2, p. 259-270, jul./dez. 1976.

ABRAMS, R. A.; AYERS, C.; VOGET, P. M. Quality assessment of dental restoration: a comparison by dentists and patients. Community Dent Oral Epidemiol, Copenhagen, v. 14, n. 6, p. 317-319, Dec. 1986.

ALMEIDA, R. V. D.; GAIÃO, L.; PADILHA, W. W. N. Avaliação do ensino odontológico em clínica integrada. Rev Pesqui Odontopediatr Clin Integrada, João Pessoa, v. 1, n. 2, p. 29-35, maio/ago. 2001.

ALMEIDA, R. V. D.; PADILHA, W. W. N. Clínica integrada: é possível promover saúde bucal numa clínica de ensino odontológico? Rev Pesqui Odontopediatr Clin Integrada, João Pessoa, v. 1, n. 3, p. 23-30, set./dez. 2001.

\footnotetext{
${ }^{1}$ De acordo com ABNT NBR-6023:2000. Abreviatura de periódicos segundo Base de Dados MEDLINE.
} 
ALVESALO, I.; UUSI-HEIKKILÄ, Y. Use of services, care-seeking behavior and satisfaction among university dental clinic patients in Finland. Community Dent Oral Epidemiol, Copenhagen, v. 12, n. 5, p. 297-302, Oct. 1984.

ARANGO, J. Clínicas integradas. In: TUMANG, A. J. Reunião do programa latino-americano de inovações em educação odontológica. Piracicaba: Faculdade de Odontologia, 1976. p. 97-99.

ARAÚJO, I. C.; ARAÚJO, M. V. A. O ensino odontológico e a sua trajetória no cenário nacional e internacional: a disciplina de clínica integrada no Brasil. Belém: Universidade Federal do Pará, 2001. 41 f. Texto científico.

ARRUDA, W. B. Variáveis intercorrentes que influenciam a produtividade de clínica no curso de graduação na disciplina de clínica integrada (Terapêutica Clínica) da Faculdade de Odontologia da Universidade de São Paulo. Contribuição ao estudo. 1997. 100 f. Dissertação (Mestrado em Clínica Integrada) - Faculdade de Odontologia, Universidade de São Paulo, São Paulo. 
ASSOCIAÇÃO BRASILEIRA DE ENSINO ODONTOLÓGICO.

Recomendações sobre o tema oficial "Saúde Bucal da XX Reunião da ABENO e XI Encontro Nacional de Dirigentes de Faculdades de Odontologia". Rev ALAFO, Guatemala, v. 17/19, n. 1/2, p. 25-26, jul. $1983 / 1985$.

ATKINSON, S. J. Anthpropology in research on the quality of health services. Cad Saúde Pública, Rio de Janeiro, v. 9, n. 3, p. 283-299, jul./set. 1993.

AZAMBUJA, T. T. Metodologia para auto-avaliação da implantação da GQT. Rio de Janeiro: Qualitymark, 1994. 64 p.

BACCI, A. V. F.; CARDOSO, C. L.; PASIAN, S. R. Locus de controle em estudantes de odontologia: uma contribuição para o estudo de aspectos da personalidade. Rev Assoc Paul Cir Dent, São Paulo, v. 56, n. 1, p. 36-41, jan./fev. 2002.

BADNER, V.; BAZDEKIS, T.; RICHARD, C. Patient satisfaction with dental care in a municipal hospital. Spec Care Dentist, Chicago, v. 12, n. 1, p. 914, Jan./Feb. 1992.

BARBISAN, A. O.; ZANON, M. A.; WEISSHEM, A. P.; FERRO, F. C.; DIAS, G. C.; SALETE, M.; GUIMARÃES, V. Parecer dos pacientes sobre a eficácia no atendimento recebido na Faculdade de Odontologia da UFRGS. Rev Fac Odontol Porto Alegre, Porto Alegre, v. 3, n. 2, p. 34-36, dez. 1995. 
BARBOSA, E. R. C. Medo de dentista. APCD J, São Paulo, n. 357, p. 18, abr. 1995.

BARROS, E. R. C. Odontologia a serviço da comunidade. Rev ABENO, Camaragibe, v. 2, n. 1, p. 3-7, jan./dez. 1981.

BERGREEN, U.; MAYNERT, G. Dental fear and avoidance: causes, symptons and conseqüences. J Am Dent Assoc, Chigago, v. 109, n. 2, p. 247-250, Feb. 1984.

BERWICK, D. M. Melhorando a qualidade dos serviços médicos, hospitalares e da saúde. São Paulo: Markon Books, 1994. 296 p.

BITTAR, O. J. N. V. Indicadores de qualidade e quantidade em saúde. Rev Adm Saúde, São Paulo, v. 3, n. 12, p. 21-28, jul./set. 2001.

BOLTANSKI, L. As classes sociais e o corpo. $3^{\text {a }}$ ed. Rio de Janeiro: Graal, 1989. $191 \mathrm{p}$.

BORDENAVE, J. D.; PEREIRA, A. M. Estratégias de ensinoaprendizagem. $6^{\underline{a}}$ ed. Petrópolis: Vozes, 1984. 317 p. 
BRASIL. Ministério da Educação e Cultura. Secretaria de Ensino Superior. Currículo mínimo do curso de odontologia. Parecer no . 840/70, aprovado em 11 de novembro de 1970. Documenta, Brasília, v. 260, p. 46-54, jul. 1982a.

BRASIL. Ministério da Educação e Cultura. Secretaria de Ensino Superior. Proposta de novo currículo mínimo para o curso de graduação em odontologia. Parecer no 370/82, aprovado em 9 de julho de 1982. Documenta, Brasília, v. 260, p. 46-54, jul. 1982b.

BRASIL. Ministério da Saúde. Conselho Nacional de Saúde, Comissão Nacional de Ética em Pesquisa. Resoluções do Conselho Nacional de Saúde sobre pesquisas envolvendo seres humanos. Disponível em: <http://www.datasus.gov.br/conselho/conselho/comissoes/etica/resolucoes.htm>. Acesso em: out. 2002.

BRASIL. Ministério da Saúde. Secretaria de Políticas da Saúde. Departamento de Atenção Básica. Área Técnica de Saúde Bucal. Projeto SB2000: condições de saúde bucal da população brasileira no ano 2000. Brasília: 2000. 43 p. Disponível em: <http://www.sb2000.cjb.net> Acesso em: out. 2002. 
BRASIL. Ministério da Saúde. Secretaria de Políticas da Saúde.

Departamento de Atenção Básica. Área Técnica de Saúde Bucal. Projeto SB2000: condições de saúde bucal da população brasileira no ano 2000: manual do examinador. Brasília: 2001. 41 p. Disponível em: <http://www.sb2000.cjb.net Acesso em: out. 2002.

BRASIL. Lei Diretrizes Bases. Lei o 9.394. Estabelece as diretrizes e bases da educação nacional, Brasília DF, 20/12/1996. Disponível em: <http://www.mec.gov.br> Acesso em: out. 2002.

BUTTERS, J. M.; WILLIS, D. O. A comparison of patient satisfaction among current and former dental school patients. J Dent Educ, San Francisco, v. 64, n. 6, p. 409-415, June 2000.

CAMPOS, V. F. Controle da qualidade total. Rio de Janeiro: Block, 1992. $83 \mathrm{p}$.

CARVALHO, G.; ROSEMBURG, C. P.; BURALLI, K. O. Avaliação de ações e serviços de saúde. Mundo Saúde, São Paulo, v. 24, n. 1, p. 72-88, jan./fev. 2000.

CHAVES, M. M. Avaliação. In: Odontologia social. $3^{\mathrm{a}}$ ed. São Paulo: Editora Santos, 1986. cap. 7, p. 297-301. 
CHU, C. H.; LO, E. C. M. Patients' satisfaction with dental services provided by a university in Hong Kong. Int Dent J, Bristol, v. 49, n. 1, p. 53-59, Feb. 1999.

CHU, C. H.; YEUNG, C. Y. Y. J.; LO, E. C. M. Monitoring patient satisfaction with university dental services under two fee-paying systems. Community Dent Oral Epidemiol, Copenhagen, v. 29, n. 5, p. 390-398, Oct. 2001.

CONSELHO FEDERAL DE ODONTOLOGIA. Estatística. Disponível em: <http://www.cfo.org.br> Acesso em: nov. 2002.

CONSELHO FEDERAL DE EDUCAÇÂO. Resolução n 04, de 03 de setembro de 1982. Fixa os mínimos de conteúdo e de duração do curso de odontologia. Diário Oficial da União, Brasília, DF, 16 set. 1982, Seção 1, p. 17.415 .

COSTA, M. C. O.; FORMIGLI, V. L. A. Quality evaluation of health care service for adolescents. Rev Saúde Pública, São Paulo, v. 35, n. 2, p. 177184, jan./fev. 2001.

COUTO, A. I. Vender bem é mais fácil. São Paulo: Gente, 1995. 120 p.

COUTO, J. L.; COUTO, R. S.; DUARTE, C. A. Prevenção e motivação na clínica odontológica. In: LASCALA, N. T. Prevenção na clínica odontológica: promoção de saúde bucal. São Paulo: Artes Médicas, 1997. cap. 6 , p. $60-80$. 
CRUZ, R. de A. Inovando no modelo de ensino. CRO Notícias, Rio de Janeiro, v. 15, n. 6, p. 12, jun. 1998.

CUNHA, M. I. O professor universitário na transição de paradigmas. Araraquara: JM, 1998. $65 \mathrm{p}$.

DAVIS, E. L.; ALBINO, J. E.; TEDESCO, L. A.; PORTENOY, B. S.;

ORTMAN, L. F. Expectations and satisfaction of denture patients in a university clinic. J Prosthet Dent, St. Louis, v. 55, n. 1, p. 59-63, Jan. 1986.

DEMING, W. E. Qualidade: a revolução da administração. São Paulo: Marques Saraiva, 1990. 95 p.

DONABEDIAN, A. Exploration in quality assessment and monitoring. The definition of quality and approaches to its assessment. Ann Arbor: University of Michigan, 1980. v. 1.

EMMERRICH, A.; DAMACENO, L. M.; GRIFFO, J. P.; SANTOS, R. O. O conhecimento livre e esclarecido na clínica odontológica e no campo da pesquisa odontológica. Rev Odontol UFES, Vitória, v. 2, n. 1, p. 20-27, jan./jun. 2000.

FITZMAURICE, J. M. What do we do when the data for medical effectiveness research are not perfect? In: GRADY, M. L.; SCHWATZ, H. A. (Eds.). Medical effectiveness research: data methods. Rockwell: Agency for Health Care Policy Research, 1992. p. 5-8. 
FRANCO, S. C.; CAMPOS, G. W. S. Avaliação da qualidade de atendimento ambulatorial em pediatria em um hospital universitário. Cad Saúde Pública, Rio de Janeiro, v. 14, n. 1, p. 1-13. jan./mar. 1998.

GALLO, E. Inovação, planejamento estratégico gestão de qualidade nas escolas médicas brasileiras. Cad FUNDAP, São Paulo, n. 15, p. 153-167, jan./abr. 1996.

GARCIA, I. R. The role and importance of research and scholarship in dental education and practice. J Dent Educ, San Francisco, v. 66, n.8, p. 925-926, Aug. 2002.

GARCIA, P. P. N. S.; CONTRERAS, E. F. R. Estratégias adotadas por cirurgiões-dentistas para a manutenção do paciente no consultório odontológico. Rev Paul Odontol, São Paulo, v. 24, n. 1, p. 27-30, jan./fev. 2002.

GIL, A. C. Como elaborar projetos de pesquisa. São Paulo: Atlas, 1991. $159 \mathrm{p}$.

GONÇALVES, S. R. M. Medo em odontopediatria: porque e do que as crianças têm medo no tratamento odontológico: técnicas de condicionamento através do toque sutil. Rev Paul Odontol, São Paulo, v. 15, n. 6, p. 35-40, nov./dez. 1993. 
GÜRDAL, P.; CANKAYA, H.; ÖNEM, E.; DINÇER, S.; YILMAZ, T. Factors of patient satisfaction/dissatisfaction in a dental faculty out patient clinic in Turkey. Community Dent Oral Epidemiol, Copenhagen, v. 28, n. 6, p. 461469, Dec. 2000.

GUYATT, G. H.; FEENY, D. H.; PATRICK, D. L. Measuring health-related quality of life. Ann Intern Med, Philadelphia, v. 118, n. 8, p. 622-629, Apr. 1993.

HANDELMAN, S. L.; FAN-HSU, J.; KIN, H. M. Patient satisfaction in four types of dental practice. J Am Dent Assoc, Chicago, v. 121, n. 5, p. 624630, Nov. 1990.

HANDELMAN, L. S.; JENSEN, E. O.; JENSEN, P.; BLACK, M. P. Patient satisfaction in a regular and after-hours dental clinic. Spec Care Dentist, Chicago, v. 16, n. 5, p. 194-198, Sept./Oct. 1996.

HIRATA, M.; COSTA, C.; CAMPOS, E. J. A.; SANTORO, C. Introdução à metodologia de ensino em clínica integrada. São Paulo: Faculdade de Odontologia da Universidade de São Paulo, 2001. 29 p. Trabalho apresentado àDisciplina de Introdução àMetodologia de Ensino em Clínica Integrada, do Mestrado de Clínica Integrada. 
HOUSE of delegates. Competencies for the new dentist. J Dent Educ, San Francisco, v. 66, n. 7, p. 849-851, July 2002.

KERR, I. L. Quality assurance and the dentist - patient relationship. Dent Clin North Am, Philadelphia, v. 29, n. 3, p. 581-588, July 1985.

KLEIMAN, M. Fear of dentists as na inhibiting factor in children's use of dental services. ASDC J Dent Child, Baltimore, v. 49, n. 3, p. 209-213, 1982.

KOSLOWSKY, M.; BAILIT, H.; VALUZZO, P. Satisfaction of the patient and the provider evaluation by questionary. J Public Health Dent, Albany, v. 34, n. 3, p. 188-194, Summer 1974.

KRAMER, P. F.; FELDENS, C. A.; ROMANO, A. R. Plano de tratamento. In: Promoção de saúde bucal em odontopediatria. São Paulo: Artes Médicas, 2000. cap. 5, p. 75-88.

LAHTI, S.; TUUTTI, H.; HAUSEN, H.; KÄÄRIÄNEN, R. Patients' expectation of na ideal dentist and their views concerning the dentist they visited: do the views conform to the expectations and what determines how well they conform? Community Dent Oral Epidemiol, Copenhagen, v. 24, n. 4, p. 240-244, Aug. 1996. 
LEÃO, A. T. T.; DIAS, K. Avaliação dos serviços de saúde prestados por faculdades de odontologia: a visão do usuário. Rev Bras Odontol Saúde Coletiva, Brasília, v. 2, n. 1, p. 40-46, jan.jun. 2001.

LOUREIRO, C. A.; ARAÚJO, V. E.; LOPES, M. I. P.; AYRES, J. R. Pesquisa de avaliação da utilização de um método sistemático de mudança em um serviço de saúde bucal, BEPREM, MG. UFES Rev Odontol, Vitória, v. 3, n. 1, p. 68-78, jan./jun. 2000.

MALIK, A. N. Desenvolvimento de recursos humanos, gerências de qualidade e cultura das organizações de saúde. Rev Adm Empres, São Paulo, v. 32, n. 4, p. 32-41, set./out. 1992.

MARCOS, B. A clínica integrada nos cursos de odontologia como sistema de atenção. Considerações. Arq Centro Estud Curso Odontol, Belo Horizonte, v. 28, n. 1/2, p. 9-15, jan./dez. 1991.

MARTINS, E. M. Saúde bucal uma necessidade socialmente construída: um estudo da experiência da clínica odontológica de São Geraldo. 1993. 191 f. Dissertação (Mestrado em Educação) - Faculdade de Educação, Universidade Federal de Minas Gerais, Belo Horizonte.

MARTINS, M. A. T. S.; MENDONÇA, S. M. S.; VARGAS, A. M. D. Tratamento odontológico na rede pública de Belo Horizonte: percepção de cirurgiões-dentistas e alunos. Rev ABO Nac, São Paulo, v. 6, n. 6, p. 362366, dez. 1998/jan. 1999. 
MASCARENHAS, A. K. Patient satisfaction with the comprenensive care model of dental care delivery. J Dent Educ, San Francisco, v. 65, n. 11, p. 1266-1271, Nov. 2001.

MASSETO, M. T. Didática: a aula como centro. $4^{a}$ ed. São Paulo: FTD, 1997. 111 p. (Coleção Aprender e Ensinar).

MATOS, D. L.; COSTA-LIMA, M. F.; GUERRA, H. L.; MARCENES, W. Bambuí project: na evaluation of private, public and unionnized dental services. Rev Saúde Pública, São Paulo, v. 36, n. 2, p. 237-243, jan./jun. 2002.

MENDES, E. V. Estado atual do sistema de prestação de serviços. Apresentado ao Congresso Mineiro de Odontologia, $3^{\circ}$ Simpósio de Odontologia Social, Juiz de Fora, 1971.

MENDES, E. V. A evolução histórica da prática médica: suas implicações no ensino, na pesquisa e na tecnologia médica. Belo Horizonte: PUC - MG/ FINEP, 1985. $124 \mathrm{p}$.

MEZOMO, J. C. Qualidade na relação hospital-paciente. Hosp Adm Saúde, São Paulo, v. 17, n. 1, p. 17-23, jan./fev. 1993.

MEZOMO, J. C. Reinventando a Universidade. Cad Univ, Brasília, v. 5, p. 254-255, set./out. 1994. 
MOYSÉS, T. S.; WATT, R. Promoção de saúde bucal: definições. In: BUISCHI, Y. P. Promoção de saúde bucal na clínica odontológica. São Paulo: Artes Médicas, 2000. cap. 1, p. 3-22.

NARVAI, P. C. Prática odontológica no Brasil: propostas e ações no período 1952-92. São Paulo, 1993. 189 f. Dissertação (Mestrado em Saúde Pública) - Faculdade de Saúde Pública, Universidade de São Paulo, São Paulo.

NEVES, L. de A. Universidade e avaliação. Estado de Minas, Belo Horizonte, 25 abr. 1995. Caderno 1, p. 6.

NEWSOME, P. R. H.; WRIGHT, G. H. A review of patient satisfaction: 1. Concepts of satisfaction. Br Dent J, London, v. 186, n. 4, p. 161-165, Feb. 1999.

NICODEMO, D.; BALDUCCI, I.; NARESSI, S. C. M.; MOLINA, V. L. I. Avaliação do ensino odontológico: um estudo exploratório sobre as opiniões do alunado. Odontol Soc, São Paulo, v. 3, n. 1/2, p. 21-26, 2001.

NUTO, S. A. S.; NATIONS, M. K. Avaliação qualitativa dos serviços como processo de construção de cidadania. Ação Coletiva, Brasília, v. 2, n. 3, p. 25-29, jul./set. 1999. 
ORCHARD, C. Comparing health care out-comes. Br Med J, São Paulo, v. 308, n. 6942, p. 1493-1499, June 1994.

PADILHA, W. W. N. Análise da situação do ensino (evolução, modelo pedagógico e enfoque curricular) da disciplina de clínica integrada nos cursos de graduação em Odontologia. 1998. 210 f. Tese (Doutorado em Clínica Integrada) - Faculdade de Odontologia, Universidade de São Paulo, São Paulo.

PADILHA, W. W. N. Da integração clínica a clínica integrada. 1994. 65 f. Tese (Titular em Clínica Integrada) - Faculdade de Odontologia, Universidade Federal Fluminense, Niterói.

PADILHA, W. W. N.; MEDEIROS, E. P. G. de; TORTAMANO, N.; ROCHA, R. G. O desenvolvimento da disciplina de clínica integrada nas instituições de ensino odontológico no Brasil. RPG, São Paulo, v. 2, n. 4, p. 193-199, out./dez. 1995.

PADILHA, W. W. N.; CARVALHO, D. M.; OLIVEIRA, V.; AMARAL, M. F.; MARTINHO, D. S. Associação entre indicadores de saúde bucal e nível sócio-econômico em pacientes da clínica integrada. Rev Pesqui Bras Odontopediatr Clin Integrada, João Pessoa, v. 1, n. 1, p. 31-44, jan./abr. 2001. 
PASCOE, G. C. Patient satisfaction in primar helath care: a literatura review and analysis. Evaluation Programa Planning, Chicago, v. 6, n. 2, p. 185210, Feb. 1983.

PEREIRA, W. R. Algumas contribuições da análise institucional para estudar as relações entre os serviços públicos de saúde e a sua clientela. Rev Bras Enferm, Brasília, v. 53, n. 1, p. 31-38, jan./mar. 2000.

PEREZ, F. E. G. Avaliação da média de tempo despendida na execução de atividade clínica, por alunos de graduação da disciplina de clínica integrada da Faculdade de Odontologia da Universidade de São Paulo. 1993. 64 f. Dissertação (Mestrado em Clínica Integrada) - Faculdade de Odontologia, Universidade de São Paulo, São Paulo.

PINHEIRO, H. H. C.; SILVA, L. G. A. Avaliação da satisfação dos usuários dos serviços de saúde bucal no município de Belém, Pará. 2002. 38 f. Monografia (Trabalho de Conclusão de Curso) - Curso de Odontologia da Universidade Federal do Pará, Belém.

PINHEIRO, J. T.; AGUIAR, C. M.; SANTOS, V. F. Estudo do comportamento do paciente frente àindumentária do cirurgião-dentista. Rev Bras Odontol, Rio de Janeiro, v. 59, n. 1, p. 57-60, jan./fev. 2002. 
PINTO, V. G. Planejamento. In: Saúde bucal coletiva. $4^{\mathrm{a}}$ ed.

São Paulo: Editora Santos, 2000. cap. 2, p. 11-30.

POI, W. R.; TAGLIANINI, R. L. Organização do trabalho em clínica integrada. Rev ABO Nac, Porto Alegre, v. 7, n. 4, p. 209-212, ago./set. 1999.

POI, W. R.; TAGLIAVINI, R. L.; SONORA, C. K.; CASTRO, J. C. M.; SALINEIRO, S. L.; PEDRINI, D.; PANZARINI, S. R. O perfil da disciplina de Clínica Integrada da Faculdade de Odontologia de Araçatuba - UNESP, após onze anos de implantação. Arq Odontol, Belo Horizonte, v. 33, n. 1, p. 35-47, jan./jun. 1997.

POPE, C.; MAYS, N. Opening the black box: na encounters in the corridors of health services research. Br Med J, London, v. 306, n. 6873, p. 315-318, Jan. 1993.

RAMOS, F. B. Como o paciente se sente ao ser atendido por um aluno de odontologia? Rev CROMG, Belo Horizonte, v. 7, n. 1, p. 10-15, jan./abr. 2001.

RAMOS, F. B. Eficácia do atendimento oferecido aos pacientes da clínica integrada da faculdade federal de odontologia de Diamantina. Rev CROMG, Belo Horizonte, v. 3, n. 2, p. 56-63, jul./dez. 1997. 
RAMOS, F. B.; FONSECA, L. L. V.; LUCAS, S. D. The meaning of a dental clinic for its patients: the experience of the faculdade federal de odontologia de Diamantina. Rev CROMG, Belo Horizonte, v. 5, n. 2, p. 87-94, maio/ago. 1999.

RIBEIRO, J. F. A odontologia social na clínica integrada: análise dos cursos de odontologia no Estado do Rio de Janeiro. 1987. $110 \mathrm{f}$.

Dissertação (Mestrado em Clínica Integrada) - Faculdade de Odontologia, Universidade Federal Fluminense, Niterói.

ROCHA, C. R.; BERCHT, S. B. Estudo do abandono do tratamento odontológico em um serviço público de Porto Alegre: o centro de saúde Murialdo. Rev Fac Odontol Univ Fed Rio Grande do Sul, Porto Alegre, v. 42, n. 2, p. 25-31, dez. 2000.

RODRÍGUEZ OUSSET, A. "Problemas, desafíos y mitos em la formación docente". Perfices Educativos. Rev Inst Geol, UNAM, México, . 63, p. 2329, jan./mar. 1994.

RUSSO, F. L. P. Gestão em odontologia. São Paulo: Lovise, 2003. 155 p.

SALA, A. A avaliação de programas de saúde. In: SCHRAIBER, L. B. (Org.). Programação em saúde hoje. São Paulo: Hucitec, 1993. cap. 3, p. 117-138. 
SANTANA, J. P. Desenvolvimento gerencial no SUS: demandas e perspectivas. Rev Espaço Saúde, Curitiba, v. 5, n. 5, p. 13, set. 1996.

SANTOS, S. R.; LACERDA, M. C. N. Fatores de satisfação e insatisfação entre os pacientes assistidos pelo SUS. Rev Bras Enferm, Brasília, v. 52, n. 1, p. 43-53, jan./mar. 1999.

SOUZA, H. M. Saúde, engenho e arte. Rev Bras Saúde Fam, Brasília, v. 53, n. 3, p. 7-16, dez. 2000.

STECHMAN NETO, J. A avaliação do aluno do curso de odontologia na clínica integrada. 1998. 112 f. Dissertação (Mestrado em Educação) Curso de Odontologia, Universidade Tuiuti do Paraná, Curitiba.

TABACOF, G. O ensino de clínica integrada nos cursos de odontologia no Brasil. Bol Fac Odontol Univ Fed Bahia, Salvador, v. 4, n. 1, p. 13-15, jan./jun. 1980.

TORTAMANO, N.; PADILHA, W. W. N.; MEDEIROS, E. P. G.; ROCHA, R. G. O desenvolvimento da disciplina de clínica integrada nas instituições de ensino odontológicos no Brasil. RPG, São Paulo, v. 2, n. 4, p. 193-197, out./dez. 1995. 
TRAD, L. A. B.; BASTOS, A. C. S.; SANTANA, E. M.; NUNES, M. O. Estudo etnográfico da satisfação do usuário do programa de saúde da família (PSF) na Bahia. Ciênc Saúde Coletiva, Rio de Janeiro, v. 7, n. 3, p. 581-589, 2002.

UNFER, B.; SALIBA, O. Avaliação do conhecimento popular e práticas cotidianas em saúde bucal. Rev Saúde Pública, São Paulo, v. 34, n. 2, p. 190-195, 2000.

UNIVERSIDADE FEDERAL DO PARÁ. Conselho Superior de Ensino e Pesquisa. Resolução no 2.811, de 22 de junho de 2001. Alteração de dispositivos da resolução no 1.853/90-CONSEP do currículo do curso de graduação em odontologia. Com a implantação da disciplina de clínica integrada na equivalência disciplinar. Belém: UFPA, 2001. p. 2.

UNIVERSIDADE FEDERAL DO PARÁ. Conselho Superior de Ensino e Pesquisa. Resolução no 2.891, de 28 de fevereiro de 2002. Define o currículo do curso de graduação em odontologia. Belém: UFPA, 2002. p. 12.

UNIVERSIDADE FEDERAL DO PARÁ. Projeto de reestruturação curricular do curso de odontologia do centro de ciências da saúde da Universidade Federal do Pará. Belém: UFPA, 2000a. p. 9. 
UNIVERSIDADE FEDERAL DO PARÁ. Lâmina intermediária, currículo do curso de odontologia. Belém: UFPA, 2000b. p. 2.

UNIVERSIDADE FEDERAL DO PARÁ. Normas para funcionamento da disciplina de clínica integrada do curso de odontologia da UFPA. Belém: UFPA, 2000c. 5 p.

VARGAS, A. M. D.; VASCONCELOS, M. A construção da clínica integrada de atenção primária da faculdade de odontologia da Universidade federal de Minas Gerais: a experiência da clínica integrada I. Arq Odontol, Belo Horizonte, v. 34, n. 2, p. 71-81, jul./dez. 1998.

VEIGA, I. P. A.; CASTANHO, M. E. L. M.; COSTA, P. Aula universitária e inovação. In: VEIGA, I. P. A.; CASTANHO, M. E. L. M. Pedagogia universitária: a aula em foco. Campinas: Papirus, 2000.133 p. (Coleção Magistério: Formação e Trabalho Pedagógico).

WANDERLEY, J. N. B.; PEREIRA, G. A. S.; PADILHA, W. W. N.; BARRETO, R. C. Estudo da efetividade dos serviços odontológicos oferecidos pela disciplina de clínica integrada da UFPB. Rev Pesqui Bras Odontopediatr Clin Integrada, João Pessoa, v. 2, n. 1, p. 37-42, jan./abr. 2002. 
WEYNE, S. C. A construção do paradigma de promoção de saúde - um desafio para as novas gerações. In: Kriger, L. Promoção de saúde bucal. São Paulo: Artes Médicas, 1997. cap. 1, p. 3-26.

WILLIAMS, B. Patient satisfaction: a valid concept? Soc Sci Med, Oxford, v. 38, n. 4, p. 509-516, Feb. 1994.

WORLD HEALTH ORGANIZATION. Oral health surveys: basic methods. $4^{\mathrm{a}}$ ed. Geneva: WHO, 1997. 66 p. 


\section{SUMMARY}

\section{PATIENT SATISFACTION ASSESSMENT IN COMPREHENSIVE DENTAL CLINIC AT PARÁ FEDERAL UNIVERSITY, SCHOOL OF DENTISTRY}

This study assessed the patient satisfaction in Comprehensive Dental Clinic at Pará Federal University, school of Dentistry, through two hundreds (200) patients amount, into a group of six hundreds (600) patients registrations, that were seen between May and June, 2002. A questionary was used with nineteen (19) closed questions and one open question. The values were found by statistical analyses using the software Epi Info $604 . d$ at $5 \%$ of significance $(p<0,05)$. The results showed that $98 \%$ of the patients seen in this work were satisfied with the methods used in the clinic of the school; the medium grade was 8,33; the work environment had an approvable of $95 \%$, but $87 \%$ of all the patients had gone to the dental clinic just for an specialized treatment, not for an comprehensive one. $94 \%$ of the students and teachers approved the treatment too, and the recomendations for a better work were about the clinic structure and triage service in the School of Dentistry of Pará Federal University. 


\section{APÊNDICES}




\section{APÊNDICE 1 - Questionário de pesquisa}

UNIVERSIDADE DE SÃO PAULO-FACULDADE DE ODONTOLOGIAUNIVERSIDADE FEDERAL DO PARÁ-CENTRO DE CIÊNCIAS DA SAÚDECURSO DE ODONTOLOGIA-MESTRADO INTERINSTITUCIONAL DE CLÍNICA INTEGRADA

\section{QUESTIONÁRIO}

TÍTULO DA PESQUISA: AVALIAÇÃO DA SATISFAÇÃO DOS PACIENTES ATENDIDOS NA CLÍNICA INTEGRADA DO CURSO DE ODONTOLOGIA DA UNIVERSIDADE FEDERAL DO PARÁ.

NOME:

IDADE:

SEXO:

TELEFONE:

ENDEREÇO:

BAIRRO:

CEP:

DATA:

1- Atualmente você está trabalhando?

( ) $\mathrm{Sim}$

( ) Não, eu estou desempregado(a)

( ) Sim, e eu também sou aposentado(a)

( ) Não, eu sou aposentado

2- Quanto é a renda de toda a sua família por mês?
( ) Nenhuma
( ) 2 a 3 Salários Mínimos
( ) 5 a 10 Salários Mínimos
( ) 1 a 2 Salários Mínimos
( ) 3 a 5 Salários Mínimos
( ) Mais de 10 Salários Mínimos

3- Qual o seu nível de escolaridade?
( ) Nenhum (não sabe ler nem escrever)
( ) Fundamental completo
( ) Médio completo
( ) Curso superior completo
( ) Fundamental incompleto.
( ) Médio incompleto.
( ) Curso superior incompleto.
( ) Pós-graduação

4- Você recebeu alguma informação sobre as suas necessidades de tratamento?

( ) Sim ( ) Não

5- Você recebeu alguma informação sobre escovação, dieta, flúor e como evitar a cárie e ou sangrento das gengivas?
( ) Sim
( ) Não

6- O aluno estava uniformizado ( luvas, máscara, gorro, bata ) ?

( ) Sim

( ) Não

7- O professor estava uniformizado (luvas, máscara, gorro, bata ) ?

( ) $\mathrm{Sim}$

( ) Não

8- Você sentiu alguma dor durante o tratamento?

( ) Sim ( ) Não 
9- Do que você mais teve medo no tratamento odontológico?
( ) Não tem medo
( ) Dos ferros que os alunos usam
( ) Da anestesia
( ) Da broca ( ) De tudo

10- O que achou do atendimento prestado pelo aluno (a) da Clínica Integrada ?

( ) Ótimo ( ) Bom ( ) Regular ( ) Péssimo

11- O que achou do atendimento prestado pelo professor (a) da Clínica Integrada ?

( ) Ótimo ( ) Bom ( ) Regular ( ) Péssimo

12- Que sugestões você daria para melhorar o atendimento da Clínica Integrada? ( ) Reduzir o tempo de espera no banco. ( ) Ser atendido mais vezes durante a semana

( ) Reduzir o tempo de atendimento na cadeira ( ) Nenhuma. Está bom assim.

( ) Deixar o atendimento na Clínica Integrada só para quem precisa

13- Qual sua opinião quanto ao fato de ser atendido em um local coletivo e público dentro da Clínica Integrada?

( ) Sem constrangimento

( ) Já estava acostumado

( ) Com constrangimento

( ) Não ligo para isso

14- Qual o motivo que o fez procurar o atendimento na Clínica Integrada do Curso de Odontologia da UFPa. ?

( ) Por indicação de colegas e amigos

( ) Por já ser conhecido do aluno e ter tido a promessa que ele iria atendê-lo

( ) Por ter sido atendido em anos anteriores e não ter concluído o tratamento

( ) Por não ter dinheiro no momento para pagar tratamento particular

( ) Para fazer tratamento especializado solicitado pelo dentista do posto ou

particular

( ) Para colocar uma prótese

( ) Porque os alunos têm mais paciência com os pacientes

15- Como você se sentiu o ambiente durante o atendimento na Clínica Integrada do Curso de Odontologia?

Organização

Conforto

Limpeza

lluminação

Pontualidade do aluno

$\begin{array}{cc}\text { Ótimo } & \text { Boa } \\ (\text { ) } & (\text { ) } \\ () & (\text { ) } \\ () & (\text { ) } \\ () & (\text { ) }\end{array}$

Regular
$($ )
$($ )
$($ )
$($ )
$($ )

Péssima

16- Foi utilizado o tempo de espera no banco para alguma atividade?

Sim ( ) Não ( )

17- Como foi o atendimento no serviço de triagem da Clínica integrada?

( ) Ótimo ( ) Bom ( ) Regular ( ) Péssimo

18- Que nota de 0 a 10, você daria para o atendimento recebido na Clínica Integrada da UFPA?
( ) 10
( ) 7
( ) 4
( ) 9
( ) 6
( 3
( ) 1 
( ) 8

( ) 5

( ) 2

19- Você recomendaria a Clínica Integrada do Curso de Odontologia para outras pessoas?

( ) Sim

( ) Não

20- Fale sobre o seu atendimento na Clínica Integrada do Curso de Odontologia (UFPA).

Pesquisador: Izamir Carnevali de Araújo 
APÊNDICE 2 - Protocolo de pesquisa

\begin{abstract}
UNIVERSIDADE DE SÃO PAULO
FACULDADE DE ODONTOLOGIA

UNIVERSIDADE FEDERAL DO PARÁ

CENTRO DE CIÊNCIAS DA SAÚDE - CURSO DE ODONTOLOGIA

MESTRADO INTERINSTITUCIONAL DE CLÍNICA INTEGRADA
\end{abstract}

PROTOCOLO DE PESQUISA

INFORMAÇÃO E CONSENTIMENTO PÓS-

INFORMAÇÃO PARA PESQUISA

NOME DO PACIENTE:

ENDEREÇO:

DOCUMENTO DE IDENTIDADE:

NOME DO PESQUISADOR:

As informações contidas nos questionários foram aplicadas pelo Mestrando Izamir Carnevali de Araújo, sob orientação do Profo Dr. Rodney Garcia Rocha e da Prof ${ }^{-}$. Dra. Regina Fátima Feio Barroso.

Objetivo : Firmar acordo por escrito mediante o qual, o voluntário da pesquisa (paciente) autoriza sua participação, com pleno conhecimento do questionário, com capacidade de livre arbítrio e sem qualquer coação, para responder itens sobre " Avaliação da satisfação dos pacientes atendidos na Clínica Integrada do Curso de odontologia da Universidade Federal do Pará".

* Observação: Para maiores informações estamos à disposição no Curso de Odontologia da UFPA no telefone ( 0xx91) 211-1495.

Belém,

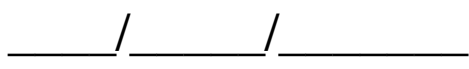




\title{
AUTORIZAÇÃO
}

Autorizo a reprodução e/ou divulgação total ou parcial da presente obra, por qualquer meio convencional ou eletrônico, desde que citada a fonte e comunicada ao autor, a referência em que consta a citação.

\section{Izamir Carnevali de Araújo}

\author{
Universidade de São Paulo \\ Faculdade de Odontologia \\ Departamento de Estomatologia \\ Disciplina de Clínica Integrada. \\ Universidade Federal do Pará \\ Curso de Odontologia \\ Departamento de Clínica Odontológica
}

São Paulo, Junho de 2003.

Av. Prof. Lineu Preste, 2277 - Cidade Universitária 05508-900, São Paulo SP - Brasil. Fone: 0055-11 3818-7816/ 3818-7413

Fax: 0055-11 3032-4409

E-mail: bibfo@fo.usp.br Belém - Pará - (91) 211-1495 Izamir@nautilus.com.br 